\title{
A Systematic Study of Airfoil-Vortex Interactions by means of Particle Image Velocimetry
}

By

\author{
David A. Schmidt, B.Eng. Aerospace
}

\author{
A thesis submitted to \\ The Faculty of Graduate Studies and Research \\ in partial fulfilment of \\ the degree requirements of \\ Master of Applied Science \\ In Aerospace Engineering \\ Ottawa-Carleton Institute for \\ Mechanical and Aerospace Engineering
}

Department of Mechanical and Aerospace Engineering

Carleton University

Ottawa, Ontario, Canada

August $23^{\text {rd }}, 2010$

Copyright $(\mathcal{C}$

2010 - David A. Schmidt 
Library and Archives

Canada

Published Heritage Branch

395 Wellington Street Ottawa ON K1A ON4

Canada
Bibliothèque et

Archives Canada

Direction du

Patrimoine de l'édition

395 , rue Wellington

Ottawa ON K1A ON4

Canada
Your file Votre référence

ISBN: 978-0-494-71562-8

Our file Notre référence

ISBN: 978-0-494-71562-8
NOTICE:

The author has granted a nonexclusive license allowing Library and Archives Canada to reproduce, publish, archive, preserve, conserve, communicate to the public by telecommunication or on the Internet, loan, distribute and sell theses worldwide, for commercial or noncommercial purposes, in microform, paper, electronic and/or any other formats.

The author retains copyright ownership and moral rights in this thesis. Neither the thesis nor substantial extracts from it may be printed or otherwise reproduced without the author's permission.
AVIS:

L'auteur a accordé une licence non exclusive permettant à la Bibliothèque et Archives Canada de reproduire, publier, archiver, sauvegarder, conserver, transmettre au public par télécommunication ou par l'Internet, prêter, distribuer et vendre des thèses partout dans le monde, à des fins commerciales ou autres, sur support microforme, papier, électronique et/ou autres formats.

L'auteur conserve la propriété du droit d'auteur et des droits moraux qui protège cette thèse. Ni la thèse ni des extraits substantiels de celle-ci ne doivent être imprimés ou autrement reproduits sans son autorisation.
In compliance with the Canadian Privacy Act some supporting forms may have been removed from this thesis.

While these forms may be included in the document page count, their removal does not represent any loss of content from the thesis.
Conformément à la loi canadienne sur la protection de la vie privée, quelques formulaires secondaires ont été enlevés de cette thèse.

Bien que ces formulaires aient inclus dans la pagination, il n'y aura aucun contenu manquant. 
The undersigned recommend to the Faculty of Graduate Studies and Research acceptance of the thesis

\title{
A Systematic Study of Airfoil-Vortex Interactions by means of Particle Image Velocimetry
}

\author{
Submitted by David A. Schmidt, \\ in partial fulfilment of the requirements for the degree of \\ Master of Applied Science \\ In Aerospace Engineering
}

D. Feszty, Thesis Supervisor

\author{
C.L. Tan, Thesis Co-Supervisor
}

M. Yaras, Chair, Department of Mechanical and Aerospace Engineering

Carleton University

2010 


\section{Abstract}

Blade-Vortex Interaction (BVI) is an unavoidable phenomenon experienced by rotorcraft in certain flight regimes. It is caused by the tip vortices of a rotor blade impacting upon the following rotor blade, causing noise and vibration. The 2D simplification of BVI is referred to as Airfoil-Vortex Interaction (AVI).

A systematic study of AVI was performed by means of Particle Image Velocimetry (PIV) to characterize the effect of varying individual parameters. Tests were conducted at velocities ranging between $8.5-15 \mathrm{~m} / \mathrm{s}(\operatorname{Re} \sim 85,000-150,000)$ on a NACA 0012 airfoil. The amplitude of lift disturbance increased with decreasing miss distances, increasing freestream velocities and increasing AOA. Surprisingly, it was also observed that an increase in vortex strength yielded smaller lift disturbances on the airfoil.

PIV results are shown also for a DU96W180 airfoil with an actively controlled flap intended for use on wind turbine blades, investigated as part of a research collaboration with TU Delft. 
Dedicated to my brother, who, for 24 years, has been my teacher of everything from colouring to cosines to calculus. Unknowingly, he has influenced more decisions in my life than I can imagine, and I am forever grateful.

... he likely won't read this, but if he does - if you are, Jon - just don't let the first comment be about the font. 


\section{Acknowledgements}

I would like to acknowledge the generous guidance and patience of my Master's supervisor, Doctor Daniel Feszty from the Department of Mechanical and Aerospace Engineering at Carleton University. I am very appreciative of being given the opportunity to work on a project with such unique attributes necessitating a diverse range of skills and abilities, which kept my research interesting and challenging.

Further, I would like to thank Daniel Brassard, Jeff Wilkins and Wes Burwash, who worked on designing, configuring and testing the equipment I would later utilize extensively in my work. This thesis is the first of many that will appreciate their contributions extensively, and for that I am grateful.

Additionally, I am thankful for the Canada-EU Student Exchange Program in Aerospace Engineering which granted me a summer abroad at the Technical University of Delft, in the Netherlands. There I worked tirelessly with René Lindeboom, Carlos Ferreira and Joost Sterenborg who welcomed me into their country and research with generosity and enthusiasm.

Finally, I would like to properly acknowledge the opportunities afforded to me by my parents, Landon and Sandra. Their advice and support has been endless throughout my personal and academic pursuits, allowing me to strive for things normally out of one's grasp. 


\section{Table of Contents}

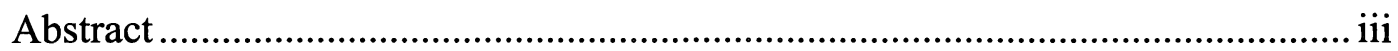

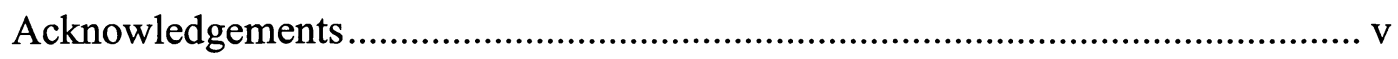

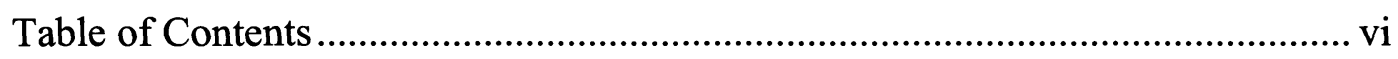

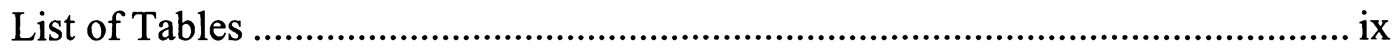

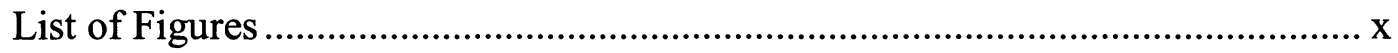

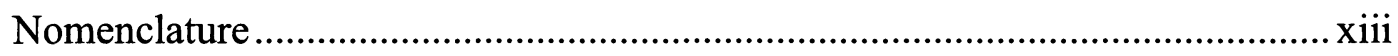

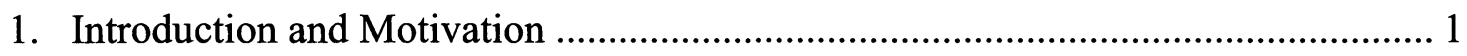

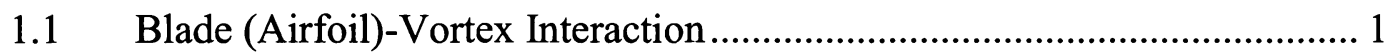

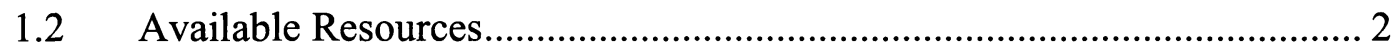

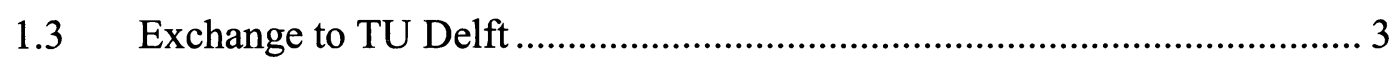

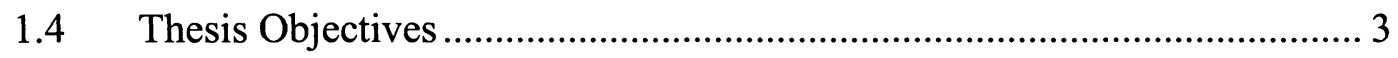

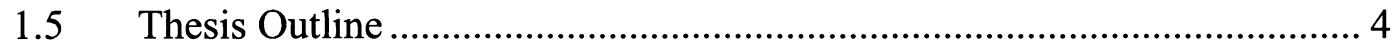

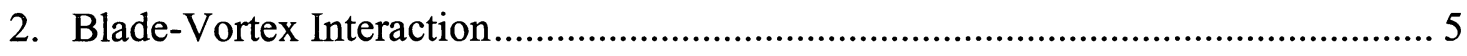

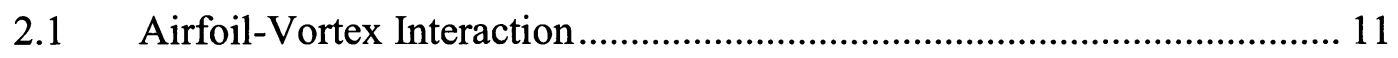

2.2 BVI Literature Review.................................................................. 12

3. Particle Image Velocimetry................................................................................ 17

4. Wind Tunnel for Two-Dimensional Flow Studies .................................................. 23

$4.1 \quad$ Purpose

$4.2 \quad$ Wind Tunnel Specifications................................................................. 24

4.2.1 Tunnel Design Constraints......................................................... 24

4.2.1.1 Space Limitations................................................................. 24

4.2.1.2 Test Section Speed .............................................................. 25

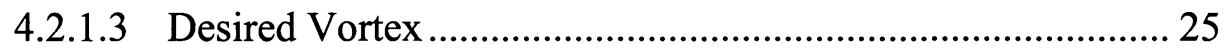

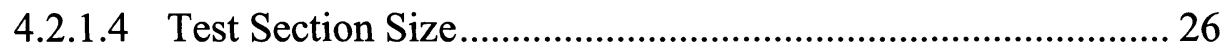

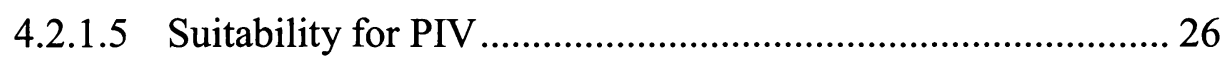

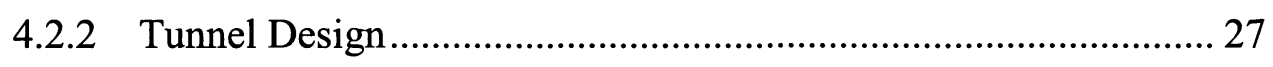

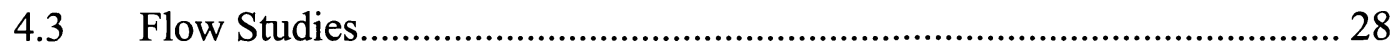




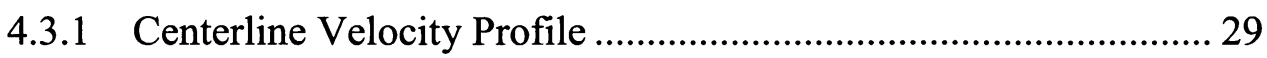

4.3.2 Flow Angularity ………………….............................................. 30

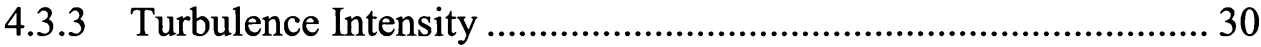

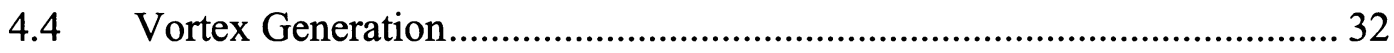

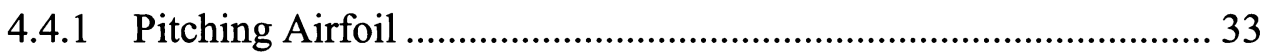

4.4.2 Numerical Analysis of Pitching Airfoil ........................................ 35

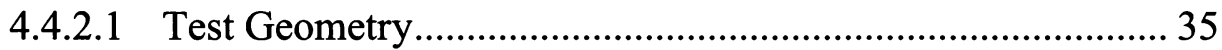

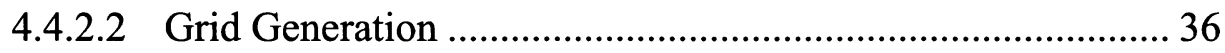

4.4.2.3 Grid Convergence Study ........................................................ 36

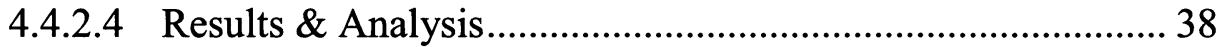

4.4.3 The Brassard Vortex Generator ................................................... 39

4.4.4 Numerical Analysis of the Brassard Vortex Generator ................. 40

4.4.4.1 Test Geometry...................................................................... 40

4.4.4.2 Grid Generation ............................................................. 42

4.4.4.3 Grid Convergence Study ...................................................... 42

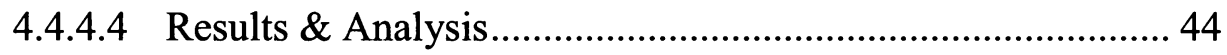

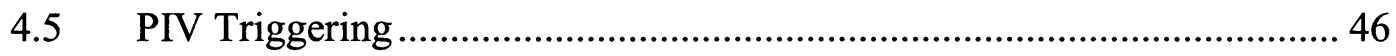

5. Experimental Results and Discussion ................................................................... 48

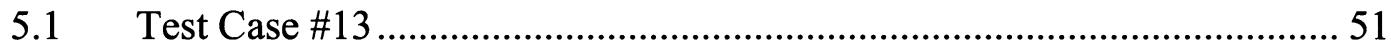

$5.2 \quad$ Complete Test Regime.......................................................................... 54

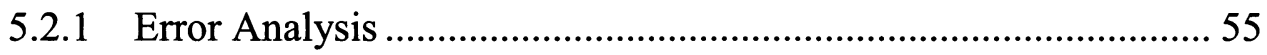

5.2.2 Effect of Miss Distance................................................................ 56

5.2.3 Effect of Angle of Attack................................................................ 58

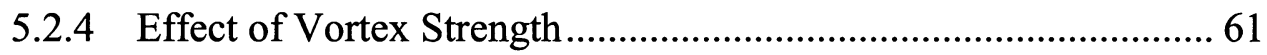

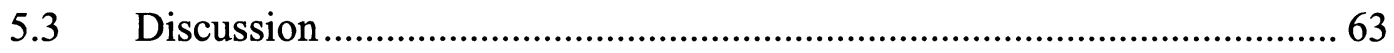

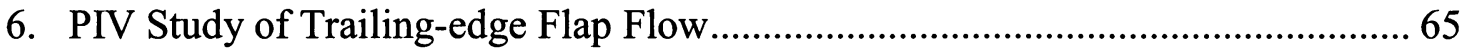

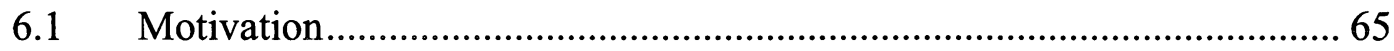

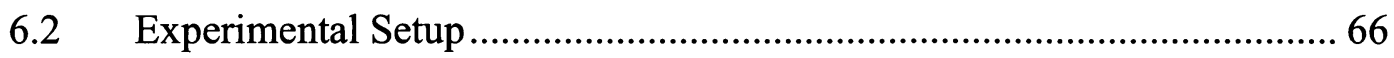


6.2.1 Low-Speed Low-Turbulence Tunnel........................................ 67

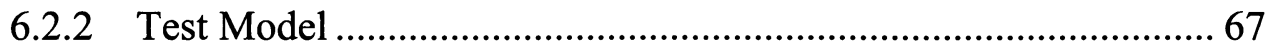

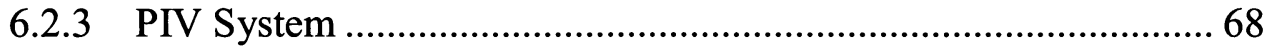

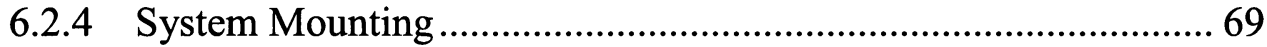

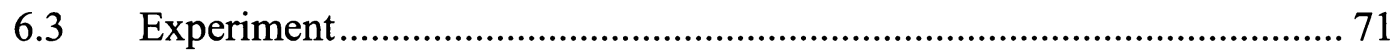

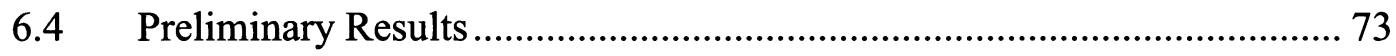

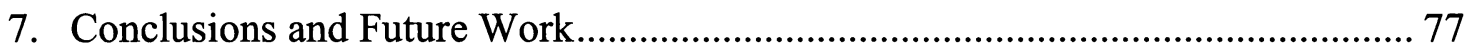

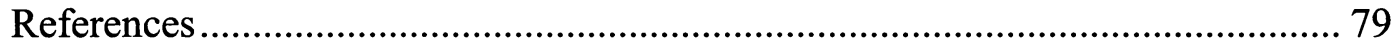

Appendix A: Functional Guide to Data Acquisition....................................... 82 


\section{List of Tables}

Table 3-1: Example tracer particles for gaseous flows [21] ........................................... 18

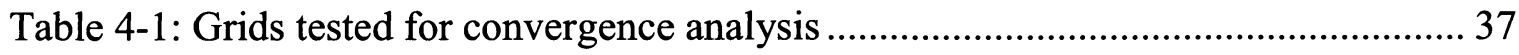

Table 4-2: Grids tested for plunging convergence analysis ............................................... 43

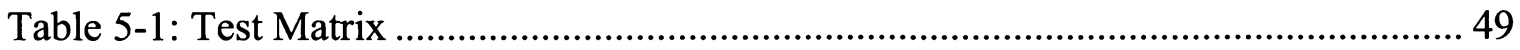

Table 5-2: Optimal PIV parameters as defined by Burwash [3] ...................................... 50

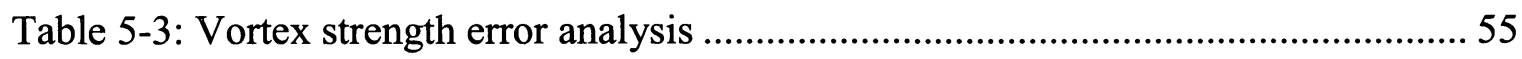

Table 5-4: Sources of relative experimental error in calculating $\Delta C L_{N D} \ldots \ldots \ldots \ldots \ldots \ldots \ldots \ldots . . . .56$

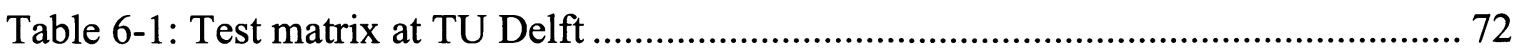




\section{List of Figures}

Figure 2-1: Conventional fixed wing aircraft tip vortices [1] .......................................... 5

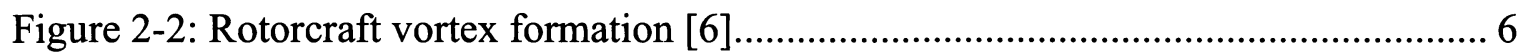

Figure 2-3: Example blade vortex interactions in descending flight (7 most significant

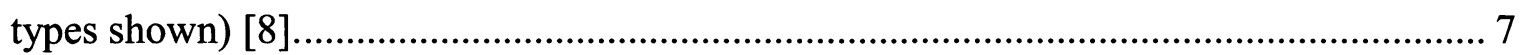

Figure 2-4: Main rotor wake in level and descending flight [9] .................................... 7

Figure 2-5: Single BVI event geometry (advancing and retreating sides) [10]................. 9

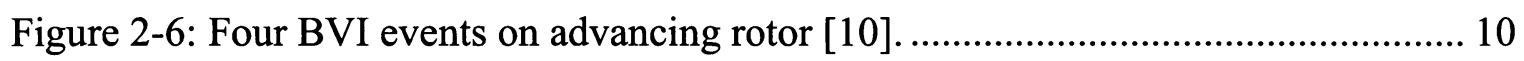

Figure 2-7: Parallel BVI and associated miss distances [3].......................................... 11

Figure 2-8: Typical vortex induced lift coefficient with instantaneous vortex position on a

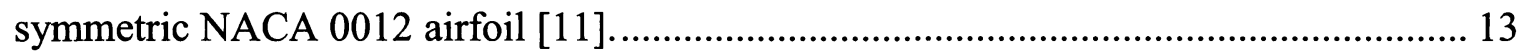

Figure 2-9: Schematic of shock wave vortex generation [18] ....................................... 14

Figure 2-10: Capture of AVI pressure contours by means of dual-pulsed holographic

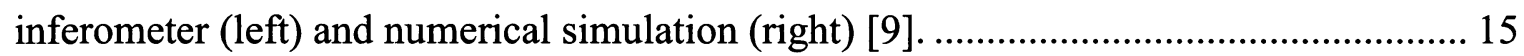

Figure 2-11: Schematic of the three-dimensional BVI apparatus by Cadadonna [19].... 16

Figure 3-1: Typical two-dimensional Particle Image Velocimetry (PIV) apparatus [20]. 17

Figure 3-2: PIV image capture (A), interrogation region selection (B), correlation (C),

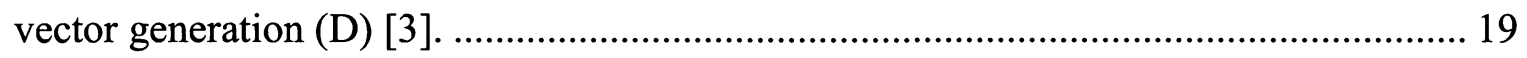

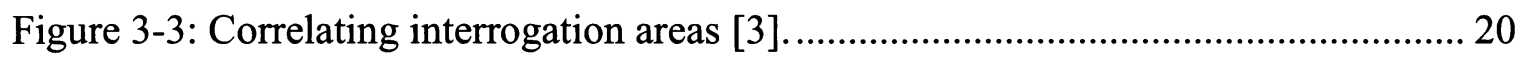

Figure 4-1: Available unused space (dimensions in meters) [1]..................................... 24

Figure 4-2: Tunnel design and placement in available space [3] .................................. 27

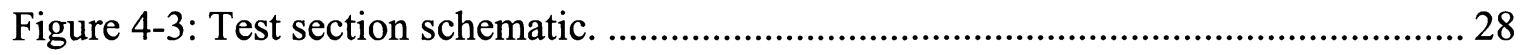

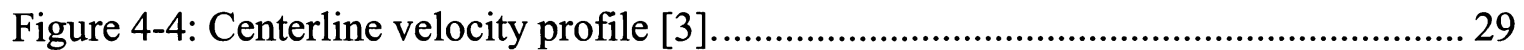

Figure 4-5: Flow angularity study at a cross section midway through the test section [2].

Figure 4-6: Hot-wire anemometry probe locations.................................................... 31

Figure 4-7: Variation of average and maximum turbulence intensities with wind speed. 32

Figure 4-8: Pitching vortex generator (spring not shown).............................................. 34

Figure 4-9: Numerical simulation geometry of flow disturbance (Not to scale).............. 36

Figure 4-10: Velocity profile one chord length downstream of airfoil for varying node

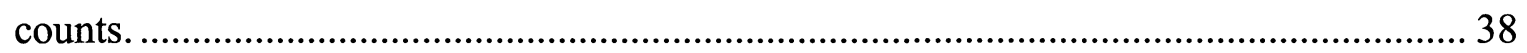

Figure 4-11: Schematic representation of the Brassard vortex generator [1] .................. 40

Figure 4-12: Vertical velocity profile of plunging Brassard-style vortex generator. ....... 41

Figure 4-13: Simulation of plunging vortex generator as compared to actual. ................ 42

Figure 4-14: Velocity profile one chord length downstream of airfoil............................. 43 
Figure 4-15: Vorticity contours with streamlines to illustrate the instantaneous angle of attack of the Brassard vortex generator.

Figure 4-16: Time-history of the Brassard-type vortex generator simulations. Vorticity contours with instantaneous streamlines shown. 45

Figure 4-17: Infrared LED timing circuits [3]. 47

Figure 4-18: Infrared beam placement [3]. 47

Figure 5-1: Case \#13 vortex impact on NACA0012 blade [3] ......................................... 52

Figure 5-2: Case \#13 vortex impact on NACA 0012 blade................................................ 53

Figure 5-3: Coefficient of lift vs. vortex position for case \#13. ..................................... 54

Figure 5-4: Effect of varying miss distance from 0.1-0.3 $c\left(0^{\circ}\right.$ AOA, $\Gamma=0.12 \ldots \ldots \ldots \ldots . . .57$

Figure 5-5: Effect of varying miss distance from 0.1-0.3 $c\left(0^{\circ} \mathrm{AOA}, \Gamma=0.080\right) \ldots \ldots . . .57$

Figure 5-6: Effect of varying miss distance from 0.1-0.3 $c\left(5^{\circ} \mathrm{AOA}, \Gamma=0.12\right) \ldots \ldots \ldots \ldots . . .57$

Figure 5-7: Effect of varying miss distance from $0.1-0.3 c\left(5^{\circ} \mathrm{AOA}, \Gamma=0.080\right)$........ 58

Figure 5-8: Effect of varying angle of attack from $0-5 \mathrm{deg}(y / c=0.1, \Gamma=0.12) \ldots . . . .58$

Figure 5-9: Effect of varying angle of attack from $0-5 \operatorname{deg}(y / c=0.1, \Gamma=0.080)$......59

Figure 5-10: Effect of varying angle of attack from $0-5 \operatorname{deg}(y / c=0.2, \Gamma=0.12)$..... 59

Figure 5-11: Effect of varying angle of attack from $0-5 \mathrm{deg}(\mathrm{y} / \mathrm{c}=0.2, \Gamma=0.080) \ldots . .59$

Figure 5-12: Effect of varying angle of attack from $0-5 \mathrm{deg}(y / c=0.3, \Gamma=0.12) \ldots . .60$

Figure 5-13: Effect of varying angle of attack from $0-5 \mathrm{deg}(y / c=0.3, \Gamma=0.080) \ldots 60$

Figure 5-14: Effect of varying vortex strength from 0.08-0.12 $\left(y / c=0.1,0^{\circ} \mathrm{AOA}\right) \ldots . .61$

Figure 5-15: Effect of varying vortex strength from 0.08-0.12 $\left(y / c=0.1,5^{\circ} \mathrm{AOA}\right) \ldots . .61$

Figure 5-16: Effect of varying vortex strength from 0.08-0.12 $\left(y / c=0.2,0^{\circ} \mathrm{AOA}\right) \ldots . .62$

Figure 5-17: Effect of varying vortex strength from 0.08-0.12 $\left(y / c=0.2,5^{\circ} \mathrm{AOA}\right) \ldots . .62$

Figure 5-18: Effect of varying vortex strength from $0.08-0.12\left(y / c=0.3,0^{\circ} \mathrm{AOA}\right) \ldots . .62$

Figure 5-19: Effect of varying vortex strength from $0.08-0.12\left(y / c=0.1,5^{\circ} \mathrm{AOA}\right) \ldots . .63$

Figure 6-1: DU96W180 airfoil, shown without flap [24]............................................. 66

Figure 6-2: DU96W180 blade prototype with 20\% hinged flap shown. ........................... 68

Figure 6-3: The TU Delft PIV System (prior to installation) without lenses.

Figure 6-4: Three-view diagram of the DU96W180 blade mounting in the TU Delft Low-

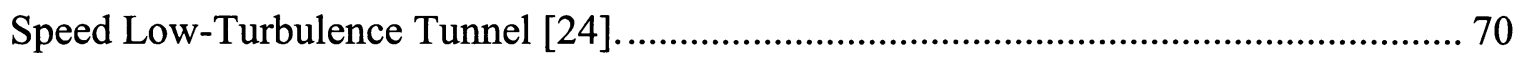

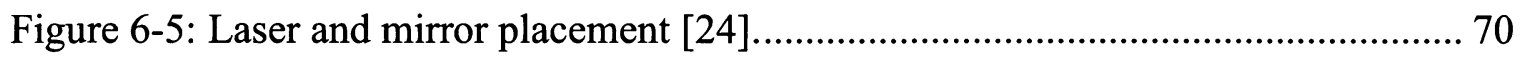

Figure 6-6: Camera position (only one camera shown) [24] .......................................... 71

Figure 6-7: Graphical depiction of camera fields of view.............................................. 73

Figure 6-8: Total velocity field at selected phase angles with $V_{\infty}=21 \mathrm{~m} / \mathrm{s}, \mathrm{AOA}=0^{\circ}$, maximum flap deflection of $2^{\circ}$ at a frequency of $2.67 \mathrm{~Hz}$, and a reduced frequency of 0.2 . 
Figure 6-9: Vorticity field for selected phase angles with $V_{\infty}=21 \mathrm{~m} / \mathrm{s}, \mathrm{AOA}=0^{\circ}$, maximum flap deflection of $2^{\circ}$ at a frequency of $2.67 \mathrm{~Hz}$, and a reduced frequency of 0.2 . .75

Figure 6-10: Pressure contour at selected phase angles with $V_{\infty}=21 \mathrm{~m} / \mathrm{s}, \mathrm{AOA}=0^{\circ}$, maximum flap deflection of $2^{\circ}$ at a frequency of $2.67 \mathrm{~Hz}$, and a reduced frequency of 0.2 . 
Nomenclature

\begin{tabular}{|c|c|c|}
\hline $\mathrm{AOA}$ & - & Angle of Attack \\
\hline AVI & - & Airfoil-Vortex Interaction \\
\hline BVI & - & Blade-Vortex Interaction \\
\hline PIV & - & Particle Image Velocimetry \\
\hline$M_{t r}$ & 1 & Mach Trace Number in BVI \\
\hline$\Omega$ & $\mathrm{rad} / \mathrm{s}$ & Angular rotor velocity \\
\hline$r_{b}$ & $m$ & Rotor blade radius \\
\hline$V_{\infty}$ & $\mathrm{m} / \mathrm{s}$ & Freestream velocity \\
\hline $\bar{V}$ & $\mathrm{~m} / \mathrm{s}$ & Mean freestream velocity \\
\hline$V_{+}$ & $V$ & Voltage \\
\hline$\varphi$ & $\circ$ & Rotor azimuth angle \\
\hline$a_{0}$ & $\mathrm{~m} / \mathrm{s}$ & Local speed of sound \\
\hline$\gamma$ & 。 & Angle between rotor blade axis and vortex axis \\
\hline$\Gamma$ & $\mathrm{m}^{2} / \mathrm{s}$ & Vortex circulation \\
\hline$\Gamma_{\mathrm{ND}}$ & - & Vortex strength $-\Gamma /\left(V_{\infty} \bar{c}\right)$ \\
\hline$x_{v}, y_{v}$ & $m$ & Horizontal, vertical vortex miss distance \\
\hline $\bar{c}$ & $m$ & Mean blade chord \\
\hline$w$ & $m$ & Blade chord \\
\hline$I$ & $\%$ & Turbulence intensity \\
\hline$\rho$ & $\mathrm{kg} / \mathrm{m}^{3}$ & Air density \\
\hline$L$ & $N$ & Lift \\
\hline$C_{L}$ & 1 & Lift coefficient \\
\hline$N$ & pixels & Interrogation region size \\
\hline$\Delta C_{L_{N D}}$ & 1 & Non-dimensional lift coefficient \\
\hline Atm & - & With reference to the atmosphere \\
\hline$P_{S}$ & $\mathrm{~Pa}$ & Static pressure \\
\hline
\end{tabular}




\section{Chapter 1}

\section{Introduction and Motivation}

This study involves the research of flow around rotary-wing airfoils under two dynamic conditions by means of Particle Image Velocimetry (PIV). The first is blade-vortex interaction, a systematic study of which was enabled by the availability of a wind tunnel for the study of two-dimensional flow phenomenon at Carleton University. The second case is that of the flow around a wind turbine blade with an actively controlled flap, which was completed during a research stay at the Technical University of Delft, in the Netherlands.

\subsection{Blade (Airfoil)-Vortex Interaction}

As a rotorcraft blade advances, high pressure air on the lower surface of the blade curls around the blade tip to the area of lower pressure on the top surface. This creates a helical tip vortex, which, most predominately during forward descent, does not escape the confined flow field surrounding the aircraft, but instead interacts with the following rotor blades, the tail rotor or the fuselage, causing undesirable vibration, noise and fatigue. The impact of the tip vortex on the main rotor blades is a phenomenon referred to as Blade-Vortex Interaction (BVI), and is an area of active research in rotorcraft advancement.

The most critical form of BVI with respect to noise and vibration is called parallel BVI, where the vortex axis is nearly parallel to the blade axis. This form can be 
simplified to a two-dimensional vortex impacting on an airfoil, which is referred to as Airfoil-Vortex Interaction (AVI).

\subsection{Available Resources}

To study the effects of parallel BVI, it is advantageous to utilize the two-dimensional simplification to AVI, as it removes the need for a rotating frame to be present within a wind tunnel or computational model. This study was largely driven by the resources available, the most notable are discussed below.

Described in detail in Chapter 5, the wind tunnel available in the Department of Mechanical and Aerospace Engineering at Carleton University provides a dedicated means of investigating AVI. Custom built by Brassard [1], Wilkins [2] and Burwash [3] to serve as a testing facility capable of many rapid repeated measurements, the tunnel was designed with a number of useful features such as: a long test section capable of accommodating a vortex generating and a test airfoil as well as a relatively high freestream velocity of $85 \mathrm{~m} / \mathrm{s}$ and a closed-loop wind tunnel design ideal for seeding with particles, and thus, PIV measurements. This thesis utilizes this tunnel and its features extensively to perform a systematic study of AVI.

Particle image velocimetry is a means of non-intrusive velocity field measurements that is commonly used to study a number of flow phenomena. PIV systems are complex and expensive, featuring high power lasers, cameras and a processing hardware and software suite. The particular wind tunnel mentioned above was designed to be dedicated for PIV experiments. 
In addition to the experimental testing, a number of computational fluid dynamics simulations were run in ANSYS CFX throughout this study to evaluate the effectiveness of potential experimental projects, or to assist in the validation of data. CFD proved to be a useful tool for examining simple flow conditions; however the time required for simulating a single AVI event is currently still prohibitively long to permit a systematic study in an acceptable (6-12 month) timeframe [4],[5].

\subsection{Exchange to TU Delft}

In the summer of 2009 , this author had the opportunity to participate in a collaborative research program related to PIV measurements of a prototype wind turbine blade at the Delft University of Technology (TU Delft) in the Netherlands. TU Delft is one of the leading European technical universities, featuring many facilities not available to academic researchers in Canada. The research collaboration was concerned with the study of a prototype wind turbine airfoil equipped with an actively controlled flap and investigated via PIV technique. This author's role was to set up the PIV system and guide the Dutch researchers in conducting their first such tests. The unique features of this work will be described in the last chapter of this thesis.

\subsection{Thesis Objectives}

The main objective of this thesis was to complete a systematic study of AVI through an experimental campaign using PIV. The main aim was to identify trends affecting rotor blade vibration. Within a two-dimensional context, blade vibration can be monitored, for example, through evaluating the lift over the test airfoil. A systematic study of AVI requires running a large number of test cases, which has been attempted in several CFD 
studies in the past [5]. However, CFD simulation of AVI is computationally expensive, requiring about 6-7 weeks on a classical Navier-Stokes equation solver [4] and 2-3 months on Large Eddy Simulation (LES) solver [5]. This prohibits running a large number of test cases with different parameters in a relatively short period of time. The wind-tunnel utilized in this study was built with this aim and with its recent completion it was available for a systematic study of AVI.

\subsection{Thesis Outline}

First, an overview of BVI and AVI will be provided in Chapter 2, followed by the description of the PIV experimental technique in Chapter 3 and of the experimental facility in Chapter 4. Chapter 5 discusses the experimental results, and finally, Chapter 6 reviews the PIV study of the actively controlled flap conducted at TU Delft. 


\section{Chapter 2}

\section{Blade-Vortex Interaction}

Any moving finite lifting surface will create helical "wingtip" vortices at both extents of its span, as high pressure fluid from the lower surface attempts to leak around the tip to the low pressure region over the upper surface. In conventional fixed wing aircraft, the wingspan of the main wing typically allows these vortices to be spaced in such a manner that they do not interfere with the fuselage or empennage (Figure 2-1). However, they can create an inconvenience for the aircraft following too closely behind, necessitating wake turbulence separation at airports for landing and departing aircraft.

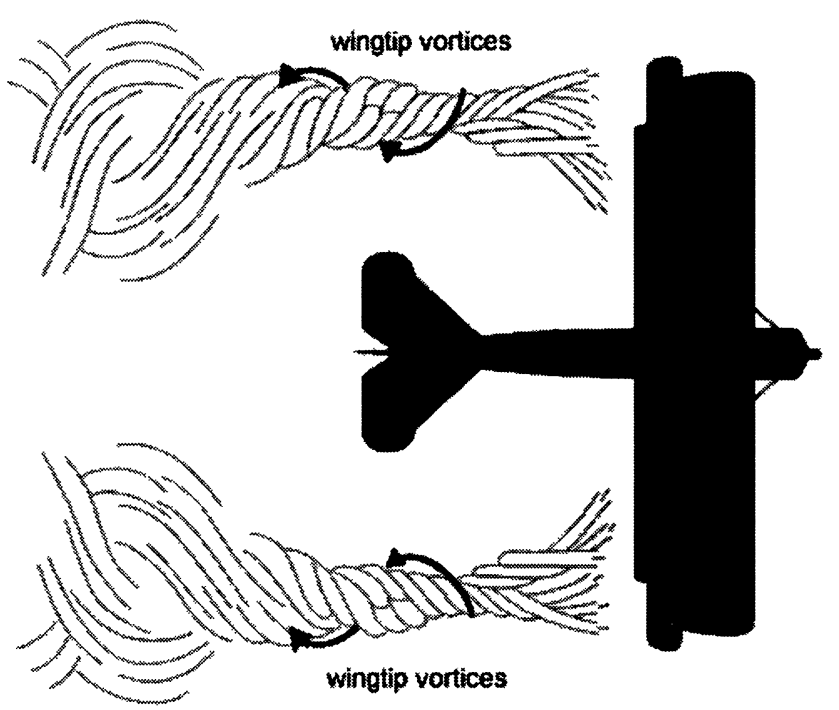

Figure 2-1: Conventional fixed wing aircraft tip vortices [1]. 


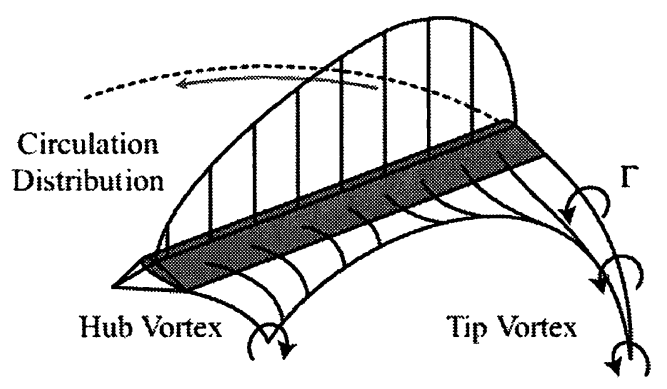

Figure 2-2: Rotorcraft vortex formation [6].

In rotorcraft, each rotor blade sheds a vortex sheet at both its tip and root (Figure 2-2). The root vortex is weaker in magnitude (due to the lower speed of the blade closer to the hub) and is typically expelled from the blade path by the strong downwash, having negligible effect [7]. The tip vortex, however, retains an appreciable integrity for several more rotations as it is carried downstream, impacting the following blades many times before finally dissipating, or leaving the flow field entirely (Figure 2-3). These occurrences are collectively referred to as blade-vortex interaction and, to an observer on the ground, are the source of the characteristic chopping noise associated with helicopters. This is especially true in descending flight, where the downwash is not as strong, thus keeping the vortices present in the blade plane for longer (Figure 2-4). BVI is also prevalent during certain rotorcraft manœuvres, particularly those executed rapidly, before the downwash can fully adjust to the new flow conditions. Interactions are also present with the fuselage, the tail boom and tail rotor, and although non-negligible, they are lower in magnitude and are not the focus of this study. 


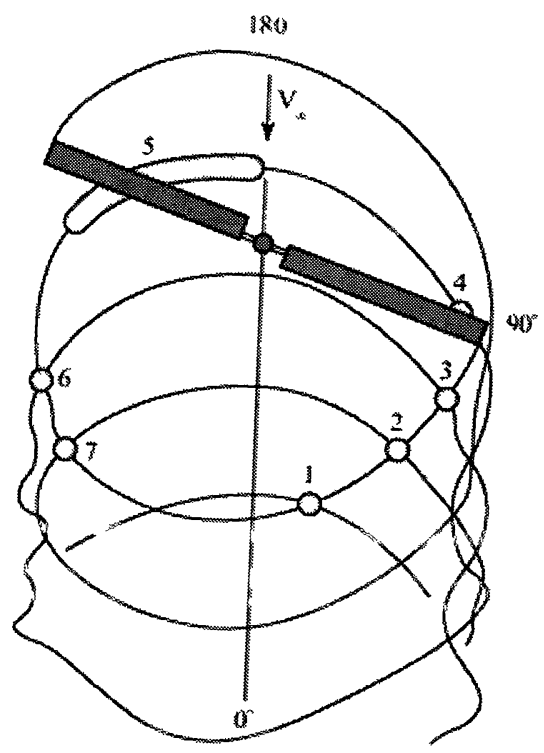

Figure 2-3: Example blade vortex interactions in descending flight (7 most significant types shown) [8].
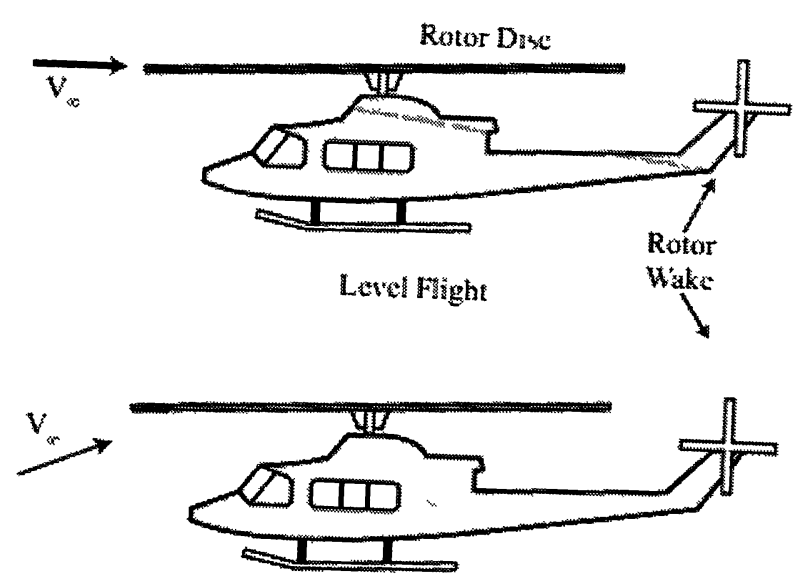

Dewendeng Finght

Figure 2-4: Main rotor wake in level and descending flight [9].

The seven interactions illustrated in Figure 2-3 represent the most significant BVI events that occur in flight. In forward flight, the blade rotation causes the advancing side of the rotor to experience a much higher velocity relative to the freestream than the retreating side. Thus, in Figure 2-3, BVI events labeled 1-4 (on the advancing side) occur 
at a much higher impact velocity, and therefore are more significant. As a way of further characterizing the magnitude of an interaction at a given blade angle and vortex position, it is useful to introduce the definition of the Mach trace number, according to Sim [10] as:

$$
M_{t r}=\frac{\Omega r_{b}+V_{\infty} \sin \psi_{b}}{a_{0} \sin \gamma}
$$

where $\Omega$ is the angular rotor velocity, $r_{b}$ is the rotor radius, $V_{\infty}$ is the freestream velocity, $\psi_{b}$ is the rotor blade azimuth angle, $a_{o}$ is the local speed of sound and $\gamma$ is the angle of the vortex axis relative to the blade axis, as shown in Figure 2-5. Upon comparing Equation 2.1 to that of the local Mach number experienced by a rotor blade element in forward flight (as shown in Equation 2.2), it is apparent that the $M_{t r}$ is scaled by the angle of vortex impact, $\gamma$.

$$
M_{t r}=\frac{\Omega r_{b}+V_{\infty} \sin \psi_{b}}{a_{0}}
$$

Note that the larger $M_{t r}$ becomes, the more significant the BVI extent will be. It becomes clear from Equation 2.1 that $M_{t r}$ increases as the relative velocity of the vortex impact increases, and is heavily dependent on the angle of the vortex axis relative to the blade axis. The graphical interpretation of this is best illustrated in Figure 2-5 for both the advancing and retreating sides of the rotor. 


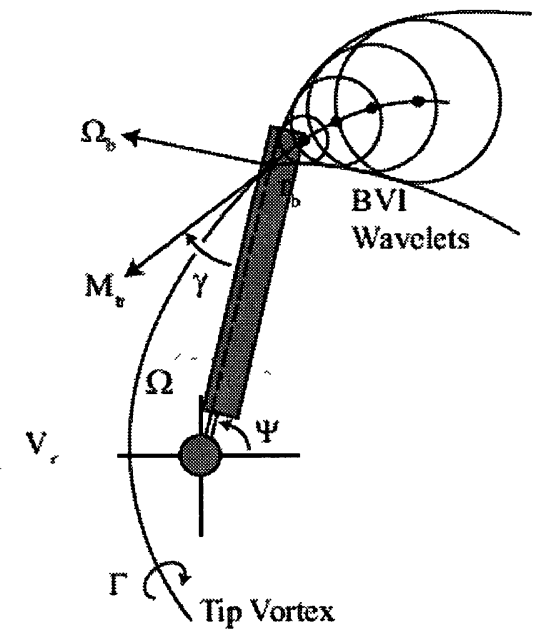

(a) Advancing Side

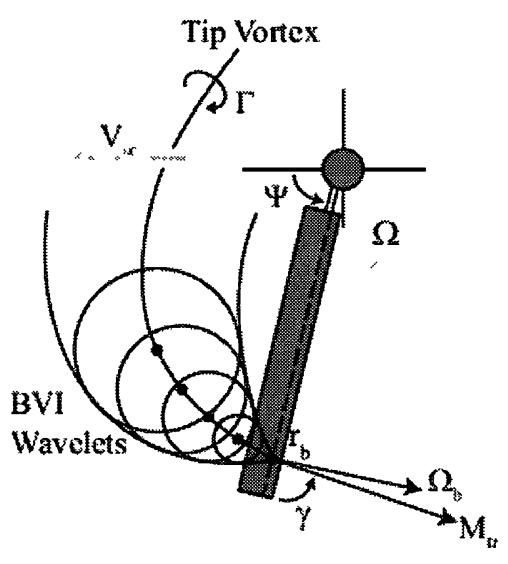

(b) Retreating Side

Figure 2-5: Single BVI event geometry (advancing and retreating sides) [10].

Logically, it follows that $M_{t r}$ becomes maximum at a certain combination of vortex position and azimuth angle, and identifying these allows one to determine the most significant type of BVI. By analyzing the four types of BVI present on the advancing blade (corresponding to points 1 through 4 as shown in Figure 2-3), it is possible to determine the Mach trace number directly as a function of the radial position of vortex impact, as shown in Figure 2-6. 


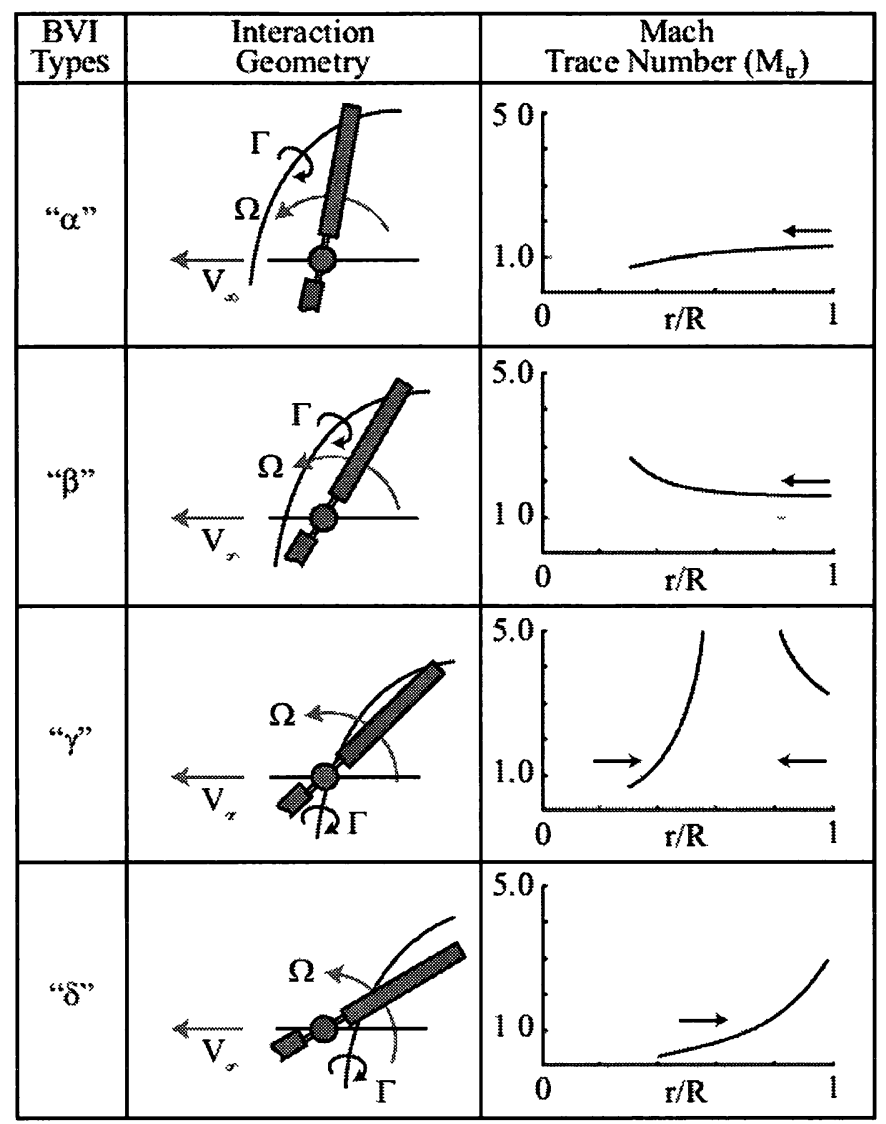

Figure 2-6: Four BVI events on advancing rotor [10].

The most significant type of BVI is that of the $\gamma$-type, occurring at approximately $70-90^{\circ}$ azimuth angle, as it presents the highest (theoretically infinite) Mach trace number. Additionally, the $\gamma$-type represents a simultaneous double impact of the same vortex, as the vortex axis is slightly curved but nearly parallel to the blade axis. As the blade rapidly advances through the vortex core, the two impact points along the blade converge to where the vortex core is tangentially parallel to the blade, resulting in a superposition of two interactions, creating higher noise and vibration than is found in other types of BVI. Thus, the $\gamma$-type is an important distinction, as it allows a new classification of BVI to be defined, namely, that of parallel blade-vortex interaction. 


\subsection{Airfoil-Vortex Interaction}

As shown above, for parallel blade-vortex interaction, the axis of the incident vortex is assumed to be directly parallel to the blade axis at the moment of impact, as shown in Figure 2-7.

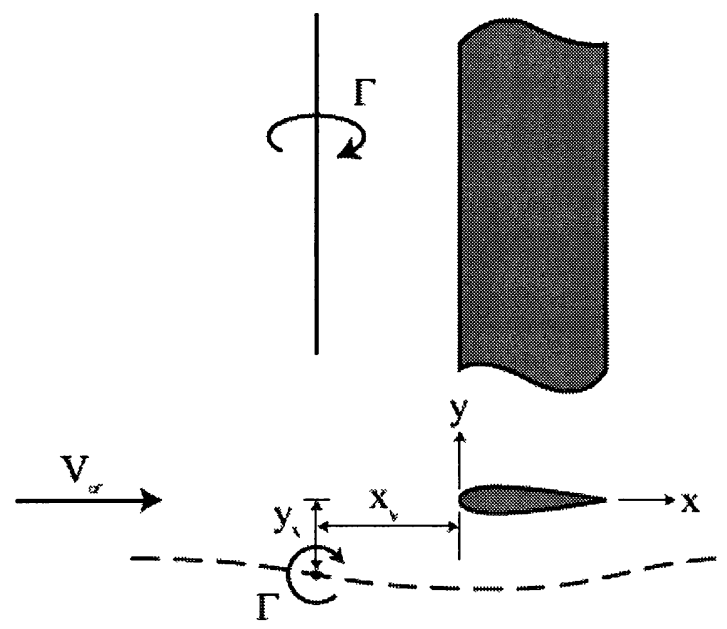

Figure 2-7: Parallel BVI and associated miss distances [3].

With parallel BVI, it is possible to simplify the event further into a strictly twodimensional approximation. This is similar to analyzing the performance of an airfoil, rather than an entire wing, neglecting the wingtip effects. Thus, an assumption can be made that an airfoil is simply impacted with a two dimensional vortex - in reality, this is simply the point where the two vortex interactions in $\gamma$-type meet. Quite understandably, these impacts are referred to collectively as airfoil-vortex interaction.

With AVI, the computational or experimental overhead of system identification is significantly reduced as the problem becomes a function of the freestream velocity $\left(V_{\infty}\right)$, the vortex circulation $(\Gamma)$, and the horizontal $\left(x_{v}\right)$ and vertical $\left(y_{v}\right)$ miss distances (Figure 2-7), along with geometrical variables such as airfoil shape and angle of attack. It is 
important to note that in this instance, $V_{\infty}$ refers to the velocity including the rotational and translational velocity components. The biggest advantage of the AVI approximation comes experimentally, where a rotating body and reference frame is no longer required to examine the effects of the most significant $(\gamma)$ type of BVI.

\subsection{BVI Literature Review}

Historically, much research has been performed on blade- and airfoil-vortex interaction in an attempt to reduce the effect on the rotor and airframe. These studies have been both numerical and experimental in nature and cover many, if not all, of the varieties of BVI experienced, as shown in Figure 2-6. Many studies have focused on producing means of reducing the effects of BVI noise and vibration through the implementation of blade design or actively controlled mechanisms. To begin, however, it is important to discuss the fundamental mechanism through with BVI affects the main rotor blade.

As a clockwise-spinning vortex becomes incident upon an airfoil (as shown in Figure 2-7), it alters the lift coefficient of the airfoil while it passes. Prior to the vortex passing the leading edge, the circulation forces the stagnation point higher on the airfoil, thereby reducing the lift. Conversely, while the vortex passes underneath the airfoil, the stagnation point is dragged lower, increasing the effective angle of attack, and hence, lift. Renzoni and Mayle [11] performed studies to characterize this behavior, and a small portion of this is presented as Figure 2-8. 


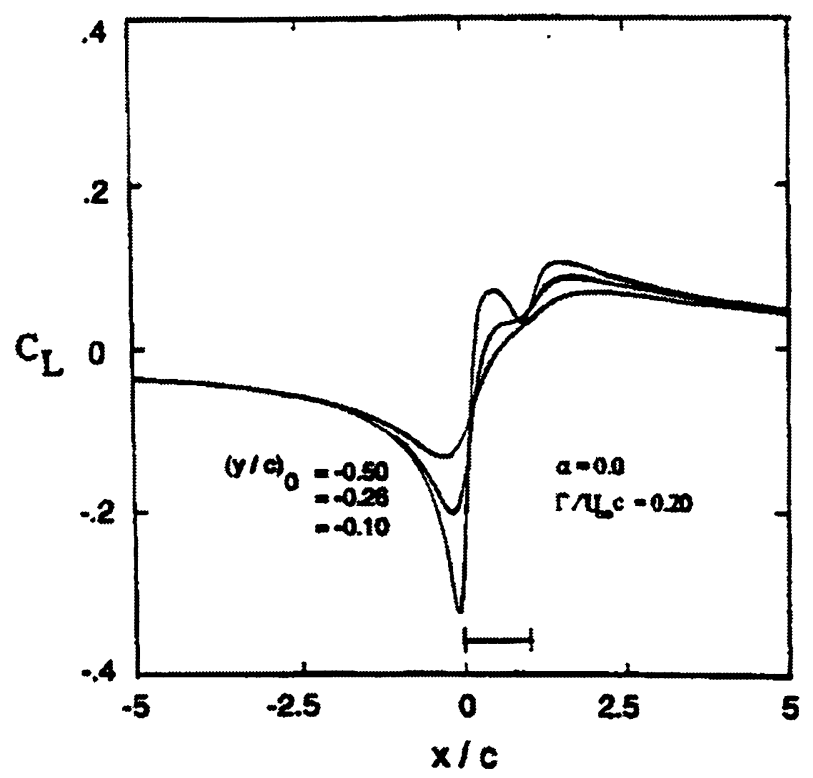

Figure 2-8: Typical vortex induced lift coefficient with instantaneous vortex position on a symmetric NACA 0012 airfoil [11].

Numerically, as has been discussed, the complex nature of BVI leads to simplifications being made if simulations are to be performed with a reasonable computational time. Computational studies have been performed by Srinivasan [12], Schmitz [13], Wong [14] and Oh [15] through the use of a Navier-Stokes solver. Berenger [16] created and then investigated the prediction efficiency of a wake analysis code by comparing with experimental work. Despite the 4 to 12 week computational time experienced by these researchers, the advantage of these studies over experimental methods lies in their ability to fully vary the flow conditions and observe small changes more easily. Typically these studies were performed well into the compressibility regime $(M>0.3)$, which is a speed far above the capabilities of many experimental facilities. The results of these studies have yielded an improved understanding of the BVI phenomenon and have led to the design of miss distance-increasing blade flapping mechanisms (such as $\mathrm{Yu}$ [17]), and noise-reducing porous leading edges (Lee [9]). At 
Carleton University, Wong [4] performed Navier-Stokes CFD simulations and utilized Volterra integral equations for nonlinear systems to characterize the nonlinear aerodynamic response of a blade undergoing AVI. However, these simulations were computationally time-consuming (6-7 weeks per run) and the AVI vortex was still too dissipative even on the fine grid used. Vortex dissipation is an inherent characteristic of classical grid-based Navier-Stokes solvers. Thus, Ilie [5] attempted to simulate 2D AVI with LES. Although in LES, the vortex dissipation can be eliminated, the run times are even longer due to a much finer grid be used - 2-3 months per simulation - prohibiting systematic study of AVI in a reasonable timeframe.

Experimentally, many different techniques have been employed to capture the BVI phenomenon; however it is the simplified parallel BVI or AVI that has been of most interest to experimental researchers, as discussed earlier. Lee [9] utilized a shock wave passing a stationary, pitched airfoil to generate a coherent vortex as shown in Figure 2-9.

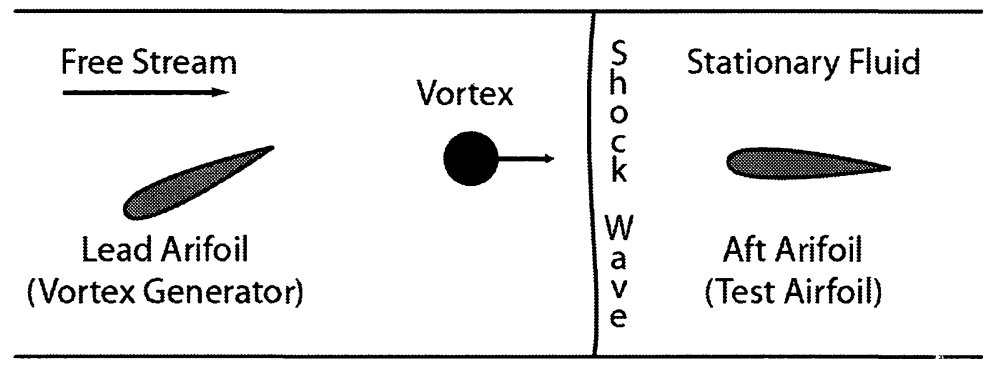

Figure 2-9: Schematic of shock wave vortex generation [18].

Lee [9] captured the interaction with a dual-pulsed holographic inferometer technique along with pressure measurements from the test airfoil. He concluded that viscous effects were significant and cannot be neglected in BVI numerical studies. Some of his numerical and experimental results are presented in Figure 2-10. 

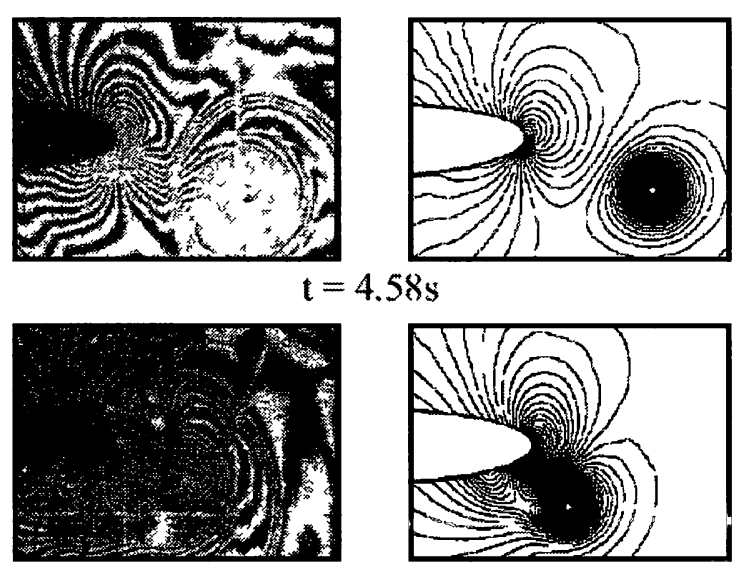
$\mathrm{t}=5.02 \mathrm{~s}$

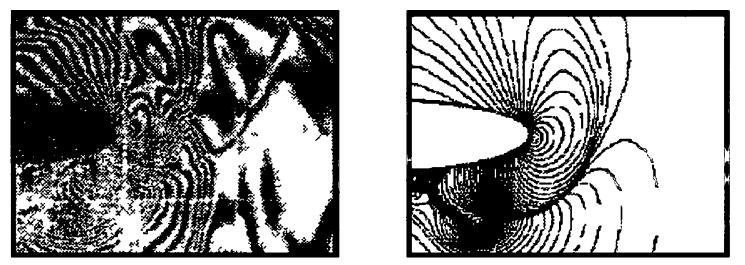

$t=5.17 \mathrm{~s}$

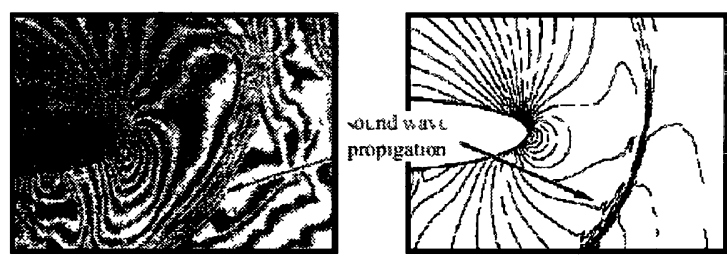

$\mathrm{t}=5.32 \mathrm{~s}$

Figure 2-10: Capture of AVI pressure contours by means of dual-pulsed holographic inferometer (left) and numerical simulation (right) [9].

Caradonna [19] experimentally captured BVI events in three-dimensions by installing an oscillating, vortex generating airfoil upstream of a fully rotating test rotor blade, as illustrated in Figure 2-11. Pressure measurements were obtained through pressure taps in the rotating blades, with hot wire anemometry used to validate the vortex creation method. 


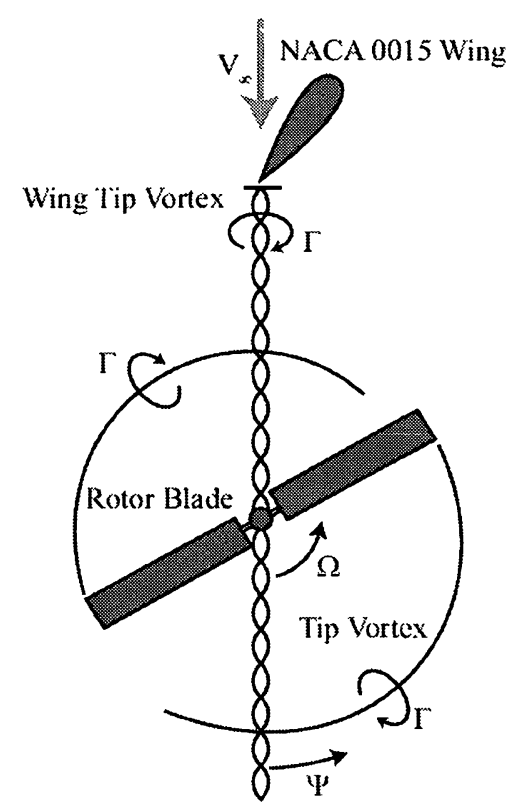

Figure 2-11: Schematic of the three-dimensional BVI apparatus by Cadadonna [19].

The studies into BVI and AVI share some similarities that will be carried into this study. By far, the majority of airfoils used, both for generating vortices and vortex impact testing, were the NACA 0012 airfoil. This study will also implement a pitching airfoil variety of vortex generator which was utilized in many studies of AVI. It will further evaluate the feasibility of a new vortex generator design, as will be discussed in Section 4.4. 


\section{Chapter 3}

\section{Particle Image Velocimetry}

Flow visualization and measurement by means of particle image velocimetry is largely non-intrusive in nature. This inherently offers many advantages over direct measuring techniques. Additionally, PIV systems are capable of capturing the velocity profile of the entire flow field simultaneously, which cannot be found with any form of direct measurement. This can be achieved in three dimensions with advanced PIV systems, or constrained to a two-dimensional cross-section of flow for conventional apparati. The most common PIV systems are of the two-dimensional type as shown in Figure 3-1, and will be discussed below.

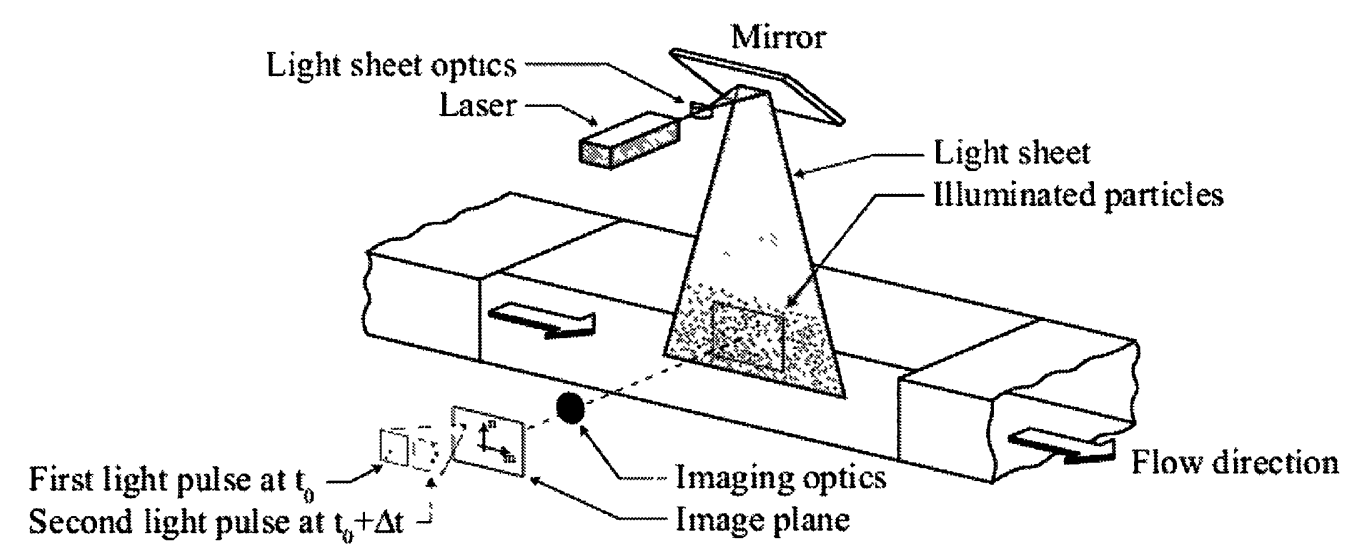

Figure 3-1: Typical two-dimensional Particle Image Velocimetry (PIV) apparatus [20].

To begin obtaining the measurement, the flow field must first be seeded with tracer particles, of a size small enough $(<100 \mu \mathrm{m})$ to be fully entrained within the flow. As such, the test section is usually contained within a closed circuit wind tunnel, to eliminate (or minimize) the need to continuously seed the flow with particles. This also 
assists in ensuring a homogenous distribution of the tracer particles throughout the flow. The tracers are typically in the order of $1-25 \mu \mathrm{m}$ in diameter for gaseous flows, and 10$100 \mu \mathrm{m}$ for liquid flows. Larger particles may not accelerate uniformly with the flow field; this causes undesirable error in the data obtained and should therefore be avoided. Example tracer particles for gaseous flow are listed in Table 3-1.

Table 3-1: Example tracer particles for gaseous flows [21].

\begin{tabular}{|c|c|c|}
\hline Type & Material & Mean Diameter $(\boldsymbol{\mu m})$ \\
\hline \multirow{4}{*}{ Solid } & Polystyrene & $0.5-10$ \\
\cline { 2 - 3 } & Aluminum & $2-7$ \\
\cline { 2 - 3 } & Magnesium & $2-5$ \\
\cline { 2 - 3 } & Glass micro-balloons & $30-100$ \\
\cline { 2 - 3 } & Granules for synthetic coating & $10-50$ \\
\cline { 2 - 3 } & Dioctylphathalate & $1-10$ \\
\hline Smoke & - & $<1$ \\
\hline Liquid & Different oils & $0.5-10$ \\
\hline
\end{tabular}

To illuminate the tracer particles, a pulsed laser is fired into a cylindrical lens, forming a sheet of intense laser light perpendicular to the flow. The monochromatic nature of laser light ensures the absence of chromatic aberrations which can occur if multiple wavelengths of light are present. The laser source must be one of a high enough power to adequately illuminate the particles throughout the field. This is especially true if the tracer particles are very small in size, which is normally desirable for the aforementioned reasons. In many modern commercial and research applications, the 
laser of choice is a Nd:YAG $(532 \mathrm{~nm})$; it offers a good compromise between illumination power and price. The laser pulse and subsequent illumination of tracer particles is very brief, typically of the order of 10 ns or less. Further, tracer particle material should be chosen carefully (index of refraction, transmissivity, etc), as to ensure proper scattering of the illuminating light.

Once illuminated, the position of all particles is captured simultaneously by a camera mounted perpendicular to both the flow and the laser sheet. After a precise delay, $\Delta t$, as determined by the velocity of the flow and desired resolution of data, the particles are illuminated and photographed again. This second illumination may be accomplished by a secondary identical laser, if the delay is shorter than the cool-down time necessitated by the high power laser system. The use of two cameras is not usually required, however, as the typical delay $(5-100 \mathrm{~ms})$ is achievable by most modern digital cameras.
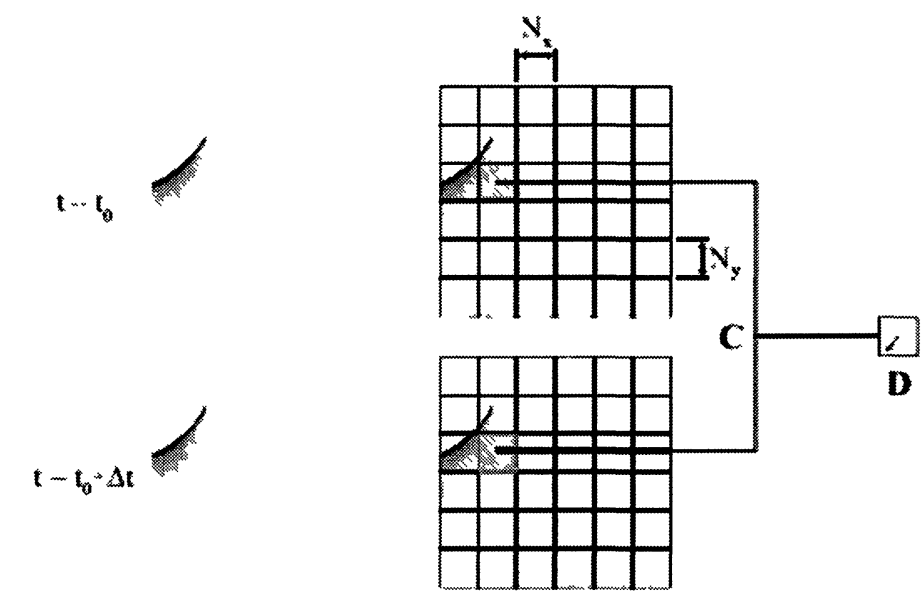

A

B

Figure 3-2: PIV image capture (A), interrogation region selection (B), correlation $(C)$, vector generation (D) [3]. 
The two images obtained are then digitally post-processed to establish the velocity field within the flow as shown in Figure 3-2. Each image is separated into much smaller regions of interest, either automatically or manually, and then compared against one another. Using an approximate value for the freestream velocity and the precise delay between the images, these interrogation regions are systematically cross-correlated to identify the path of the majority of the tracer particles contained within. From there, a velocity vector is obtained for each interrogation region (Figure 3-3). Thus, if there is sufficient seeding of particles, the interrogation regions can be small enough in size to reveal the velocity of the fluid at many discrete intervals throughout the flow. High accuracy of the velocity measurements can be achieved, with errors of typically less than $1 \%$.
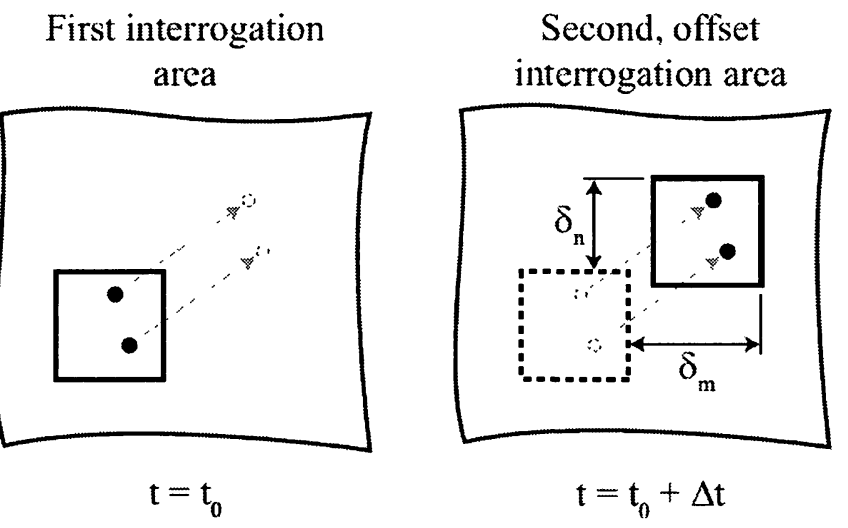

Figure 3-3: Correlating interrogation areas [3].

With modern computers, basic data processing typically can almost be accomplished in real time. However, situations may arise that must be handled manually, or by a combination of manual and automatic techniques. For instance, the grid of velocity vectors returned by the system must be examined for artifacts, which are erroneous vectors generated by an error within image capture or post-processing. These 
artifacts can be simply eliminated from the flow field, or re-generated using a weighted average of neighboring vectors. Artifacts can be automatically detected by establishing 'expected' values for the velocity and direction of motion at various points throughout the flow. Noise filters may also be applied manually as required.

The result of the imaging process coupled with advanced post-processing is a digital set of data, capable of visualization of the velocity field throughout the field of view. From this velocity vector map, it is possible to obtain the vorticity field by the two dimensional curl of the velocity at each point, as shown in Equation 3.1:

$$
\omega=\frac{\delta V_{y}}{\delta x}-\frac{d V_{x}}{d y}
$$

It is also possible to manipulate the velocity vectors to obtain other parameters, such as the pressure, by means of Bernoulli's principle, given as Equation 3.2:

$$
\frac{1}{2} \rho V_{1}^{2}+\rho g z_{1}+P_{a t m}=\frac{1}{2} \rho V_{2}^{2}+\rho g z_{2}+P_{s}
$$

It is possible to neglect the gravitational terms as the change in height is negligible, as well as the $V_{1}$ term due to the atmospheric pressure, $P_{a t m}$, being observed with zero initial velocity. Thus, the equation simplifies as follows to Equation 3.3:

$$
\begin{aligned}
& P_{a t m}=\frac{1}{2} \rho V_{2}^{2}+P_{s} \\
& P_{s}=P_{a t m}-\frac{1}{2} \rho V_{2}^{2}
\end{aligned}
$$

Thus, 
Alternatively, one can combine Bernoulli's equation to derive the coefficient of pressure directly from the velocity field, as shown in Equation 3.4:

$$
C_{P}=1-\left(\frac{V}{V_{\infty}}\right)^{2}
$$

It is important to note that these are all time-averaged parameters over the length of the delay between exposures. Thus, it is important to select a small delay between exposures if rapid changes in velocity are expected (i.e. leading edge of a bluff body). Conversely, the resolution can be increased by capturing less of the flow field at once, thereby capturing more unique tracer particles. For a comprehensive review of PIV theory, including additional information on tracer particles, laser theory, CCD cameras, and post-processing, see Burwash [3]. For a comprehensive guide to the usage of the PIV system in the tunnel outlined in Chapter 4, see Appendix A. 


\section{Chapter 4}

\section{Wind Tunnel for Two-Dimensional Flow Studies}

\subsection{Purpose}

The main aim of this study was to investigate means of mitigating or alleviating the negative effects of BVI by first understanding, and then controlling this phenomenon. To accomplish this effectively, one needs to understand which parameters of BVI should be controlled for the most significant reduction of noise and/or vibration. This can be performed best via systematic identification.

Such a study requires a large number of tests to be performed, either numerically or experimentally. As outlined in Section 2.2, simulation run times can be prohibitive when attempting to run multiple tests. Given the processing power available at the time of these studies, it was clear that if a large number of parameters are to be investigated over a wide range of testing conditions, a numerical approach is not practical within the timeframe required.

However, performing a study of AVI experimentally permits large number of runs to be completed at a relatively much faster rate, once the experimental facility has been set up. The challenge here is to reproduce the convection, speed and strength of AVI vortices experienced by rotorcraft under repeatable laboratory conditions in a wind tunnel designed for AVI system identification. 


\subsection{Wind Tunnel Specifications}

The task of designing and constructing a wind tunnel at Carleton University suitable for PIV studies of two-dimensional AVI events was accomplished by Brassard [1], then later commissioned by Wilkins [2] and configured for PIV testing by Burwash [3]. This was the tunnel utilized in this study and will be described briefly below.

\subsubsection{Tunnel Design Constraints}

During the design phase, a number of requirements were placed upon the tunnel, and the five most notable of which are discussed below.

\subsubsection{Space Limitations}

The design of the tunnel was physically limited by the space available behind a large open-circuit wind tunnel in the laboratory room. This space would have to be sufficiently large for tunnel construction, operation and maintenance. The available space is shown as Figure 4-1.

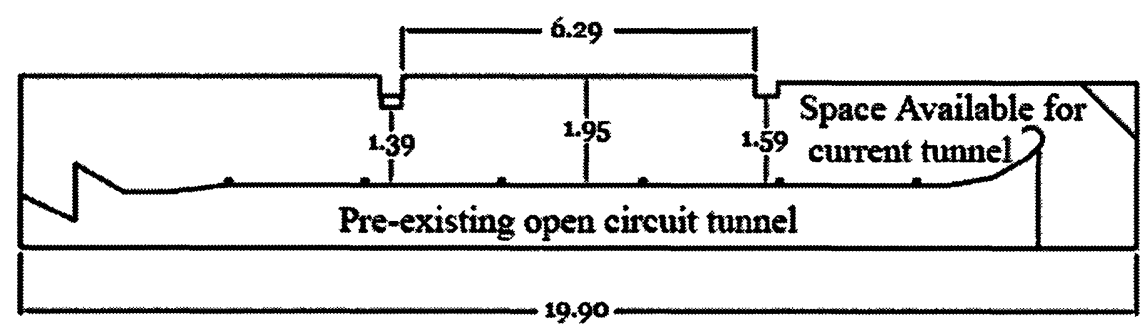

Figure 4-1: Available unused space (dimensions in meters) [1].

In Figure 4-1, the three meters of vertical space available is not shown but was important to consider while designing the tunnel. This space would have to be utilized, 
given the limited amount of floor area available for a closed circuit tunnel, which are typically horizontally tracked.

\subsubsection{Test Section Speed}

The desired tunnel speed was set to be $100 \mathrm{~m} / \mathrm{s}$ or 0.3 Mach, a value well above the typical wind tunnel speeds used for AVI studies [3], but still below the expected impact speed for $\gamma$-type BVI. These impacts occur at approximately 0.5-0.6 Mach, due to the freestream velocity $(\sim 0.2 \mathrm{M})$ combining with the rotor velocity at the point of impact ( 0.4 Mach, see Figure 2-6). Nevertheless, this was deemed to be the best compromise between the $\gamma$-type BVI impact speed experienced by rotorcraft, tunnel fan power requirements and experimental vortex generating abilities in practice.

\subsubsection{Desired Vortex}

Designing the tunnel to permit comparison to full size rotorcraft on the basis of Reynolds number would have required the size of the test airfoil chord lengths, the test section and the blower to be greater than the space and budget constraints. Therefore, the dimensions of the tunnel were chosen such that it will accommodate vortices of a similar strength to that found on a typical rotorcraft. Specifically, the main rotor of the Bell $407^{1}$ was investigated and was found to generate a vortex circulation of $3.22 \mathrm{~m}^{2} / \mathrm{s}$ during level flight or a constant descent [1]. This was then non-dimensionalized, with respect to the approximate freestream velocity and chord length, ${ }^{2}$ thereby yielding a vortex strength of 0.119 [1]. Further, the core diameter size has been determined to be approximately the

\footnotetext{
${ }^{1}$ The Bell 407 features a Boeing VR-7 (12\%) airfoil at the root, blending to a Narramore (8\%) at the tip, with a mean chord length of $25.5 \mathrm{~cm}$ and a rotor diameter of $10.7 \mathrm{~m}$. The tip speed is $231 \mathrm{~m} / \mathrm{s}$. [28]

${ }^{2} \Gamma_{\mathrm{ND}}=\Gamma /\left(V_{\infty} \bar{c}\right)$
} 
thickness of the generating blade [12]. These targets were then selected as performance targets for the tunnel. Various vortex generation techniques will be discussed in Section 4.4 .

\subsubsection{Test Section Size}

The test section was designed according to a number of criteria, driving much of the design. First, it had to be sufficiently large in the streamwise direction to accommodate both a vortex generating and test airfoil, with adequate separation distance to investigate vortex deterioration. Chordwise, it must be wide enough to minimize any wall effects present, while not so wide as to ensure the flow remains two dimensional. Vertically, the section should permit a vortex strength of 0.119 , as mentioned above, to travel downstream essentially unconstrained by the walls. Further, the cross-sectional area must be adequate to avoid blockage effects larger than $5 \%$, to preclude having to apply correction factors [22].

\subsubsection{Suitability for PIV}

The tunnel also had to easily accommodate the implementation of the selected measurement technique, namely, PIV. As discussed, this requires that one wall and the floor of the test section to be constructed from a transparent material with low refractive indices. As PIV relies on particles being entrained in the flow, a closed-circuit tunnel was desired to enable particle seeding to be possible. PIV also necessitates a large number of averaged tests in order to accurately establish flow conditions. This further reinforces the requirement that the testing should be simple but with the added constraint of being repeatable over many runs. 


\subsubsection{Tunnel Design}

To meet the above design requirements, a vertical closed-circuit tunnel was selected, as shown in Figure 4-2.
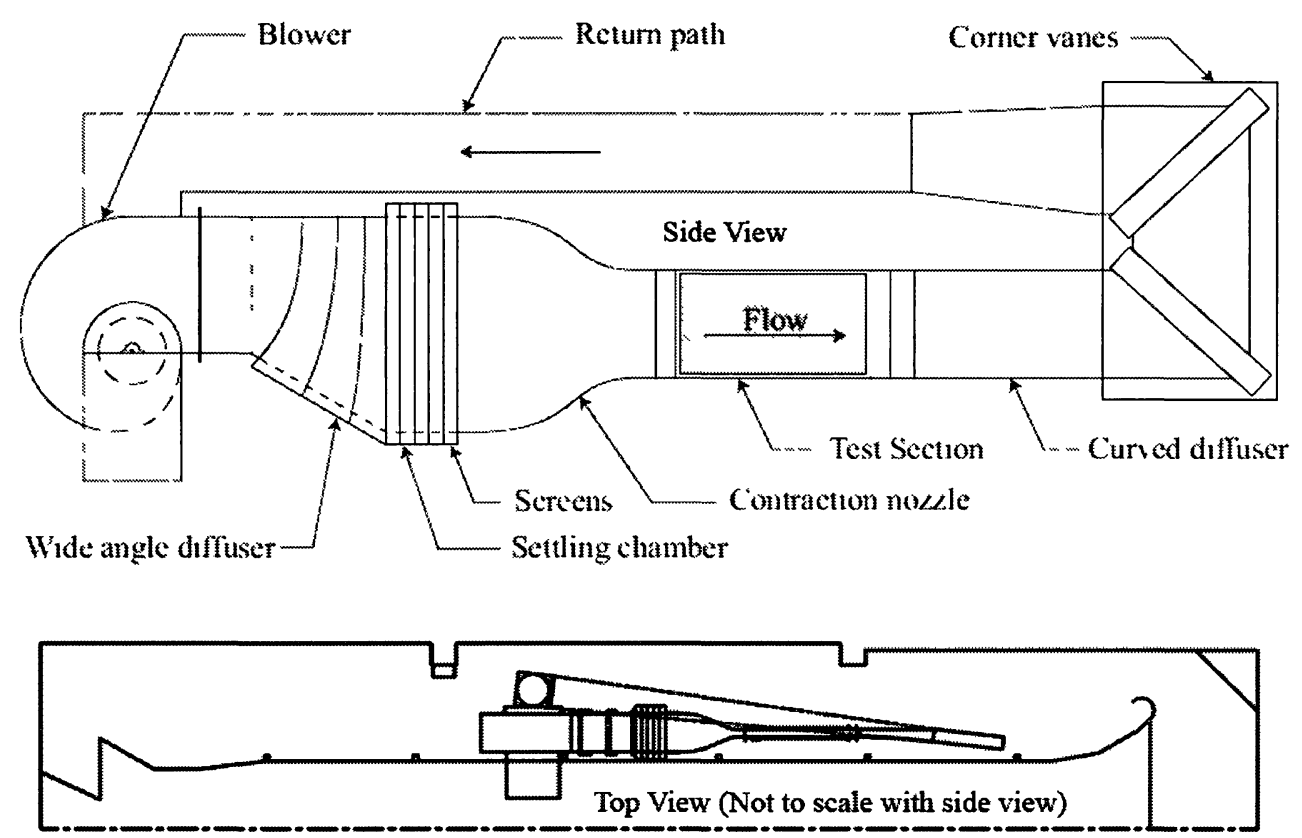

Figure 4-2: Tunnel design and placement in available space [3].

A $25 \mathrm{~kW}$ centrifugal blower was used, which offers an advantage over axial fans as it eliminates one set of corner vanes since the blower itself rotates the flow through ninety degrees. However, as the inlet to the blower is perpendicular to the output, it necessitates the tunnel return path to deviate from the center line of the test section, creating a fifth corner, as shown in the top view of Figure 4-2.

Speeds are controlled by means of a variable frequency drive, which is capable of digitally controlling the blower frequency from $0-60 \mathrm{~Hz}$. It enables repeated measurements to be performed at the same velocity. This led to a maximum velocity of 
approximately $90 \mathrm{~m} / \mathrm{s}$ in the test section, somewhat below the desired $100 \mathrm{~m} / \mathrm{s}$, but still in the acceptable range [2].

The width and height of the test section match that of the contraction nozzle, at $0.127 \mathrm{~m}$ and $0.737 \mathrm{~m}$, respectively. This accommodates airfoils of an appropriate testing size, minimizes wall effects, potential blockage and maintains two-dimensional flow with an aspect ratio of nearly $6: 1$. A section length of $1.80 \mathrm{~m}$ was constructed to enable results from many chord lengths downstream of the test airfoil to be examined. The section is shown schematically as Figure 4-3.

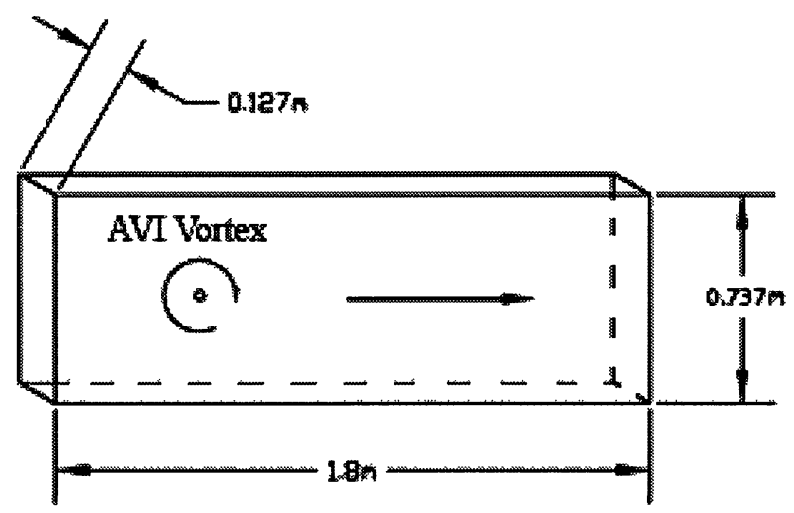

Figure 4-3: Test section schematic.

A glass-covered slot was created in the bottom of the test section to permit the PIV laser sheet to pass vertically into the tunnel. Additionally, the walls were constructed of transparent, removable Lexan panels to aid with PIV data capture.

\subsection{Flow Studies}

To fully understand the flow conditions in the undisturbed test section, a number of flow studies were performed. Initially, the velocity profile at the centerline of the tunnel and 
the flow angularity were examined by Wilkins [2], followed by research into turbulence intensity levels. These were conducted by the author and are documented in detail in the following sections.

\subsubsection{Centerline Velocity Profile}

As the PIV measurements of any AVI event will occur down the centerline of the test section, it is important to investigate the flow conditions there to understand how any wall effects might affect the velocity profile changes from inlet to outlet. Measurements were taken by Wilkins [2] at a number of cross sectional locations by a handheld manometer, as shown in Figure 4-4; the experimental error in these values are estimated to be of $\pm 5 \%$ due to the installation, calibration and precision of the manometer. Note that the velocities at the inlet are remarkably uniform throughout the centerline, at a range of test section speeds. At the outlet, however, the velocity has slowed slightly at the top and bottom edges of the flow due to boundary layer wall effects. If the two data points closest to the top and bottom are omitted, the inlet and outlet velocity profiles only deviate by $0.3 \%$ and $1 \%$, respectively [3].
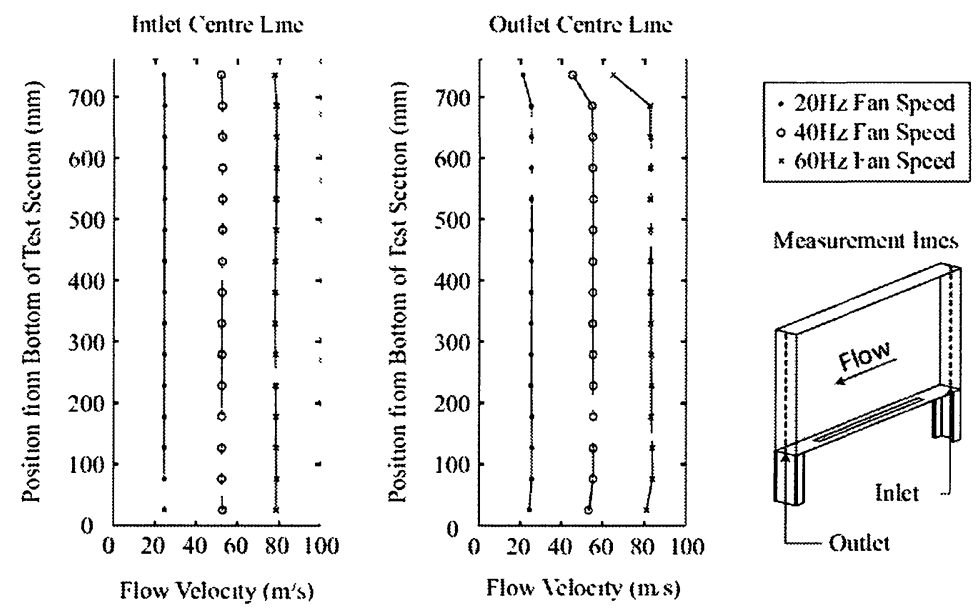

Figure 4-4: Centerline velocity profile [3]. 


\subsubsection{Flow Angularity}

The flow angularity data for blower settings of $20 \mathrm{~Hz}, 40 \mathrm{~Hz}$ and $60 \mathrm{~Hz}$ are shown as Figure 4-5. Measurements were obtained by means of a three hole pitot probe with experimental errors of $\pm 0.5^{\circ}$ due primarily to probe alignment and calibration inconsistencies [2]. Note that these blower frequencies gave freestream velocities of approximately $24 \mathrm{~m} / \mathrm{s}, 55 \mathrm{~m} / \mathrm{s}$ and $83 \mathrm{~m} / \mathrm{s}$ and have corresponding maximum angularity of $1.3^{\circ}, 1.5^{\circ}$ and $1.6^{\circ}$, respectively [2].
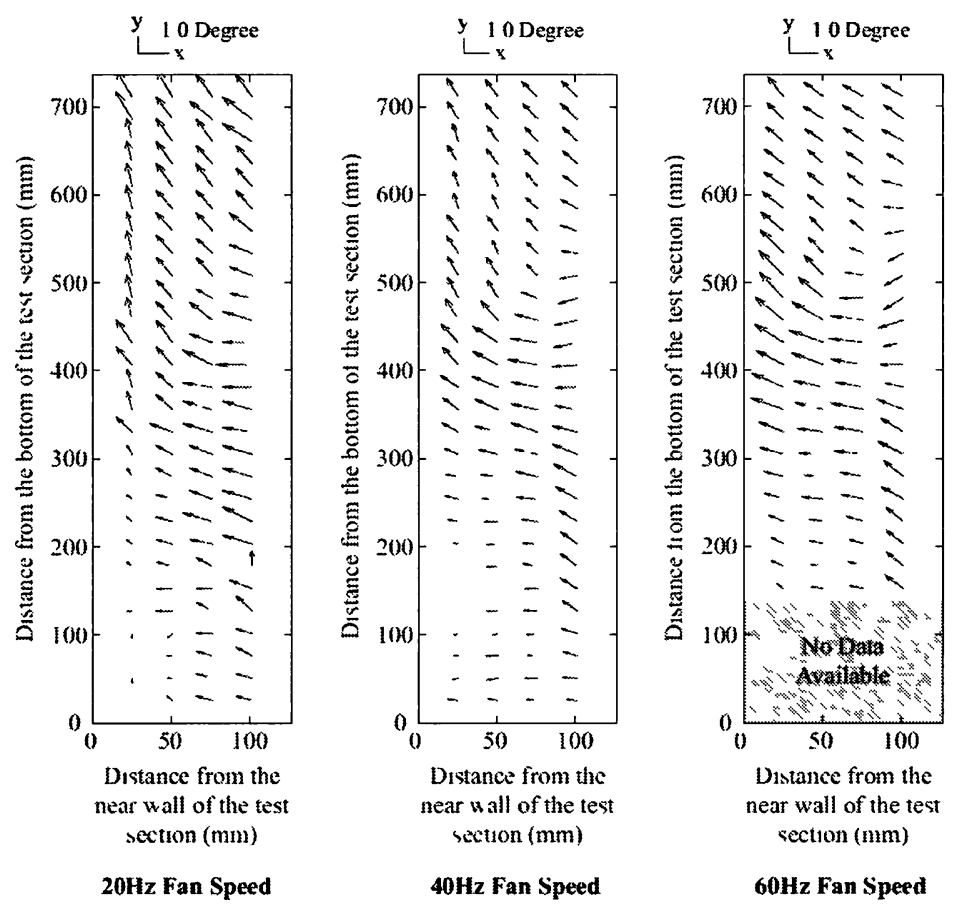

Figure 4-5: Flow angularity study at a cross section midway through the test section [2].

\subsubsection{Turbulence Intensity}

The tunnel was examined for turbulence intensity by this author both upstream and downstream of the test section by means of an AA-Labs Systems AN-1005 constant temperature hot wire anemometry probe. The probe, as configured, measured velocity 
with an experimental error of within $0.1 \%$. It was secured in the flow at 21 different cross-sectional probe locations $(3 \times 7$ grid with $9 \mathrm{~cm}$ vertical separation and $3 \mathrm{~cm}$ horizontal separation, centered along the centerline of the test section) both upstream and downstream of the test section (Figure 4-6) to ensure the flow had comparable qualities throughout. Measurements of velocity were recorded over the full range of tunnel flow speeds at a rate of $500 \mathrm{~Hz}$.

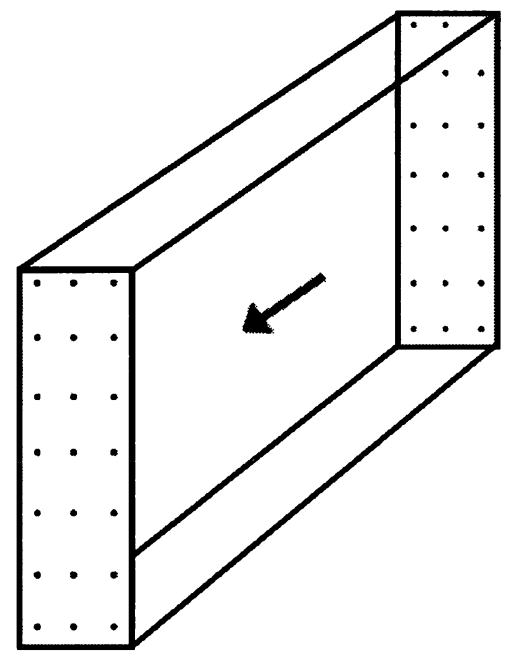

Figure 4-6: Hot-wire anemometry probe locations.

These velocities were then normalized by the mean speed of the recorded sample, $\bar{V}$, deriving the non dimensional turbulence intensity as shown in Equation 4.1.

$$
I=\frac{|V-\bar{V}|}{\bar{V}}
$$

It was observed that, in sample set of 10,000 measurements over 20 seconds, both the maximum and average turbulence intensity varied less than $0.02 \%$ across the crosssectional area at a given flow location and velocity. However, the flow was observed to 
become more turbulent as it moved downstream, and with increasing velocity as expected, as shown in Figure 4-7.

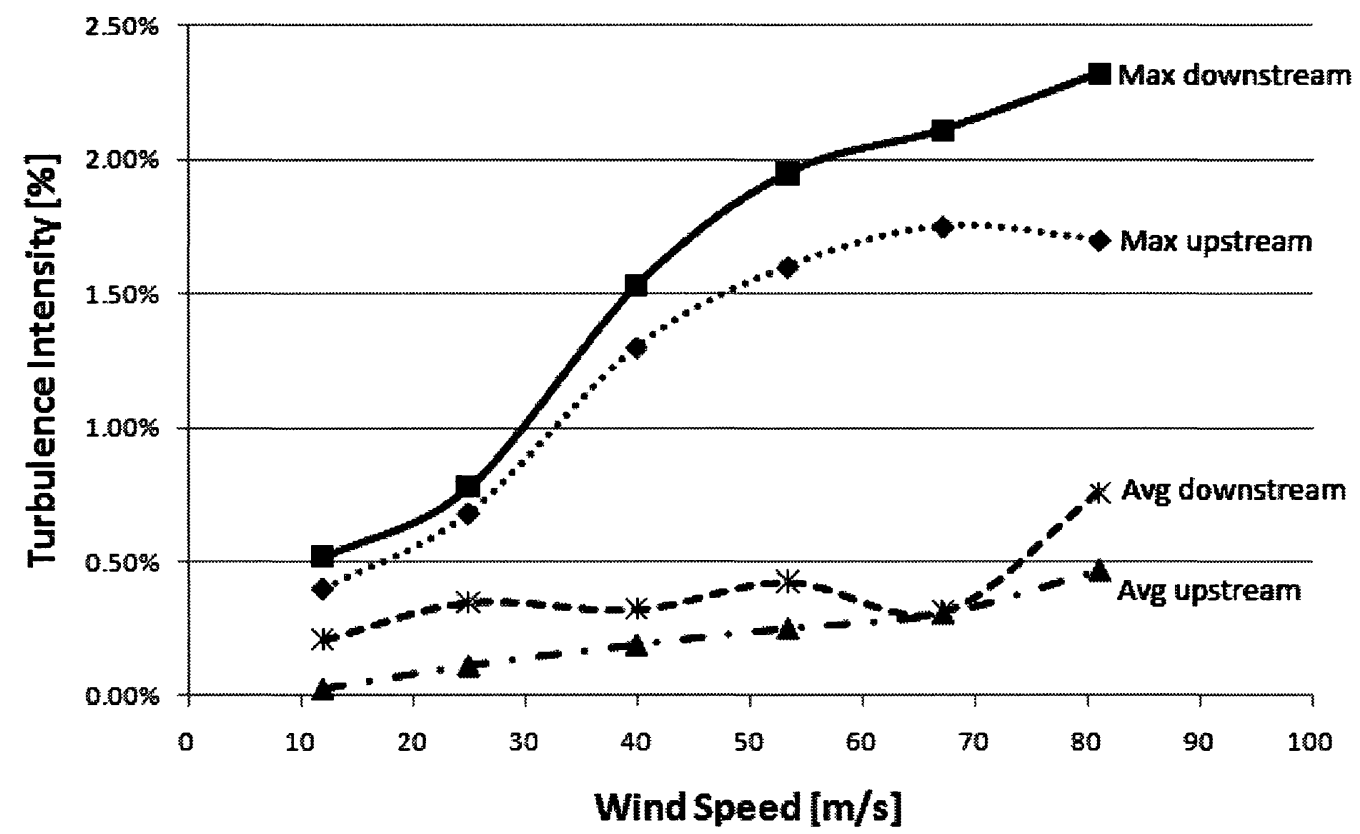

Figure 4-7: Variation of average and maximum turbulence intensities with wind speed.

It should be noted that, both the peak and average values of turbulence are considered to be at a low level for a closed-circuit tunnel of this type. Tunnels used for aerodynamic study of steady flows typically feature turbulence intensity levels of 0.02 $3 \%$.

\subsection{Vortex Generation}

To study an AVI event experimentally, a vortex must be convected downstream into a test airfoil. This vortex must be artificially generated in a controllable and repeatable manner. Two methods of generating vortices were considered: a conventional pitching airfoil and a new plunging method proposed by Brassard [1]. 


\subsubsection{Pitching Airfoil}

Within the control volume of air surrounding an airfoil, the net circulation will always remain zero. Thus, as an airfoil begins to generate lift, it sheds an equal but opposite vortex downstream to counteract its own bound vortex. For an airfoil of constant shape, circulation can be expressed as a function of the freestream velocity and lift coefficient, as shown in Equations 4.2 to 4.4 below.

$$
\begin{gathered}
\Gamma=\frac{L}{\rho_{\infty} v_{\infty}} \\
L=\frac{1}{2} \rho_{\infty} v_{\infty}^{2} C_{L} \bar{c}
\end{gathered}
$$

Where $L$ is the lift per unit length, $\rho_{\infty}$ is the freestream density, $v_{\infty}$ is the freestream velocity, $C_{L}$ is the lift coefficient and $\bar{c}$ is the chord length. Thus, the change in circulation $(\Delta \Gamma)$ as a result of changing the airfoil lift due to pitching $\left(\Delta C_{L}\right)$ will be:

$$
\frac{\Delta \Gamma}{\bar{c}}=\frac{1}{2} v_{\infty} \Delta C_{L}
$$

Therefore, any rapid change in the circulation surrounding an airfoil, including changes in angle of attack or velocity, will induce a starting vortex of known strength. This effect can be utilized to generate a vortex in a wind tunnel suitable for investigating AVI. As abruptly changing the freestream velocity is neither practical nor feasible for experimental purposes, it is more useful to generate a vortex by quickly changing the 
angle of attack of an airfoil, and hence, its lift coefficient. For small pitch changes, the change in lift coefficient for an airfoil without camber can be expressed, in degree as [3]:

$$
\Delta C_{L} \approx 0.11 \Delta \alpha
$$

Where $\Delta \alpha$ is the change in the angle of attack in degrees. Thus, by combining Equations 4.4 and 4.5 , we can obtain an expression for predicting the shed vortex circulation from a camber-less airfoil undergoing a small, rapid change in pitch:

$$
\frac{\Delta \Gamma}{\bar{c} W}=0.055 V_{\infty} \Delta \alpha
$$

This can be accomplished by positioning an airfoil in the test section, affixed to a notched spring-loaded rotating variable radius cam, as shown in Figure 4-8. As the cam is rotated manually, the airfoil slowly pitches down, before rapidly pitching upwards, generating and shedding a starting vortex. In the setup installed in the current wind tunnel, the pitch angle change generated by the mechanism is about $3^{\circ}$.

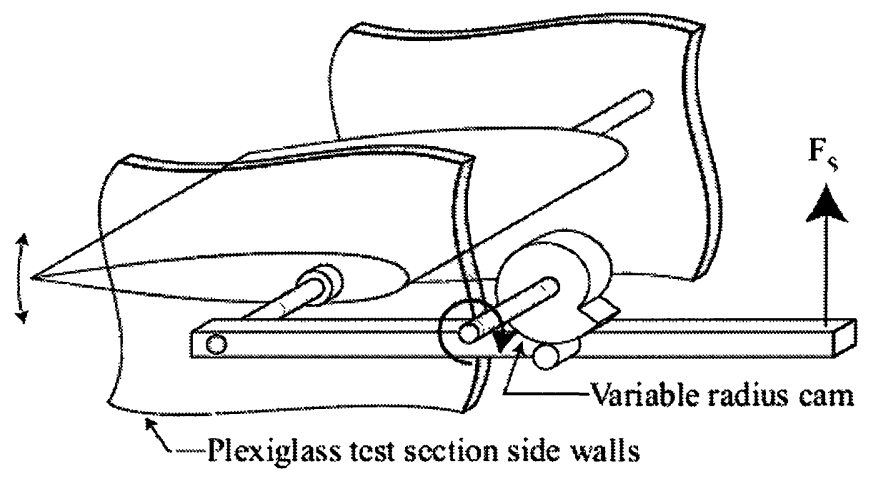

Figure 4-8: Pitching vortex generator (spring not shown). 
The pitching airfoil is typically similar in chord length to that of the test airfoil, which aids in generating the appropriate vortex size [1]. Its construction must be rigid but lightweight to permit the rapid pitching motion; sculpted styrofoam or wood are often used. It is preferred to design the vortex generator using a symmetric airfoil, in an attempt to minimize the effect of tunnel blockage, as discussed below. This method has become the standard way of vortex generation in wind tunnels, especially those for investigating parallel BVI.

\subsubsection{Numerical Analysis of Pitching Airfoil}

A pitching airfoil vortex creation method presents a problem as the generating airfoil will remain in the flow upstream of the test airfoil throughout the experiment. This could cause undesirable unsteady flow over the test blade, potentially compromising the AVI data obtained. Thus, a numerical evaluation of the interference effect of the vortex generator and test airfoils was performed.

\subsubsection{Test Geometry}

Since both the vortex generator as well as the test airfoil were supposed to be of NACA0012 type, two such airfoils were simulated in the ANSYS CFX commercial CFD code. The vortex generator was placed directly ahead of the test blade to represent an extreme case for generating disturbed flow. Various streamwise spacings were examined, from one to five chord lengths between airfoils, to determine the minimum spacing distance that provides undisturbed flow over the test airfoil. An example of this is shown in Figure 4-9. 


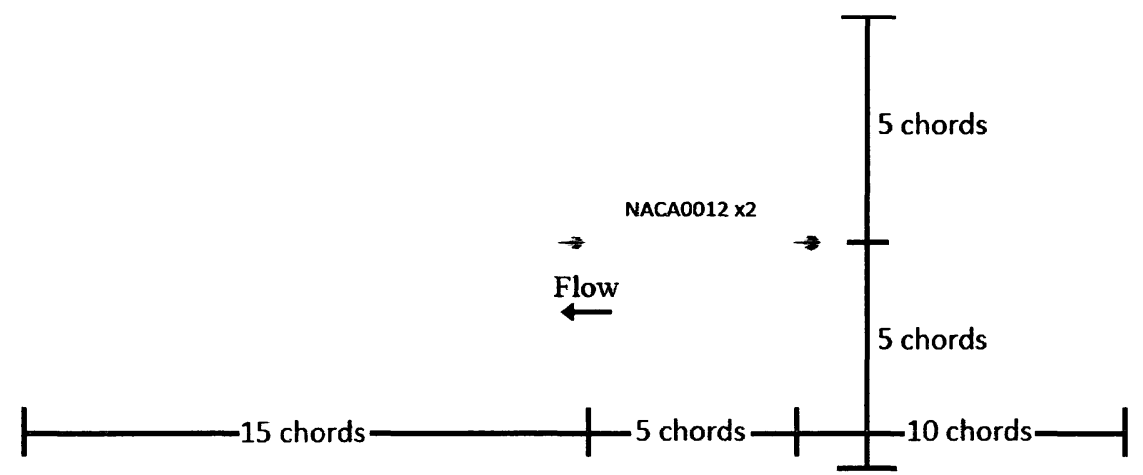

Figure 4-9: Numerical simulation geometry of flow disturbance (Not to scale, velocity contours plotted).

\subsubsection{Grid Generation}

As this study is limited to two-dimensional flow, the volume mesh was generated as an extruded two-dimensional grid, one node deep. The computational domain was 30 chord lengths long and 10 chord lengths high, and was discretized into an unstructured mesh. The nodes are concentrated in the region of interest, namely the center line surrounding the airfoils, by implementing a line of decreased spacing (grid convergence is discussed below, in Section 4.4.2.3). A relatively coarse grid was generated upstream and surrounding the airfoils due to the uniformity of the flow. Additionally, inflation layers were created around each airfoil to capture the flow near the wall. This configuration allowed the flow to properly develop over the airfoils while permitting sufficient data points for analysis, and reducing computational time. The walls were set as free slip, and at the outlet it is fixed at one atmosphere pressure.

\subsubsection{Grid Convergence Study}

A grid convergence analysis was performed, whereupon the wake of a single airfoil in a $20 \mathrm{~m} / \mathrm{s}$ freestream was investigated under varying grid sizes and node distributions. 
$20 \mathrm{~m} / \mathrm{s}$ was selected as the test velocity as this was the approximate upper limit of vortex stability by means of the airfoil pitching generation method, as discussed in Chapter 5 . The grids generated and tested are shown in Table 4-1.

Table 4-1: Grids tested for convergence analysis

\begin{tabular}{|c|c|c|c|c|c|}
\hline$\#$ & Name & Body Spacing & Inflation & Line Spacing & \# Nodes \\
\hline 1 & Default & $2 \mathrm{~mm}$ & None & None & 2064 \\
\hline 2 & Inflation only & $2 \mathrm{~mm}$ & 5 layers, $2 \mathrm{~mm}$ thick & None & 2316 \\
\hline 3 & Decreased Body Spacing & $1 \mathrm{~mm}$ & None & None & 5738 \\
\hline 4 & Smaller Body Spacing & $0.5 \mathrm{~mm}$ & None & None & 28,356 \\
\hline 5 & With Line Spacing & $2 \mathrm{~mm}$ & 5 layers, $2 \mathrm{~mm}$ thick & $1 \mathrm{~mm}$ & 50,968 \\
\hline 6 & Line \& Body Spacing & $1 \mathrm{~mm}$ & 5 layers, $2 \mathrm{~mm}$ thick & $0.5 \mathrm{~mm}$ & 74,690 \\
\hline
\end{tabular}

By observing an appropriate parameter downstream of the airfoil for the grids above, it is possible to determine when a sufficiently dense grid has been generated. One could monitor a number of parameters for grid convergence studies of two airfoils, but for the purposes of simulating wake interference effects, a suitable parameter appears to be the velocity at a point in the wake of the vortex generator airfoil. When the velocity at this point is unchanged between successive grid refinements, one can be confident that the proper grid density has been achieved for simulating the wake. Therefore, the velocity of a point one chord length downstream of the vortex generator was recorded and plotted as Figure 4-10. 


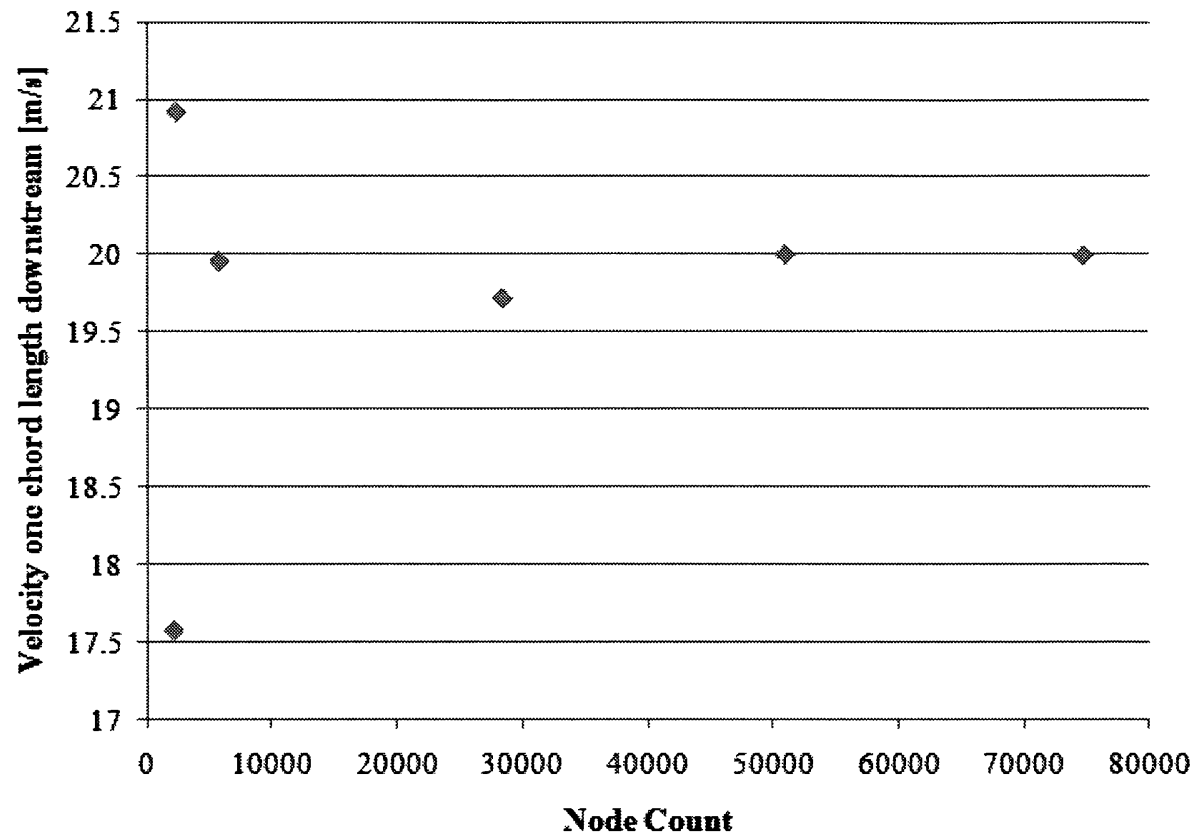

Figure 4-10: Velocity profile one chord length downstream of airfoil for varying node counts.

The procedure was repeated for several different places in the domain, with the results all demonstrating that grid \#5, with 50,968 nodes was sufficient for a converged solution. Results using this design were validated by comparing the known coefficients of pressure, lift and drag. This then allowed similar settings to be utilized to investigate the two parallel airfoils, yielding a grid of 132,342 nodes in the domain.

\subsubsection{Results \& Analysis}

As the computational time for an individual test case was relatively small compared to establishing the grid, a large number of test cases were run to residual RMS convergence levels of the $\mathrm{x}$ - and $\mathrm{y}$-momentum and mass to the order of $10^{-6}$ by a second order backward Euler scheme. Velocities of 5,10,15 and $20 \mathrm{~m} / \mathrm{s}$ were tested at separation distances of $1,2,3,4$ and 5 chord lengths downstream. The negligible 
threshold was set at $0.1 \%$ difference in the lift coefficient of the test airfoil from the normal, undisturbed flow. The lift coefficient was monitored as any change from the expected result would be apparent immediately.

As a result of the numerical analysis, it was established that, if the vortex generator in its neutral symmetric position was to have a negligible effect on any downstream airfoil of interest, the streamwise spacing should be at least 2 chord lengths between airfoils. Recognizing that the neutral position is an idealized situation, it is recommended to maintain greater than 4 chord spacings between airfoils.

\subsubsection{The Brassard Vortex Generator}

As discussed in Section 4.4.1, it is possible to generate and shed a vortex by means of changing the angle of attack of an airfoil. This can be done by quickly pitching the airfoil or by changing the effective angle of attack by accelerating the blade perpendicular to the flow. Brassard [1] proposed plunging a horizontal airfoil into the desired vortex position, where it would then be rapidly decelerated. This change in effective angle of attack would alter the bound circulation and shed a vortex in the desired path line. It was determined that in order to generate the required vortex circulation, the Brassard generator would have to induce a final $2.2^{\circ}$ effective angle of attack. The plunging airfoil would then be retracted slowly from the flow, leaving the test airfoil in an undisturbed wake. A schematic diagram is shown as Figure 4-11. 


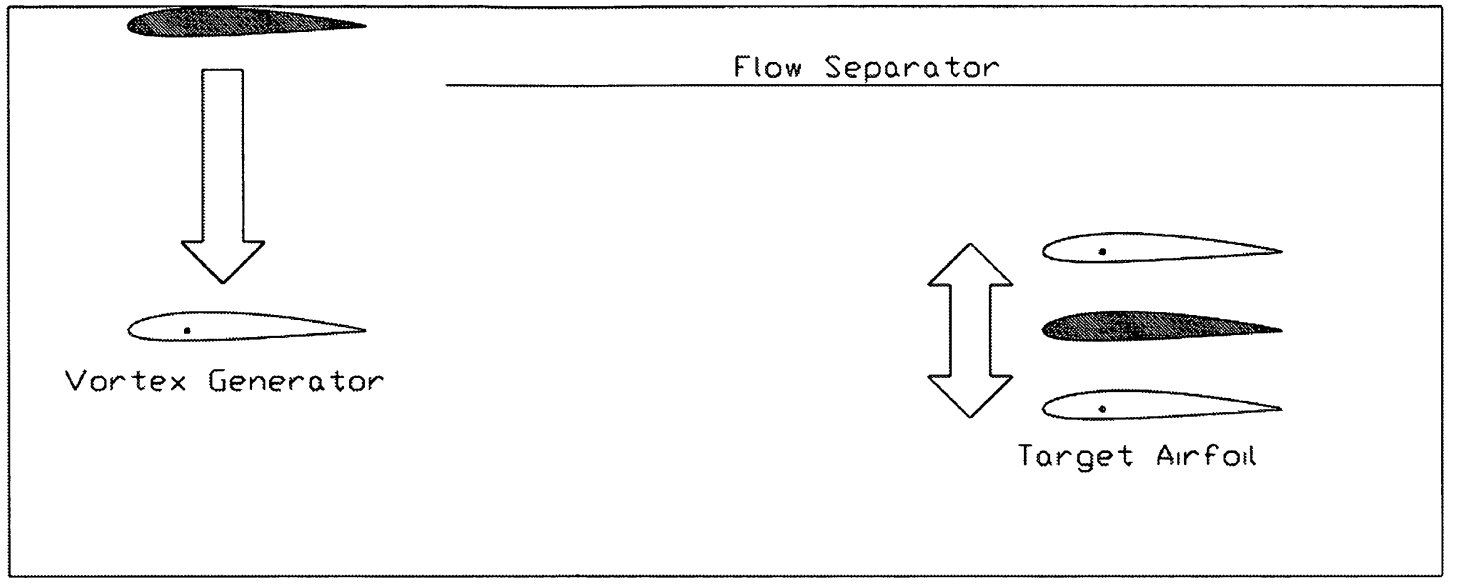

Figure 4-11: Schematic representation of the Brassard vortex generator [1].

\subsubsection{Numerical Analysis of the Brassard Vortex Generator}

Before the Brassard vortex generator could be used experimentally to investigate AVI, its performance characteristics had to be investigated. This was done numerically to assess a number of issues. First, the flow characteristics downstream of the airfoil as it plunges into the freestream needed to be examined to determine their effect on the test airfoil, if any. Second, the vortex shed needed to be singular, coherent and predictably sized, with an appropriately sized vortex core. Finally, potential issues arising from removing the airfoil from the freestream were also investigated.

\subsubsection{Test Geometry}

Again, a NACA0012 airfoil was considered as the vortex generator. Rather than simulating the airfoil moving through a stationary domain, it was deemed equivalent and simpler to vary the inlet flow angle in time to represent an accelerating plunging airfoil. This is easily performed in ANSYS CFX by configuring the inlet parameters of velocity to be a function of the current time step, in both the horizontal and vertical directions. 
For example, to vary the vertical inlet velocity, $\mathrm{V}$, to simulate a plunging (and then rapidly stopping after a period of time) airfoil, as shown in Figure 4-12 below, one would employ the use of the step function within the CFX code.

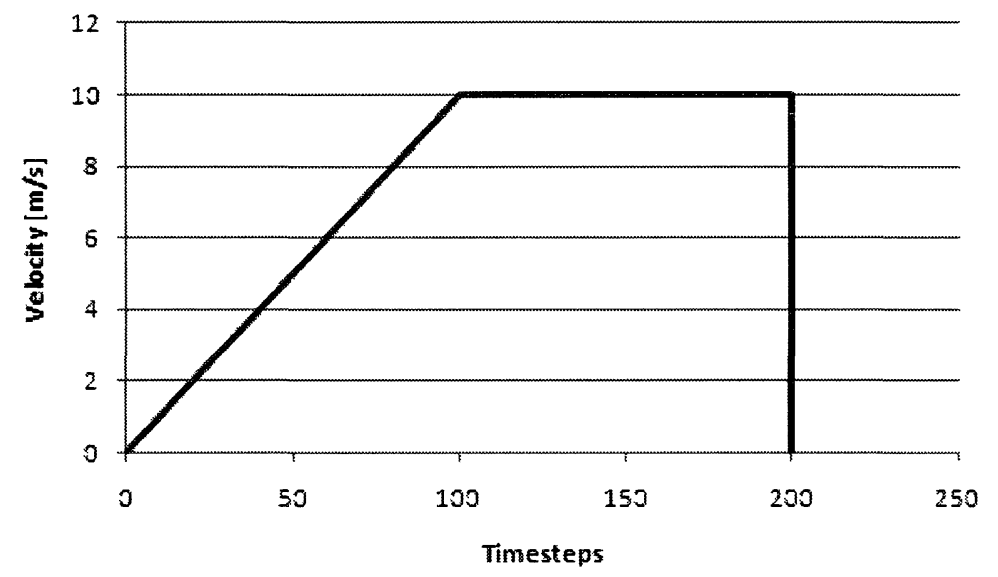

Figure 4-12: Vertical velocity profile of plunging Brassard-style vortex generator.

Two distinct functions must be controlled using the step function, while maintaining the proper units for computation, as shown as Equation 4.7. Note that the CFX understood "timestep" has been abbreviated to " $t$ " for brevity.

$$
\begin{gathered}
V=\left(\frac{t *\left[\frac{1}{s}\right]}{10}\right) * 1\left[\frac{m}{s}\right]-\operatorname{step}\left(t *\left[\frac{1}{s}\right]-100\right) *\left[\left(\frac{t *\left[\frac{1}{s}\right]}{10}\right)-10\right] * 1\left[\frac{m}{s}\right] \\
-\operatorname{step}\left(t *\left[\frac{1}{s}\right]-200\right) *\left(10\left[\frac{m}{s}\right]\right)
\end{gathered}
$$

Note that this method of simulating the change in effective angle of attack by manipulating the input conditions to the domain does not completely represent the actual velocity field experienced by the actual plunging effect of an airfoil. Despite the inlet conditions changing instantly, the airfoil does not experience this for a period of time, as the velocity propagates throughout the flow field. However, this is comparable to the delay in decelerating the physical plunging vortex generator, as shown in Figure 4-13. 


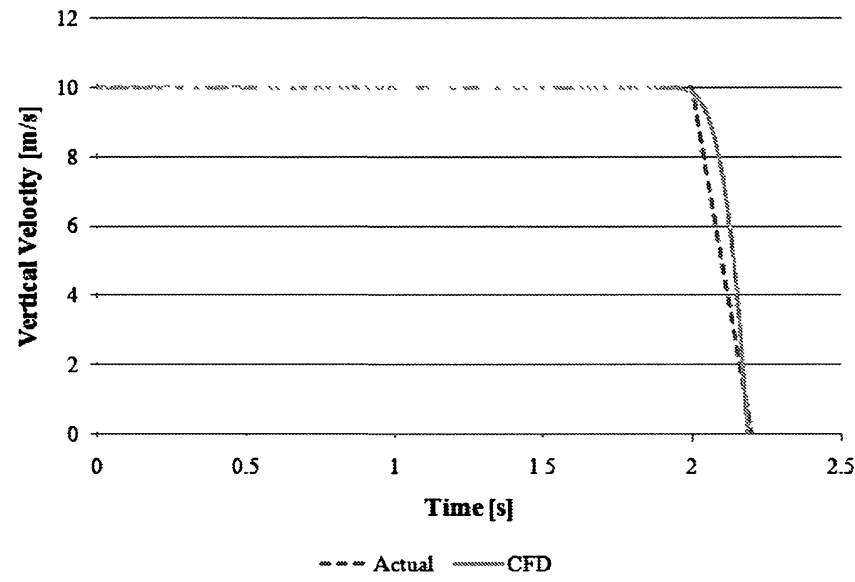

Figure 4-13: Simulation of plunging vortex generator as compared to actual.

\subsubsection{Grid Generation}

As this study is also two-dimensional, the volume mesh was generated as an extruded two-dimensional grid, one node deep. The computational domain was generated with a parabolic inlet shape, as shown in Figure 4-16. Approximately 10 chord length separation between walls and the airfoil was maintained and the volume was discretized into an unstructured mesh. Inflation layers were created around the airfoil to properly resolve the flow field. The walls were set to be periodic, as to properly simulate the plunging with varying inlet velocity. Further, at the outlet, it was fixed at one atmosphere pressure.

\subsubsection{Grid Convergence Study}

A grid convergence analysis was performed, whereupon the lift of a single airfoil within a constant velocity inlet simulation of $5^{\circ} \mathrm{AOA}$ was investigated under varying grid sizes and styles. The grids generated and tested are shown in Table 4-2. 
Table 4-2: Grids tested for plunging convergence analysis

\begin{tabular}{|c|c|c|c|c|}
\hline$\#$ & Name & Body Spacing & Inflation & \# Nodes \\
\hline 1 & Default & $2 \mathrm{~mm}$ & None & 1482 \\
\hline 2 & Inflation only & $2 \mathrm{~mm}$ & 5 layers, $2 \mathrm{~mm}$ thick & 1832 \\
\hline 3 & Decreased Body Spacing & $1 \mathrm{~mm}$ & None & 4620 \\
\hline 4 & Smaller Body Spacing & $0.5 \mathrm{~mm}$ & None & 22,428 \\
\hline 5 & Inflation \& Body Spacing & $1 \mathrm{~mm}$ & 5 layers, $2 \mathrm{~mm}$ thick & 5260 \\
\hline 6 & Inflation \& Smaller Spacing & $0.5 \mathrm{~mm}$ & 5 layers, $2 \mathrm{~mm}$ thick & 23,852 \\
\hline
\end{tabular}

By monitoring the lift of the airfoil in each of these simulations, it is possible to determine when a sufficiently dense grid has been generated. One could monitor a number of parameters for grid convergence, but for the purposes of investigating the starting vortices, a suitable parameter appears to be the lift of the airfoil. When the lift at this point is unchanged between successive grid levels, one can be confident that the proper grid density has been achieved. Therefore, the lift of the airfoil under different grids was recorded and plotted as shown in Figure 4-10.

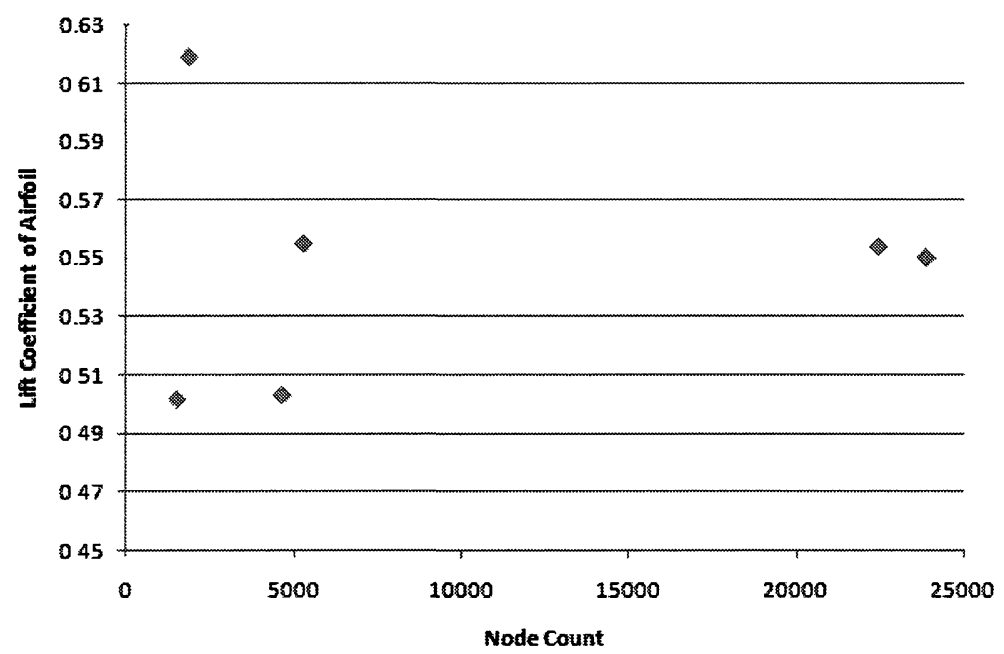

Figure 4-14: Velocity profile one chord length downstream of airfoil 
This procedure demonstrated that grid \#5, with just 5260 nodes was sufficient to yield a converged, grid independent solution. Again, this mesh design was validated by comparing the known coefficients of pressure, lift and drag against those obtained in the simulation.

\subsubsection{Results \& Analysis}

Tests were run to residual RMS convergence levels of the $\mathrm{x}$ - and $\mathrm{y}$-momentum and mass to the order of $10^{-6}$ by a second order backward Euler scheme, and typically required less than 2 iterations to converge per time step, or approximately 10 hours per run. It was determined that as an airfoil accelerates into the freestream at the necessary rate to generate the $2.2^{\circ}$ effective angle of attack in the allotted space, it sheds a series of smaller vortices, as shown in Figure 4-15. These vortices are due to the rapid acceleration of the airfoil increasing the effective angle of attack, and thus, circulation of the airfoil. It was found that these vortices were present sufficiently far downstream to cause interference with an AVI test blade.

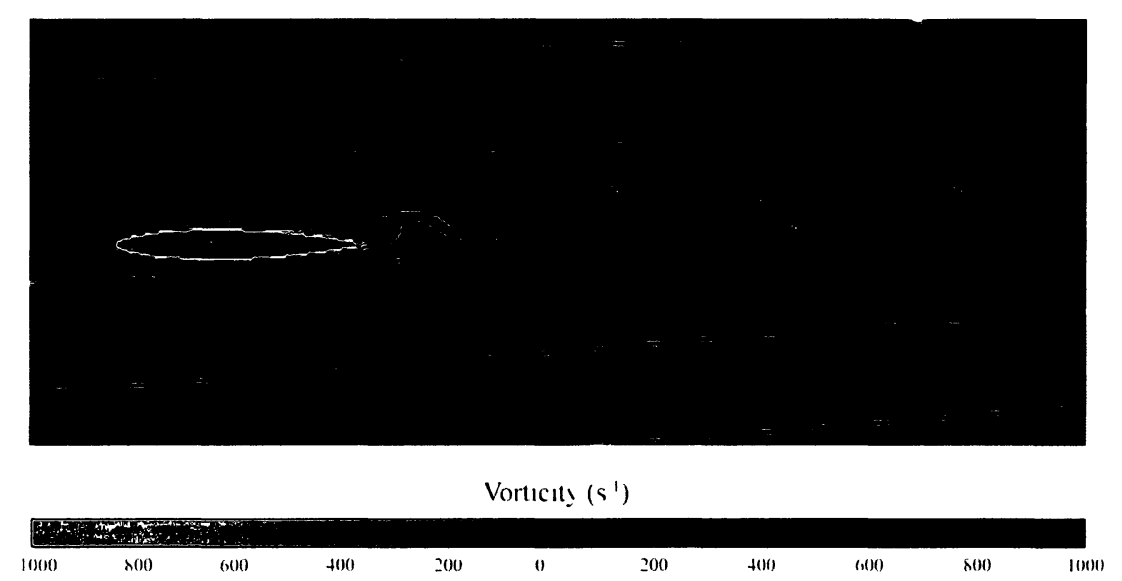

Figure 4-15: Vorticity contours with streamlines to illustrate the instantaneous angle of attack of the Brassard vortex generator. 
Further, as shown in Figure 4-16, it is clear that as the airfoil decelerates rapidly, it sheds a pair of counter-rotating vortices in quick succession. This is undesirable as a single coherent vortex is what is required for $\mathrm{AVI}$ studies.

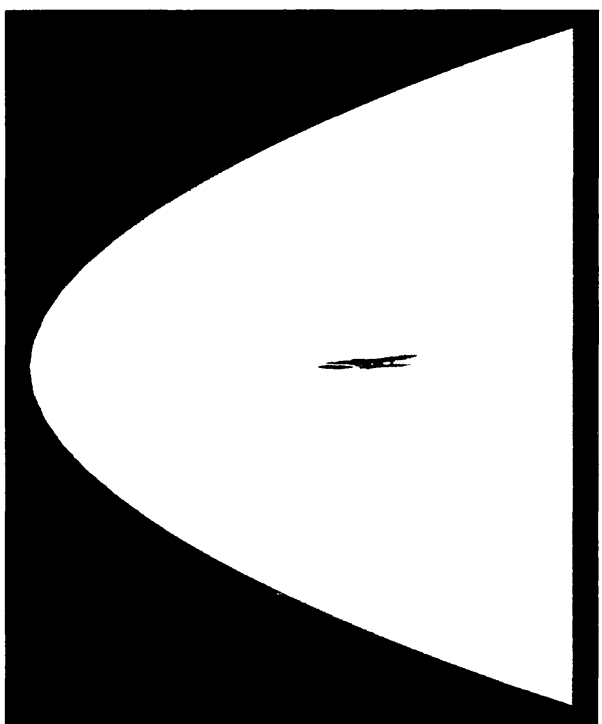

a) Maximum downward plunge velocity

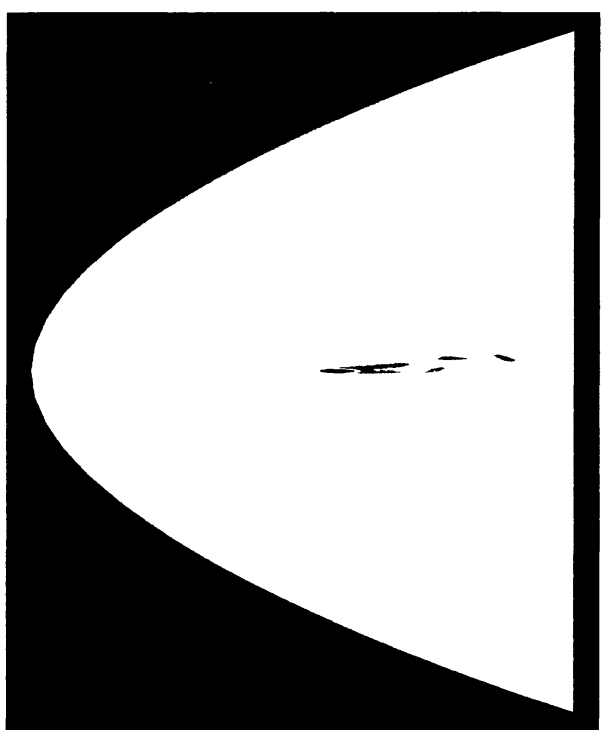

c) Opposing vortices being shed

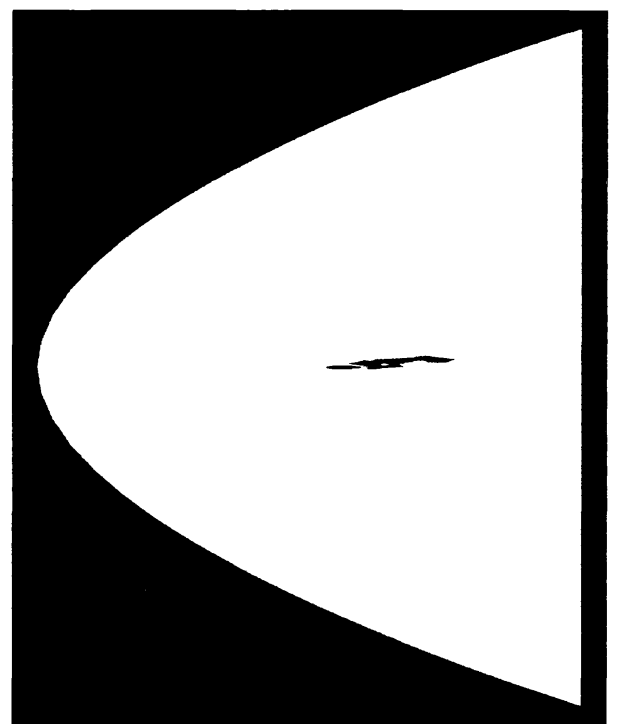

b) Immediately following plunge deceleration

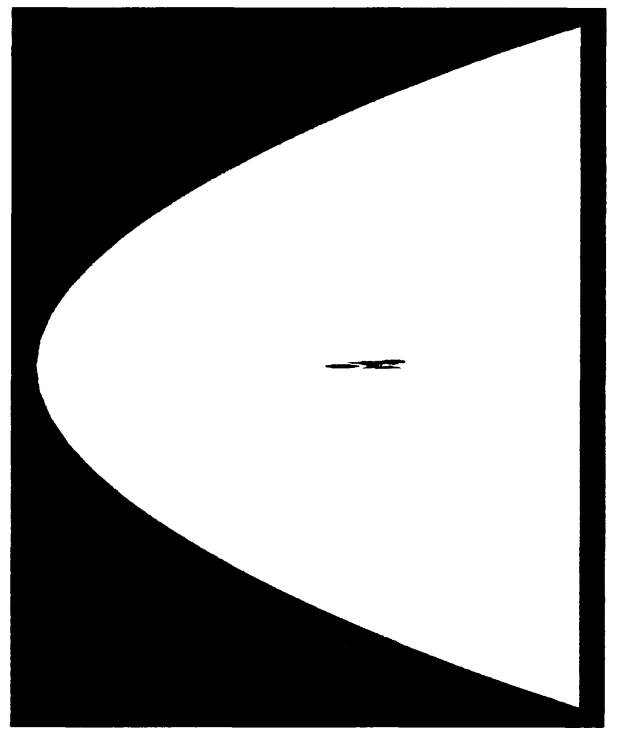

d) Opposing vortices convecting downstream

Vorticity (口')

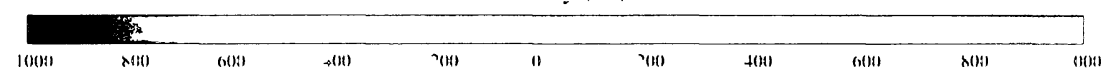

Figure 4-16: Time-history of the Brassard-type vortex generator simulations. Vorticity contours with instantaneous streamlines shown. 
Finally, the effect of plunging the airfoil out of the flow to provide undisturbed flow to the test blade was examined. The airfoil was found to either accelerate out of the flow too slowly (leaving a disturbed wake for an unacceptable length of time) or too quickly (generating another starting vortex as the effective angle of attack was changed).

As a result of these tests, it was determined that although the Brassard plunging airfoil vortex generation technique is novel in concept, it does not offer advantages over the classical pitching airfoil vortex generator for AVI studies. Therefore, the traditional pitching airfoil was selected for the purpose of this study. However, it is conceivable that for different vortex requirements, the Brassard design could find a use in experimental fluid mechanics.

\subsection{PIV Triggering}

In order to accurately capture the position of a vortex after it has been created, the exact time of creation must be known. A programmable delay can then be configured into the PIV capture software to enable multiple measurements of vortices at the exact same position in space. An optically triggered electronic circuit was utilized, where an infrared light emitting diode (LED) generated a beam horizontally across the test section. The simple schematic of the circuit is shown as Figure 4-17. 


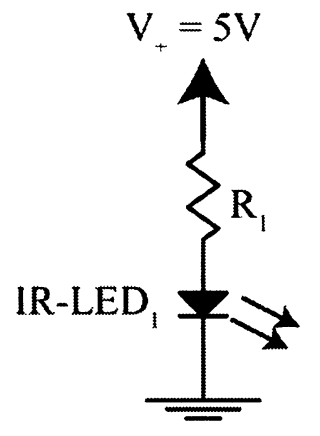

Emitter Circuit

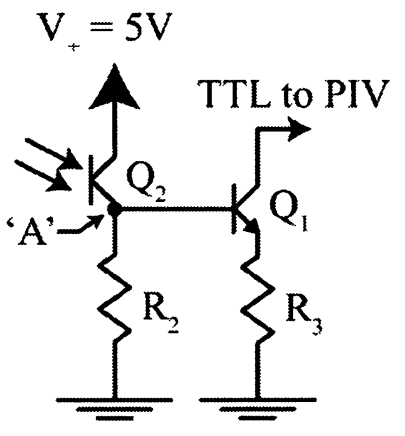

Receiver Circuit

Figure 4-17: Infrared LED timing circuits [3].

The beam was placed to be blocked by the trailing edge of the pitching airfoil in the most positive angle of attack expected, as shown in Figure 4-18. For a $10 \mathrm{~cm}$ chord blade, and a $3^{\circ}$ pitch, this occurs at approximately $4 \mathrm{~mm}$ below the neutral position of the trailing edge. As the airfoil pitches through the beam (and then rapidly pitches down due to the cam system), the circuit triggers a TTL $(5 \mathrm{~V})$ digital pulse which is sent to the PIV control system. It is important to note that aligning of the infrared beam to be broken at exactly the most upward position of the airfoil is somewhat trivial, as long as repeatable measurements are obtainable.

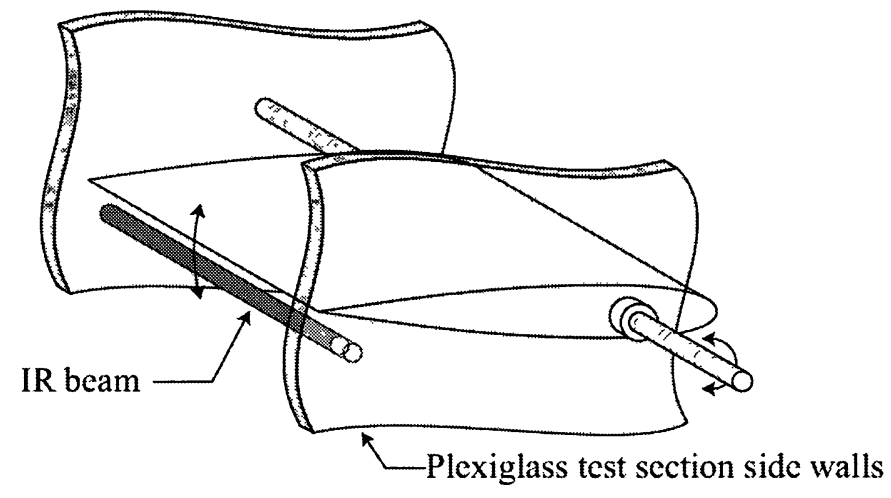

Figure 4-18: Infrared beam placement [3]. 


\section{Chapter 5}

\section{Experimental Results and Discussion}

The main purpose of this thesis was to extend of the work completed by Burwash [3]; who set up the PIV system but was only able to run one sample AVI test case. This enabled the wind tunnel to be configured to run a large number of test cases to investigate controlled changes in AVI events by means of PIV. In this study, this represented 36 separate test cases involving variations in: tunnel speed, test blade angle of attack, vortex strength and vortex miss distance. The test matrix is shown below in Table 5-1.

The test plan was determined by evaluating several limiting factors when using the wind tunnel described in Chapter 4. It has been determined previously that vortex creation above freestream velocities of approximately $15 \mathrm{~m} / \mathrm{s}$ produces incoherent and unstable vortices. Unfortunately, this is well below the speed capabilities of the tunnel as well as below the speed at which AVI occurs in practice. In the future, vortex generation should be revisited to facilitate the use of the full range of the wind tunnel speeds (i.e. up to $85 \mathrm{~m} / \mathrm{s}$ ) Thus, a range of $8.5-15 \mathrm{~m} / \mathrm{s}$ was examined to investigate vortex impacts at reproducible speeds. For the airfoil tested, these velocities represent Reynolds numbers of approximately $85,000-150,000$, respectively. Further, two angles of attack of the test blade were tested, representing an unloaded $\left(0^{\circ} \mathrm{AOA}\right)$ and a partially loaded $\left(5^{\circ} \mathrm{AOA}\right)$ blade. Additionally, the cam system operating the vortex generator was varied mechanically to enable two pitching angles $\left(2^{\circ}\right.$ and $\left.3^{\circ}\right)$ and, therefore, vortex strengths to be tested. Finally, three vertical miss distances were examined, representing similar miss 
distances tested by Wong [4]. All test cases were carried out with the vortex generator two chord lengths ahead of the test blade.

Table 5-1: Test Matrix

\begin{tabular}{|c|c|c|c|c|c|c|c|c|c|c|c|c|}
\hline Test \# & 1 & 2 & 3 & 4 & 5 & 6 & 7 & 8 & 9 & 10 & 11 & 12 \\
\hline Frequency \& Speed & \multicolumn{8}{c|}{$7.5 \mathrm{~Hz} \& \sim 8.5 \mathrm{~m} / \mathrm{s}$} \\
\hline Test Blade AOA & \multicolumn{8}{c|}{$0^{\circ}$} & \multicolumn{7}{c|}{$5^{\circ}$} \\
\hline Vortex Strength & \multicolumn{3}{|c|}{$\Gamma=0.12$} & \multicolumn{3}{c|}{$\Gamma=0.080$} & \multicolumn{3}{c|}{$\Gamma=0.12$} & \multicolumn{3}{c|}{$\Gamma=0.080$} \\
\hline Miss Distance & $0.1 \bar{c}$ & $0.2 \bar{c}$ & $0.3 \bar{c}$ & $0.1 \bar{c}$ & $0.2 \bar{c}$ & $0.3 \bar{c}$ & $0.1 \bar{c}$ & $0.2 \bar{c}$ & $0.3 \bar{c}$ & $0.1 \bar{c}$ & $0.2 \bar{c}$ & $0.3 \bar{c}$ \\
\hline
\end{tabular}

\begin{tabular}{|c|c|c|c|c|c|c|c|c|c|c|c|c|}
\hline Test \# & 13 & 14 & 15 & 16 & 17 & 18 & 19 & 20 & 21 & 22 & 23 & 24 \\
\hline Frequency \& Speed & \multicolumn{8}{c|}{$10 \mathrm{~Hz} \& \sim 11 \mathrm{~m} / \mathrm{s}$} \\
\hline Test Blade AOA & \multicolumn{8}{c|}{$0^{\circ}$} & \multicolumn{7}{c|}{$5^{\circ}$} \\
\hline Vortex Strength & \multicolumn{3}{|c|}{$\Gamma=0.12$} & \multicolumn{3}{c|}{$\Gamma=0.080$} & \multicolumn{3}{c|}{$\Gamma=0.12$} & \multicolumn{3}{c|}{$\Gamma=0.080$} \\
\hline Miss Distance & $0.1 \bar{c}$ & $0.2 \bar{c}$ & $0.3 \bar{c}$ & $0.1 \bar{c}$ & $0.2 \bar{c}$ & $0.3 \bar{c}$ & $0.1 \bar{c}$ & $0.2 \bar{c}$ & $0.3 \bar{c}$ & $0.1 \bar{c}$ & $0.2 \bar{c}$ & $0.3 \bar{c}$ \\
\hline
\end{tabular}

\begin{tabular}{|c|c|c|c|c|c|c|c|c|c|c|c|c|}
\hline Test \# & 25 & 26 & 27 & 28 & 29 & 30 & 31 & 32 & 33 & 34 & 35 & 36 \\
\hline Frequency \& Speed & \multicolumn{10}{c|}{$12.5 \mathrm{~Hz} \& \sim 15 \mathrm{~m} / \mathrm{s}$} \\
\hline Test Blade AOA & \multicolumn{8}{|c|}{$0^{\circ}$} & \multicolumn{8}{c|}{$5^{\circ}$} \\
\hline Vortex Strength & \multicolumn{3}{|c|}{$\Gamma=0.12$} & \multicolumn{3}{|c|}{$\Gamma=0.080$} & \multicolumn{3}{c|}{$\Gamma=0.12$} & \multicolumn{3}{c|}{$\Gamma=0.080$} \\
\hline Miss Distance & $0.1 \bar{c}$ & $0.2 \bar{c}$ & $0.3 \bar{c}$ & $0.1 \bar{c}$ & $0.2 \bar{c}$ & $0.3 \bar{c}$ & $0.1 \bar{c}$ & $0.2 \bar{c}$ & $0.3 \bar{c}$ & $0.1 \bar{c}$ & $0.2 \bar{c}$ & $0.3 \bar{c}$ \\
\hline
\end{tabular}

For each test case, the PIV parameters were kept constant, and were similar to the optimal ones established by Burwash [3] through sensitivity testing. The most relevant parameters are included as Table 5-2. 
Table 5-2: Optimal PIV parameters as defined by Burwash [3]

\begin{tabular}{|c|c|}
\hline Parameter & Value \\
\hline Final interrogation window size & $32 \mathrm{px} \times 32 \mathrm{px}$ \\
\hline Adaptive \& Refinement iterations & 3 \\
\hline$\Delta t$ & $N /\left(4 V_{\infty}\right)$ \\
\hline Interrogation region overlap & $75 \% \times 75 \%$ \\
\hline Window filter & $k=0.5$ \\
\hline Low-pass filter & $k=3.0$ \\
\hline Moving average validation area & $3 \times 3$ \\
\hline Average filter area & $3 \times 3$ \\
\hline Data sets averaged & 30 \\
\hline
\end{tabular}

To capture the flow field surrounding the airfoil, 4 fields of view had to be employed, each capturing an image $94 \mathrm{~mm}$ wide $\times 94.6 \mathrm{~mm}$ tall. This resulted in a scaling factor of 10.354 , which refers to the ratio of digital image size to the real life image size captured. This must be calibrated for each focal distance by placing a grid of known size in the image plane before measurements can begin. Each image overlapped by a margin of $25 \%$ to ensure that the data could be merged together efficiently. Data averaging is a standard process in PIV data acquisition to assist in filtering out erroneous data points. It was determined by Burwash [3] that 30 sets are sufficient for capturing the flow fields present in this tunnel.

As the laser sheet illuminated from below the airfoil, only the lower surface behaviour could be investigated with any degree of precision. An attempt was made to reflect the laser sheet by means of a mirrored surface placed in the flow (as performed on 
a larger scale in Figure 6-5), but results varied in time to too large of a degree to be useful. However, the change in behaviour of the lower surface is far more critical to investigate as that is where most of the rapid pressure changes due to BVI occur [4].

\subsection{Test Case \#13}

Due to the large number of test cases, only a single case will be presented in detail, with comparison results highlighted below. The selected case was \#13 (as it could be a means of comparison to Burwash [3]), featuring a blower setting of $10 \mathrm{~Hz}, 0^{\circ}$ test blade AOA, vortex strength of $\Gamma=0.12$ and a vertical miss distance of $0.1 \bar{c}$. The vorticity found by Burwash is presented graphically as Figure 5-1 in $2 m s$ intervals, beginning with the vortex entering the visible domain at $t=0 \mathrm{~ms}$. 

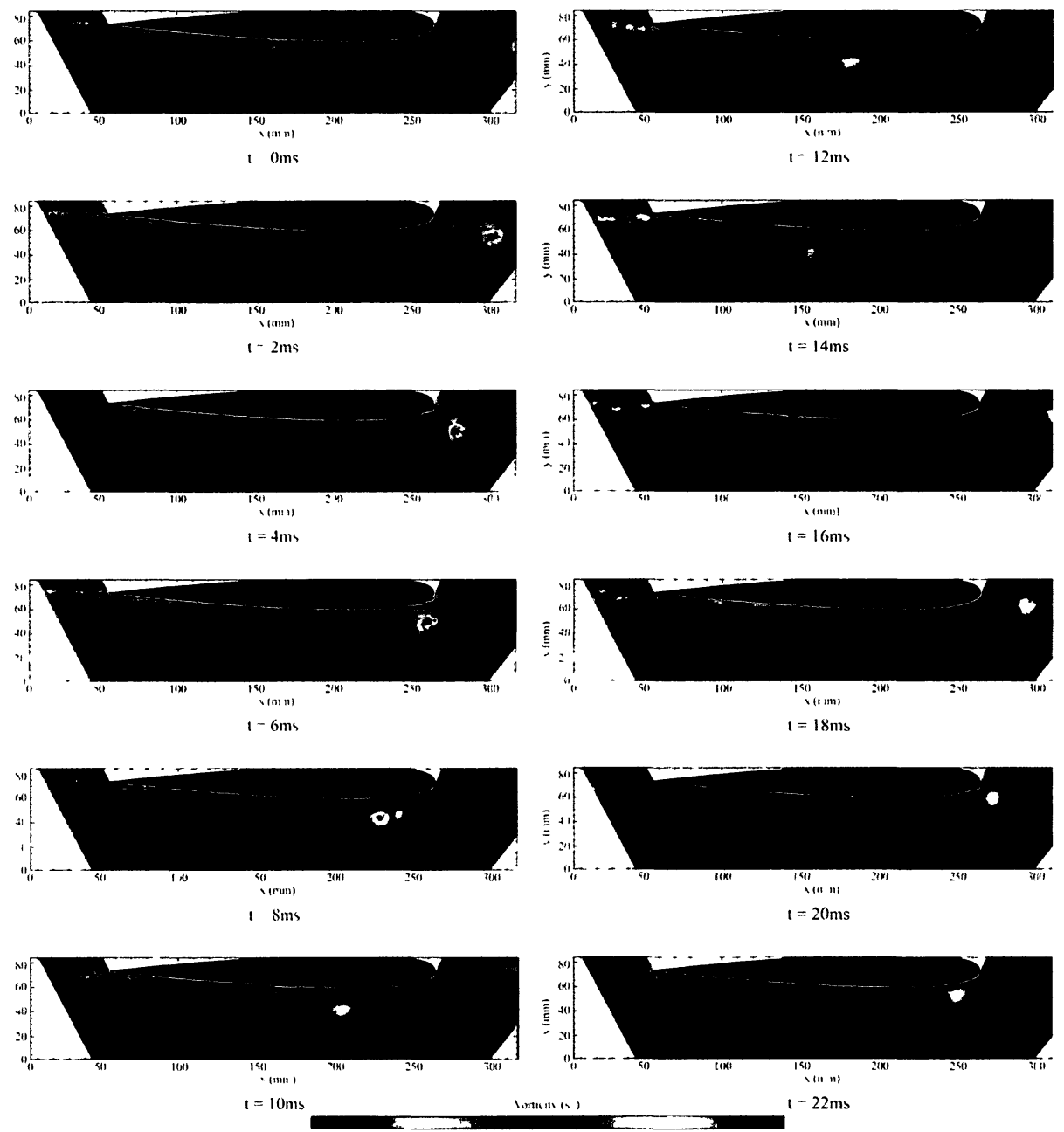

Figure 5-1: Case \#13 vortex impact on NACA0012 blade [3].

The test case was repeated to ensure the consistency of results, and is plotted as Figure 5-2 in $4 \mathrm{~ms}$ intervals, beginning with the vortex entering the visible domain at $t=0 \mathrm{~ms}$. It is observed that these results very closely match those obtained by Burwash previously [3]. 

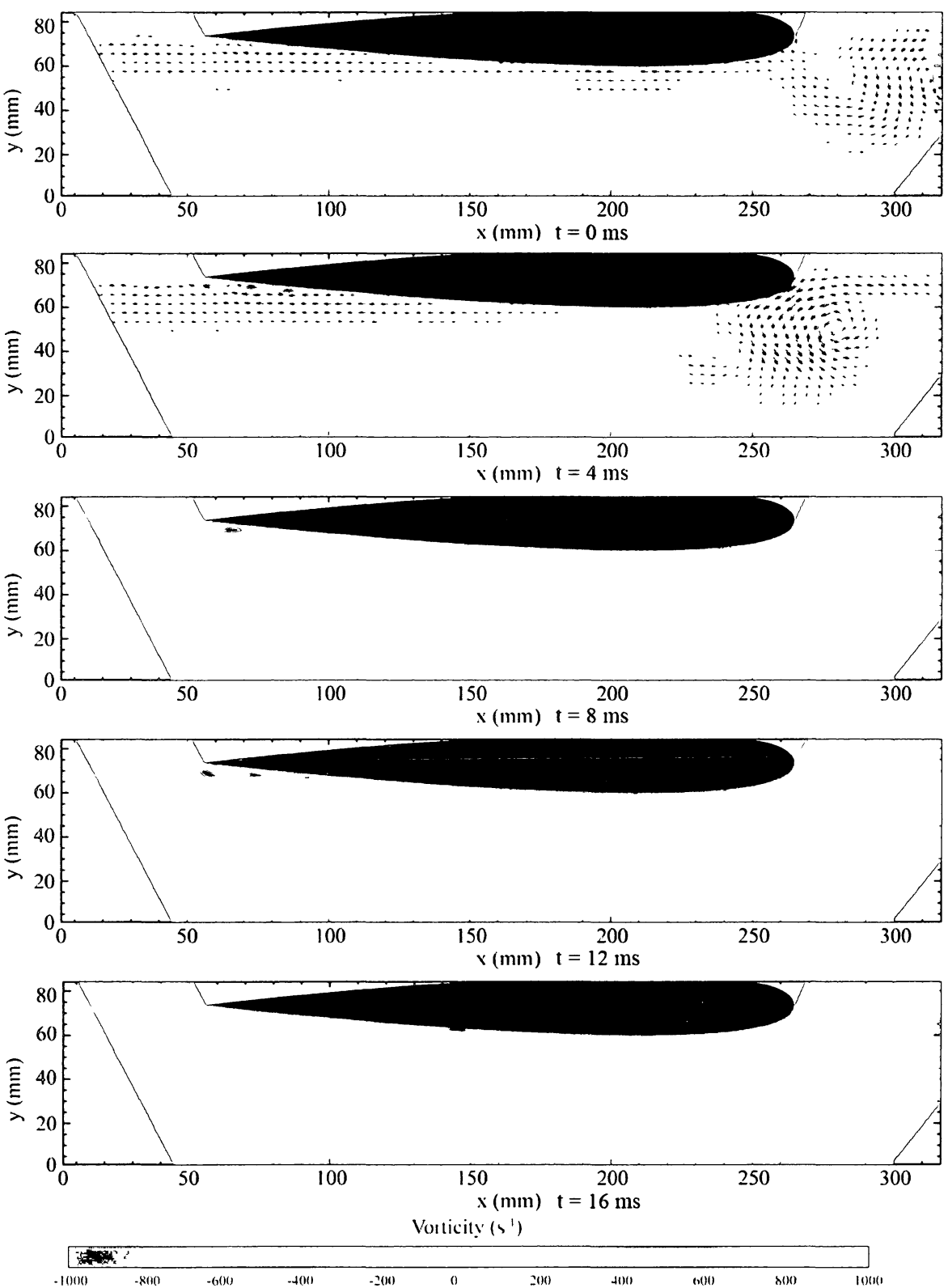

Figure 5-2: Case \#13 vortex impact on NACA 0012 blade.

By examining the pressure changes at the airfoil surface as the vortex passes, it is possible to determine the pressure distribution of the airfoil as a function of vortex position (or time). Note that the static pressure contours were obtained by means of applying Bernoulli's principle to the recorded atmospheric pressures, temperatures and PIV-obtained velocities along the surface. The pressure distribution - for all test cases - 
was integrated to determine the lift coefficient as a function of vortex position. For case $\# 13$, this is shown in Figure 5-3. Note that although this means of comparison was not available for the results generated by Burwash [3], it does compare with the expected vortex behavior as outlined by Renzoni and Mayle [11].

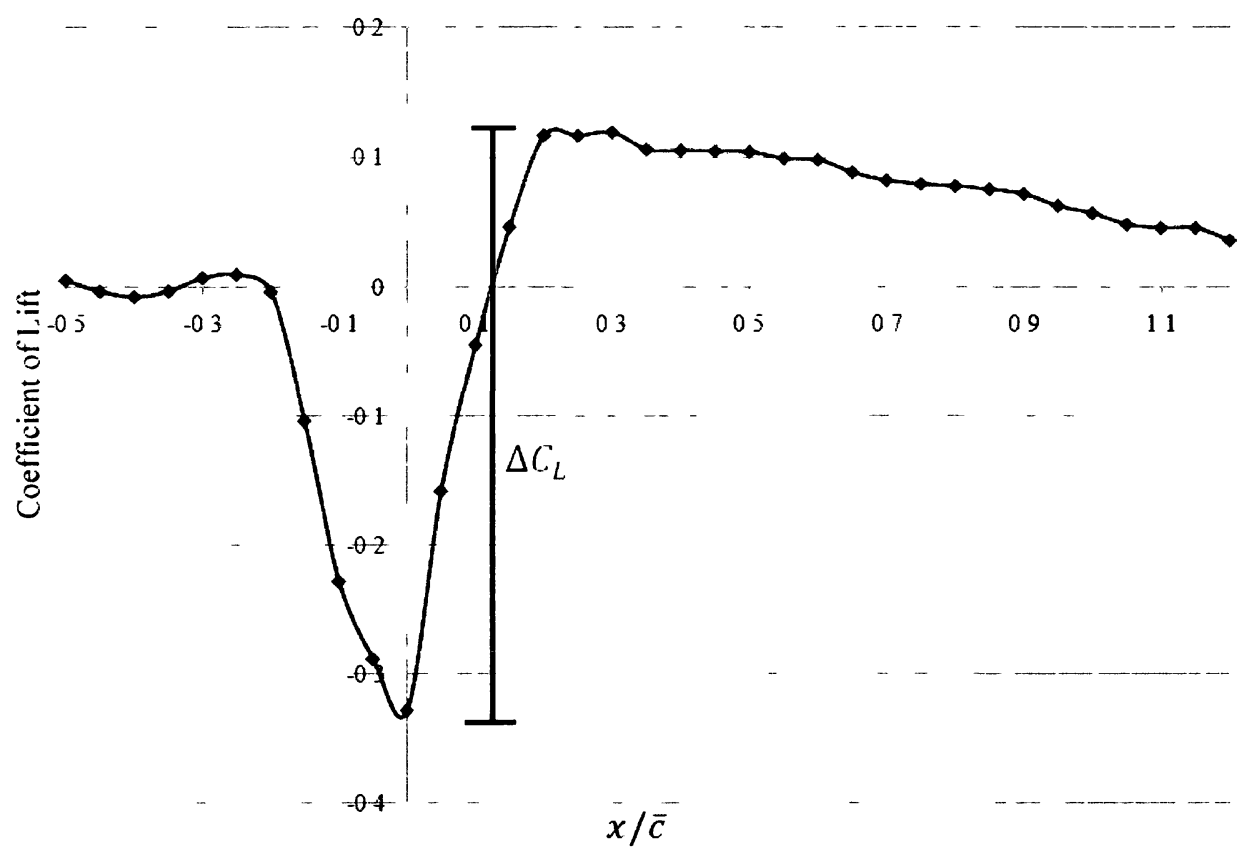

Figure 5-3: Coefficient of lift vs. vortex position for case \#13.

\subsection{Complete Test Regime}

By utilizing the method presented by Renzoni and Mayle [11] to normalize the maximum change in lift coefficient $-\Delta \mathrm{C}_{\mathrm{L}}$ - as the vortex passes, it is possible to compare the AVI effects between all 36 test cases. This is accomplished by means of Equation 5.1.

$$
\Delta \mathrm{C}_{\mathrm{L} \text { N }}=\frac{\Delta \mathrm{C}_{\mathrm{L}} \mathrm{V}_{\infty} \overline{\mathrm{C}}}{\Gamma}
$$

As there are a number of different variables to evaluate, it is best to observe the changes in one while holding the others constant. Thus, the figures below illustrate 
variations in the normalized coefficient of lift due to alterations in miss distance, angle of attack and vortex strength as a function of freestream velocity.

\subsubsection{Error Analysis}

In experimental research, it is important to assess the many sources of error that may propagate through an experiment. For this campaign, Equation 5.1 yields values of $\Delta \mathrm{C}_{\mathrm{L}_{\mathrm{ND}}}$ based on several different parameters, each with their own error. When possible, the error was directly observed by examining the variance in repeated identical measurement sets. An example of this is the vortex strength which was observed to deviate slightly from the mean as shown in Table 5-3. Note that these deviations were observed from a PIV-averaged set of 30 measurements each.

Table 5-3: Vortex strength error analysis

\begin{tabular}{|c|c|c|c|}
\hline Mean Vortex Strength & Maximum observed & Minimum observed & Deviation \\
\hline 0.080 & 0.07995 & 0.08034 & $0.49 \%$ \\
\hline 0.12 & 0.11989 & 0.12053 & $0.53 \%$ \\
\hline
\end{tabular}

When a parameter was not readily measurable, such as the laser power fluctuation, known values from literature were employed to complete the analysis. The error analysis was based on the method performed in [23], and is summarized in Table $5-4$, resulting in a total relative experimental error of $\pm 5.27 \%$. 
Table 5-4: Sources of relative experimental error in calculating $\Delta C_{L_{N D}}$.

\begin{tabular}{|c|c|c|c|c|}
\hline Parameter & Category & Error Type & Error Source & Error \\
\hline \multirow{8}{*}{$\Delta \mathrm{C}_{\mathrm{L}}$} & \multirow{3}{*}{ Calibration } & Laser sheet, camera \& flow alignment & Observed & $2.10 \%$ \\
\hline & & Reference image & From [23] & $0.40 \%$ \\
\hline & & Image distortion by lens \& CCD & System parameter & $0.86 \%$ \\
\hline & \multirow{2}{*}{ Acquisition } & Laser power fluctuation & System parameter & $0.50 \%$ \\
\hline & & Image distortion by lens \& CCD & From [23] & $0.86 \%$ \\
\hline & \multirow{2}{*}{ Experimental } & $3 \mathrm{D}$ effects & From [23] & $0.73 \%$ \\
\hline & & Pulse delay & System parameter & $0.05 \%$ \\
\hline & \multicolumn{3}{|c|}{ Root sum square to determine total $\Delta \mathrm{C}_{\mathrm{L}}$ error: } & $2.61 \%$ \\
\hline $\mathrm{V}_{\infty}$ & Experimental & Tunnel speed fluctuation & Observed & $2.14 \%$ \\
\hline $\bar{c}$ & - & Negligible & Measured & - \\
\hline$\Gamma_{\mathrm{ND}}$ & Experimental & Variation in vortex strength & Observed & $0.52 \%$ \\
\hline
\end{tabular}

Total: $\quad 5.27 \%$

\subsubsection{Effect of Miss Distance}

Figure 5-4 through Figure 5-7 illustrate the changes in the normalized lift coefficient due to changes in freestream velocity and vortex miss distance. It is observed that an increase in velocity or a decrease of miss distance both increase the maximum difference in the change in lift coefficient. This is an intuitive and expected result, as a vortex passing quickly or near an airfoil would affect the blade more than a vortex passing slowly or in the far field. 


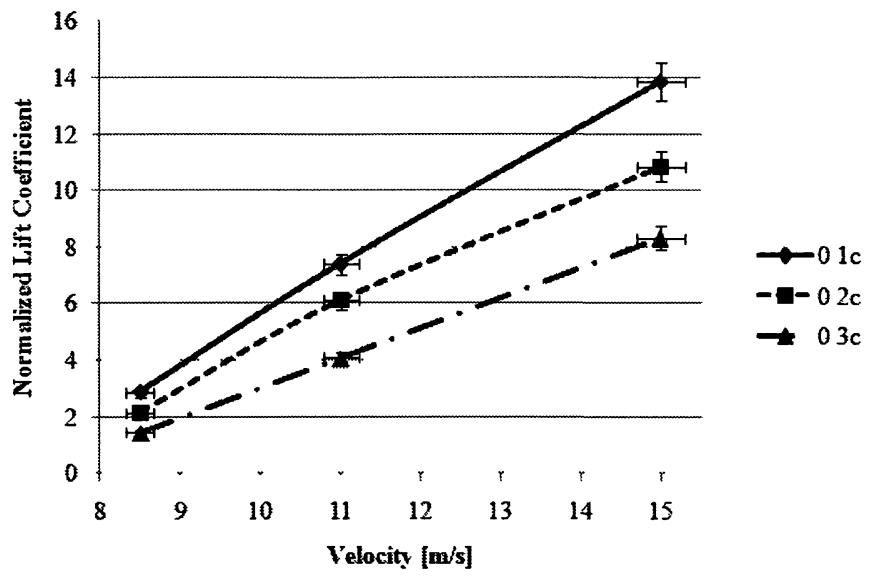

Figure 5-4: Effect of varying miss distance from 0.1-0.3 $\bar{c}\left(0^{\circ} \mathrm{AOA}, \Gamma=0.12\right)$.

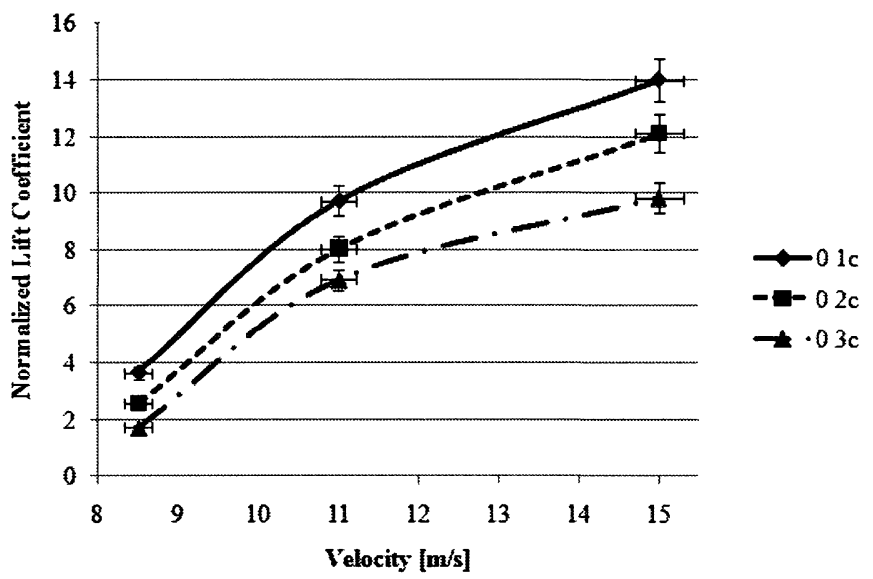

Figure 5-5: Effect of varying miss distance from 0.1-0.3 $\bar{c}\left(0^{\circ} \mathrm{AOA}, \Gamma=0.080\right)$.

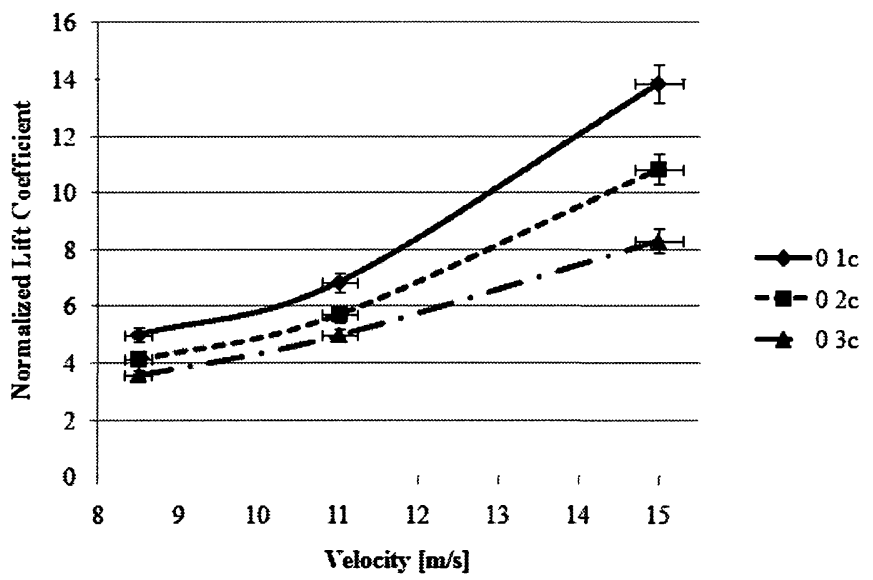

Figure 5-6: Effect of varying miss distance from 0.1-0.3 $\bar{c}\left(5^{\circ} \mathrm{AOA}, \Gamma=0.12\right)$. 


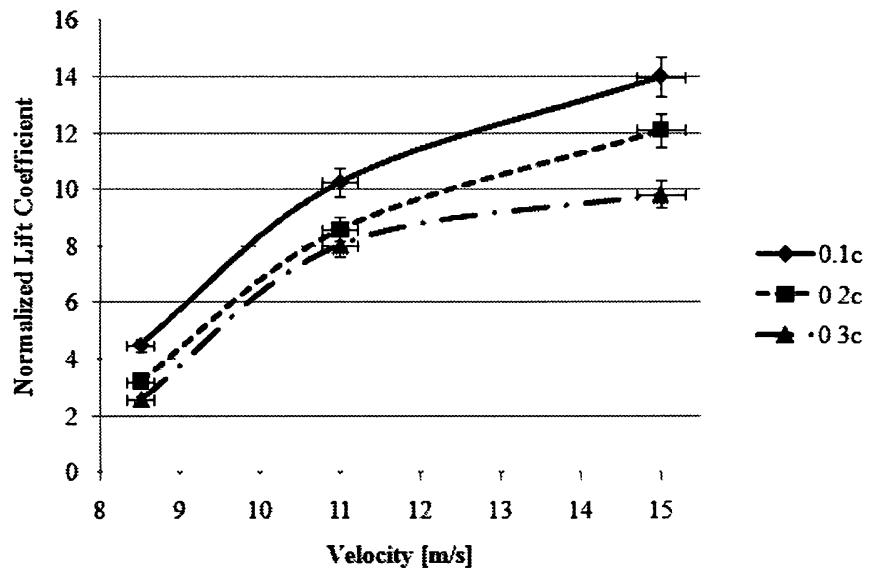

Figure 5-7: Effect of varying miss distance from 0.1-0.3 $\bar{c}\left(5^{\circ} A O A, \Gamma=0.080\right)$.

\subsubsection{Effect of Angle of Attack}

Similarly, one can observe Figure 5-8 through Figure 5-13 to visualize the changes in the normalized lift coefficient due to changes in freestream velocity and test blade angle of attack. It is interesting to note how the normalized change in lift coefficient converges to the same value for both a loaded and unloaded blade, especially at the higher test velocities. As it is unclear as to why the blade behaves in this manner, further study into this phenomenon is recommended.

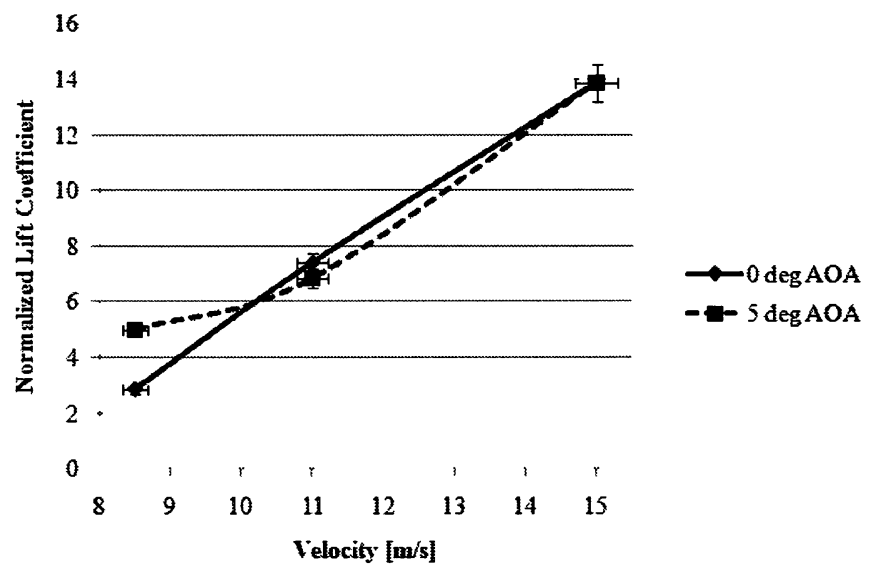

Figure 5-8: Effect of varying angle of attack from 0-5 deg $(y / c=0.1, \Gamma=0.12)$. 


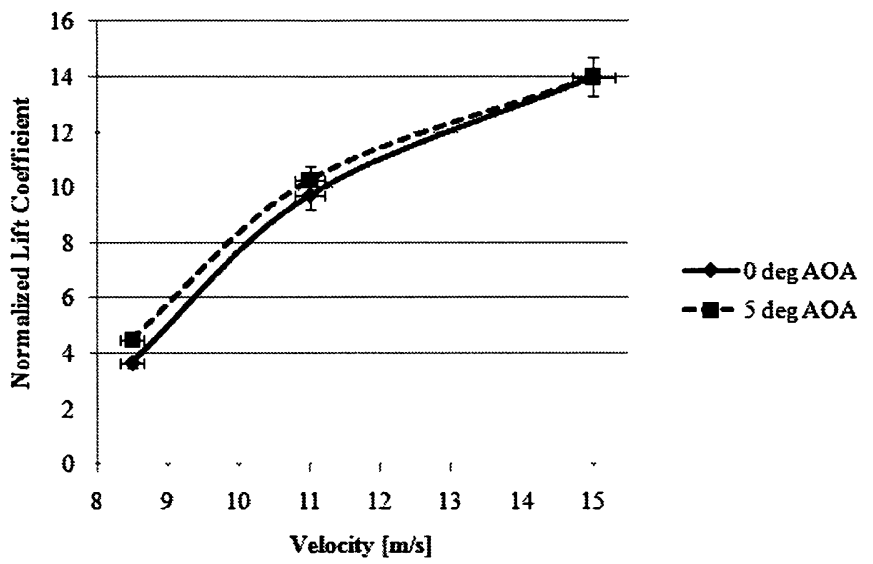

Figure 5-9: Effect of varying angle of attack from 0-5 deg $(y / c=0.1, \Gamma=0.080)$.

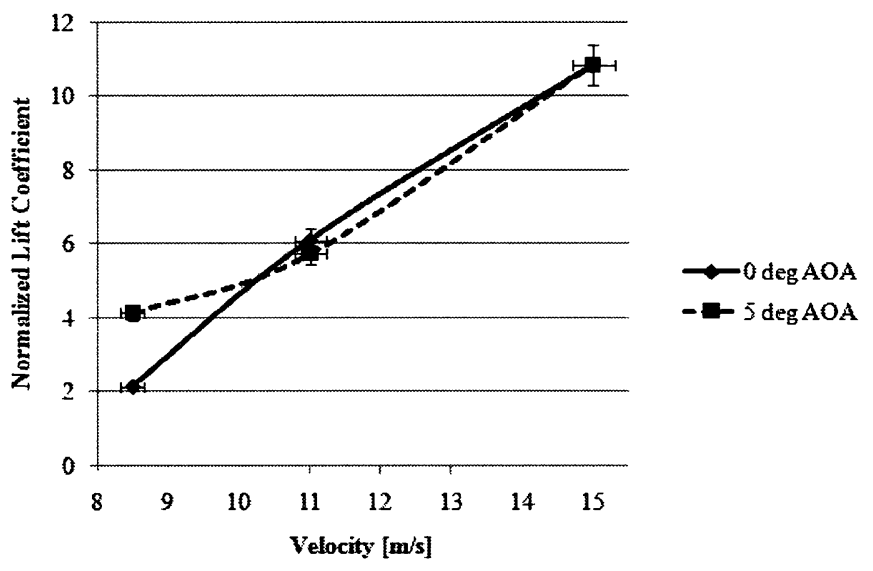

Figure 5-10: Effect of varying angle of attack from 0-5 deg $(y / c=0.2, \Gamma=0.12)$.

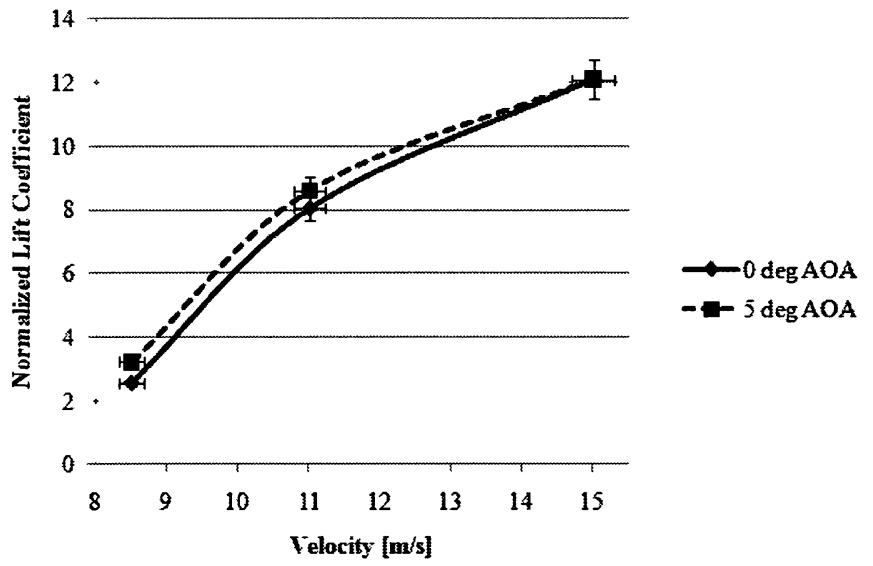

Figure 5-11: Effect of varying angle of attack from $0-5 \mathrm{deg}(\mathrm{y} / \mathrm{c}=0.2, \Gamma=0.080)$. 


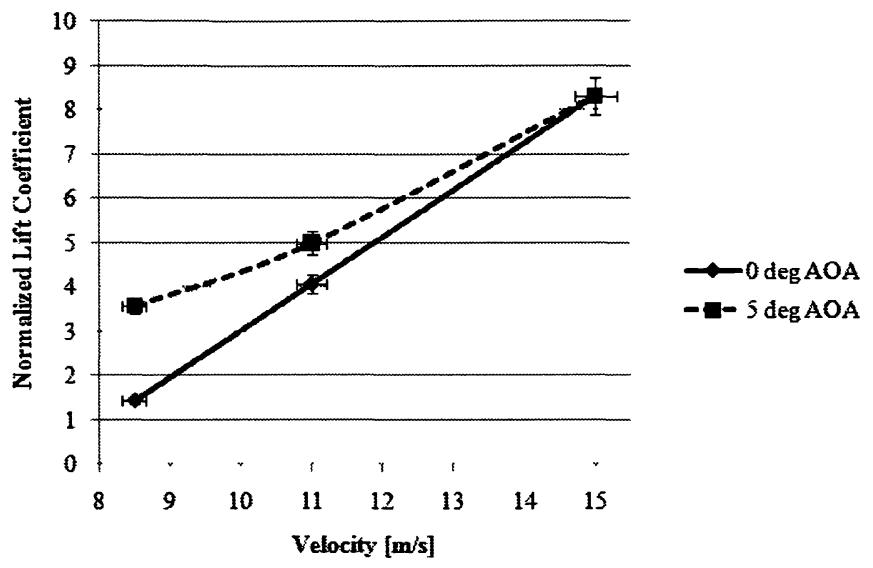

Figure 5-12: Effect of varying angle of attack from 0-5 deg $(y / c=0.3, \Gamma=0.12)$.

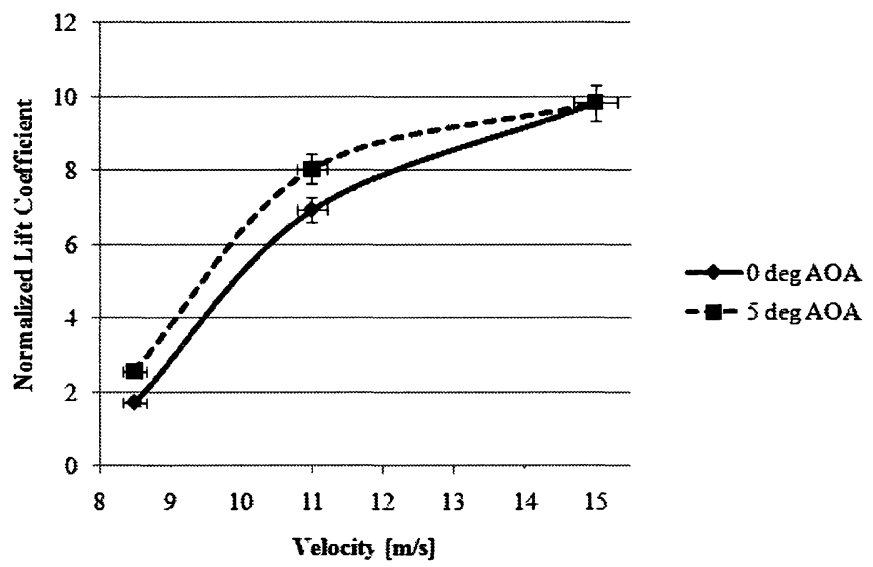

Figure 5-13: Effect of varying angle of attack from $0-5 \mathrm{deg}(y / c=0.3, \Gamma=0.080)$. 


\subsubsection{Effect of Vortex Strength}

Finally, the effects on the normalized lift coefficient due to changes in freestream velocity and vortex strength are shown in Figure 5-14 through Figure 5-19.

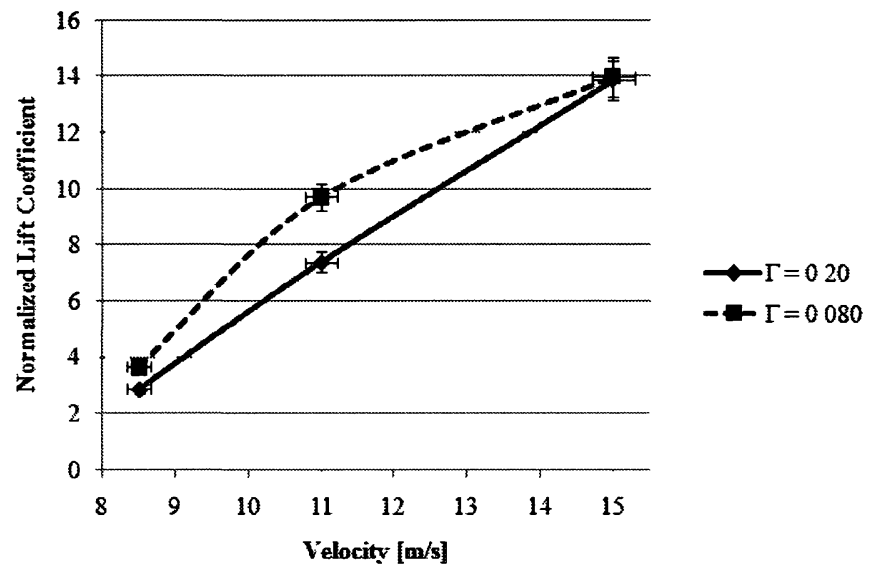

Figure 5-14: Effect of varying vortex strength from 0.08-0.12 $\left(y / c=0.1,0^{\circ} \mathrm{AOA}\right)$.

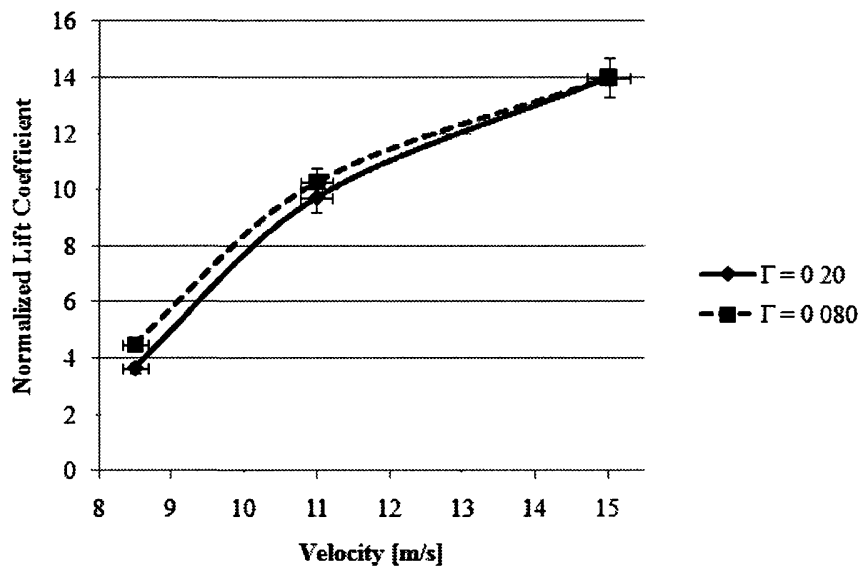

Figure 5-15: Effect of varying vortex strength from 0.08-0.12 $\left(y / c=0.1,5^{\circ} \mathrm{AOA}\right)$. 


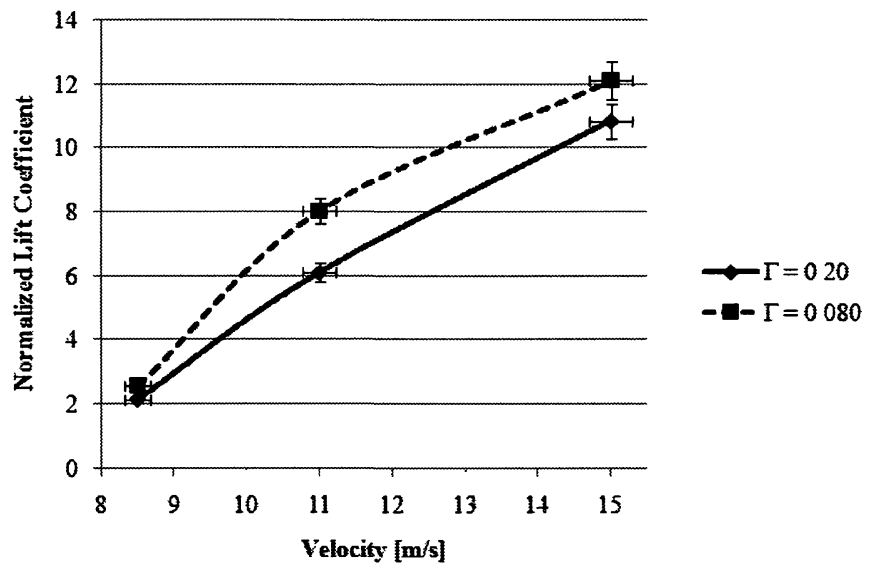

Figure 5-16: Effect of varying vortex strength from $0.08-0.12\left(y / c=0.2,0^{\circ} \mathrm{AOA}\right)$.

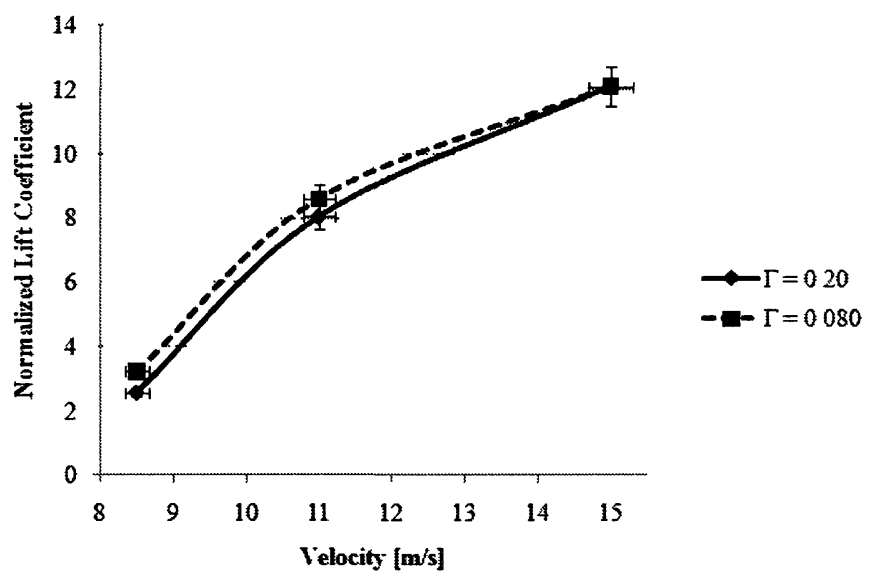

Figure 5-17: Effect of varying vortex strength from 0.08-0.12 $\left(y / c=0.2,5^{\circ} \mathrm{AOA}\right)$.

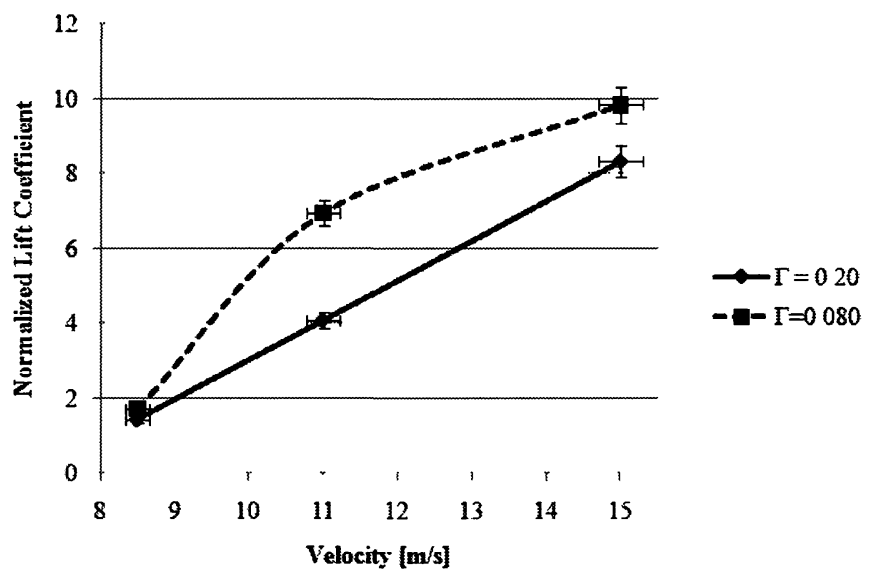

Figure 5-18: Effect of varying vortex strength from 0.08-0.12 $\left(y / c=0.3,0^{\circ} \mathrm{AOA}\right)$. 


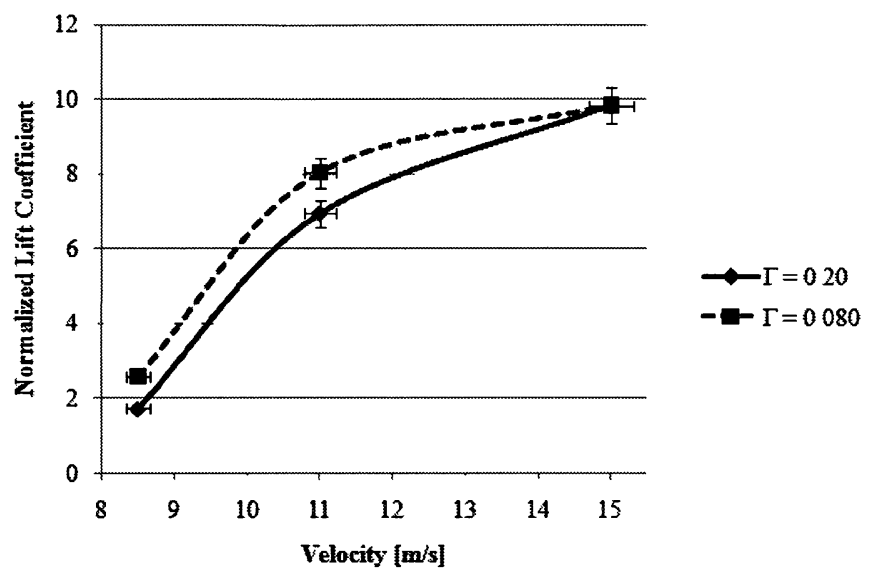

Figure 5-19: Effect of varying vortex strength from 0.08-0.12 $\left(y / c=0.1,5^{\circ} \mathrm{AOA}\right)$.

\subsection{Discussion}

The normalized lift coefficient, $\mathrm{C}_{\mathrm{L}_{\mathrm{ND}}}$, provides a good measure of the overall effect of the vortex interaction with regards to vibration and noise. It is therefore interesting to note the trends observed from the test cases, illustrated in Figure 5-4 through Figure 5-19 above.

It was observed that as the freestream velocity increases, the effect of the vortex impact increases. This is an expected result, and was apparent across all test cases.

Variations in miss distance also yielded a change in the vortex effect on the airfoil. As expected, it was observed that as the miss distance increased, the effect on the airfoil diminished. It is important to note that, as the freestream velocity increases, the effect of the miss distance appears to have a greater influence on the vortex interaction.

As the angle of attack of the incident airfoil was changed, fluctuations in vortex effect were only apparent at lower testing speeds. As the angle of attack increased, larger 
values of $C_{L_{N D}}$ were observed. At speeds of $11 \mathrm{~m} / \mathrm{s}$ and $15 \mathrm{~m} / \mathrm{s}$, the change in AOA produced negligible effects on the vortex interaction.

Finally, as the vortex strength increases, it was observed that $\mathrm{C}_{\mathrm{L}_{\mathrm{ND}}}$, and therefore likely noise and vibration too, would be decreased. As this result is different from what has been found in other research, it is especially interesting to note. This is most true for the $0^{\circ}$ AOA test cases, where the change appeared to be the most evident. For the $5^{\circ}$ AOA cases, the decrease in $C_{L_{N D}}$ is still apparent but is significantly reduced. It is this subset of data that provides the most interesting conclusions and is fully worth investigating further in the future. 


\section{Chapter 6}

\section{PIV Study of Trailing-edge Flap Flow}

Through the Canada-EU Student Exchange Program in Aerospace Engineering (CESAer), this author was presented with an opportunity to assist with ongoing research at the Delft University of Technology (TU Delft) in the Netherlands between MayAugust 2009. The study was to be performed experimentally on a prototype wind turbine airfoil under driven dynamic conditions via PIV in the Low-Speed Low-Turbulence Tunnel (LTT) in the Faculty of Aerospace Engineering. This chapter is included in this thesis as a separate project, as it was fundamentally different from the main work accomplished but shared many of the same theories, technologies and experimental knowledge.

\subsection{Motivation}

An airfoil designed for wind turbines, the DU96W180 (Figure 6-1) is a subject of much interest in the European Research Program Upwind. Several universities and organizations are involved in investigating means of alleviating blade loads, especially those causing fatigue. It was proposed to implement a series of spanwise-distributed sensors and aerodynamic control apparatus [24]. In principle, the blade could adapt itself to the real time aerodynamic forces acting upon it, reducing the loads, and therefore fatigue failure. 


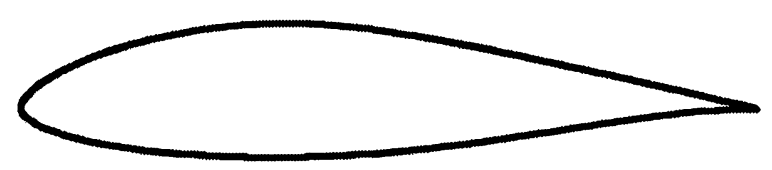

Figure 6-1: DU96W180 airfoil, shown without flap [24].

The Dutch researchers proposed the addition of a $20 \%$ chord flap as a means of alleviating the aerodynamic loads. In order to design the flap control mechanism required, the dynamic behavior of the airfoil and flap in several flow conditions must be examined by means of PIV.

\subsection{Experimental Setup}

The Faculty of Aerospace Engineering at TU Delft is well equipped to perform a large scale study as it is an academic leader in wind turbine research. Many different facilities and resources are at the disposal of students and faculty members. This includes the use of several extensive machine shops - complete with abilities for computer aided composite, mechanical and electrical construction - as well as access to comprehensive measurement packages and computational resources. Experiments can be performed in a number of available wind and water tunnels, with capabilities for testing up to Mach 11.0. Of particular note to this study, however, are three tunnels: the new open jet facility $(3$ meter jet capable of $30 \mathrm{~m} / \mathrm{s})$, the TST-27 transonic tunnel $(40 \times 40 \mathrm{~cm}$ test section capable of $35 \mathrm{~m} / \mathrm{s}$ ) and the Low-Speed Low-Turbulence Tunnel (LTT), which is described below. 


\subsubsection{Low-Speed Low-Turbulence Tunnel}

Although a number of experimental facilities are available to researchers at TU Delft; the low-speed low-turbulence tunnel is best equipped to perform the required tests on the DU96W180. It is a large closed-loop atmospheric tunnel with a contraction ratio of 17.8. This is advantageous as it permits the use of PIV particles to be entrained in the flow more easily than an open loop tunnel. In addition, it features large removable test sections $(1.8 \mathrm{~m} \mathrm{~W} \times 1.25 \mathrm{~m} \mathrm{H} \mathrm{x} 2.6 \mathrm{~m} \mathrm{~L})$ with glass panels available on the sides, top, and bottom for PIV laser and camera penetration.

Its maximum velocity of $120 \mathrm{~m} / \mathrm{s}$ is obtained via a $525 \mathrm{~kW}$ DC motor powering a 6-bladed fan, yielding a maximum Reynolds number for testing of approximately $3.5 \times 10^{6}[25]$. However, for the purposes of this study, the maximum velocity studied was limited to $21 \mathrm{~m} / \mathrm{s}$, corresponding to a Reynolds number of 700,000 for the DU96W180 prototype blade [24]. The LTT has been commissioned to determine the undisturbed flow conditions; a turbulence intensity level of only $0.015 \%$ is experienced in the speed regime examined.

\subsubsection{Test Model}

A prototype DU96W180 blade section was constructed by a third party manufacturer by means of a carbon fiber layup with a foam core. The prototype had a chord of $0.5 \mathrm{~m}$ and a span of $1.8 \mathrm{~m}$, featuring a $20 \%$ flap across the entire span. The flap was hinged to permit deflection only in the downward direction, dynamically driven by electronic servos or, later, by a linear actuator. The construction dimensional tolerances were 
checked by a three dimensional laser scanner to ensure the blade profile was known precisely.

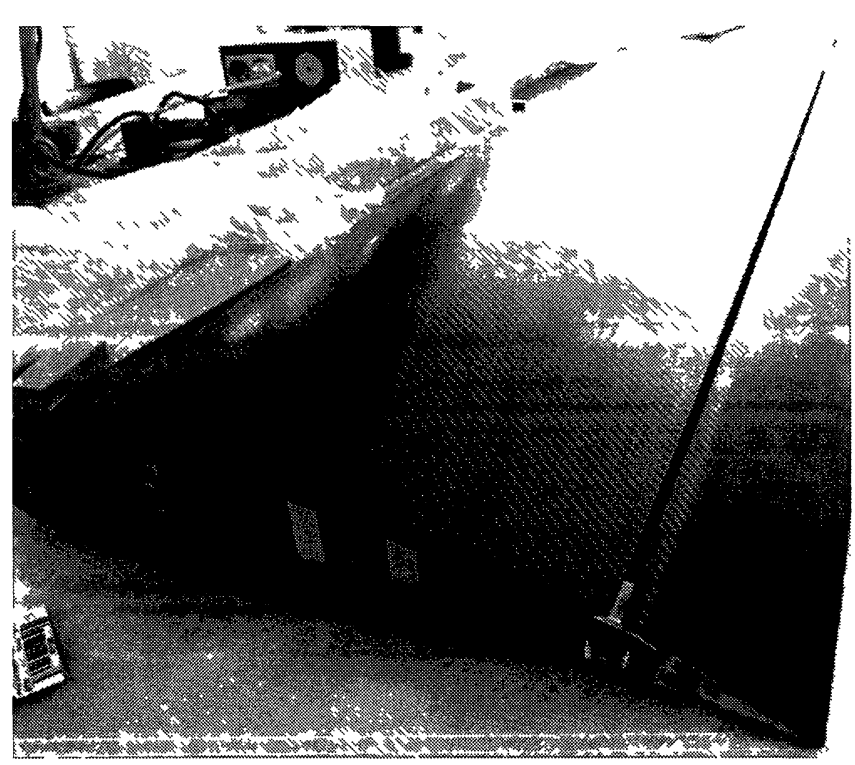

Figure 6-2: DU96W180 blade prototype with 20\% hinged flap shown.

Furthermore, as early turbulence transition was desirable, zigzag turbulence inducing tape was applied to both the lower and upper surface of the blade at $5 \%$ chord along the entire span.

\subsubsection{PIV System}

The PIV system utilized at TU Delft was manufactured by Big Sky Laser and utilized a double pulsed Nd:YAG laser, producing up to $40 \mathrm{~mJ}$ per shot. The tracer particles were a glycol-based solution, commercially available for use in fog machines. Two cameras (1 Megapixel Imager Intense, fitted with Nikon $60 \mathrm{~mm}$ Macro lenses, capable of $30 \mathrm{~Hz}$ capture) were used to expedite the capture of the entire flow field. The PIV system, prior to installation, is shown in Figure 6-3. 


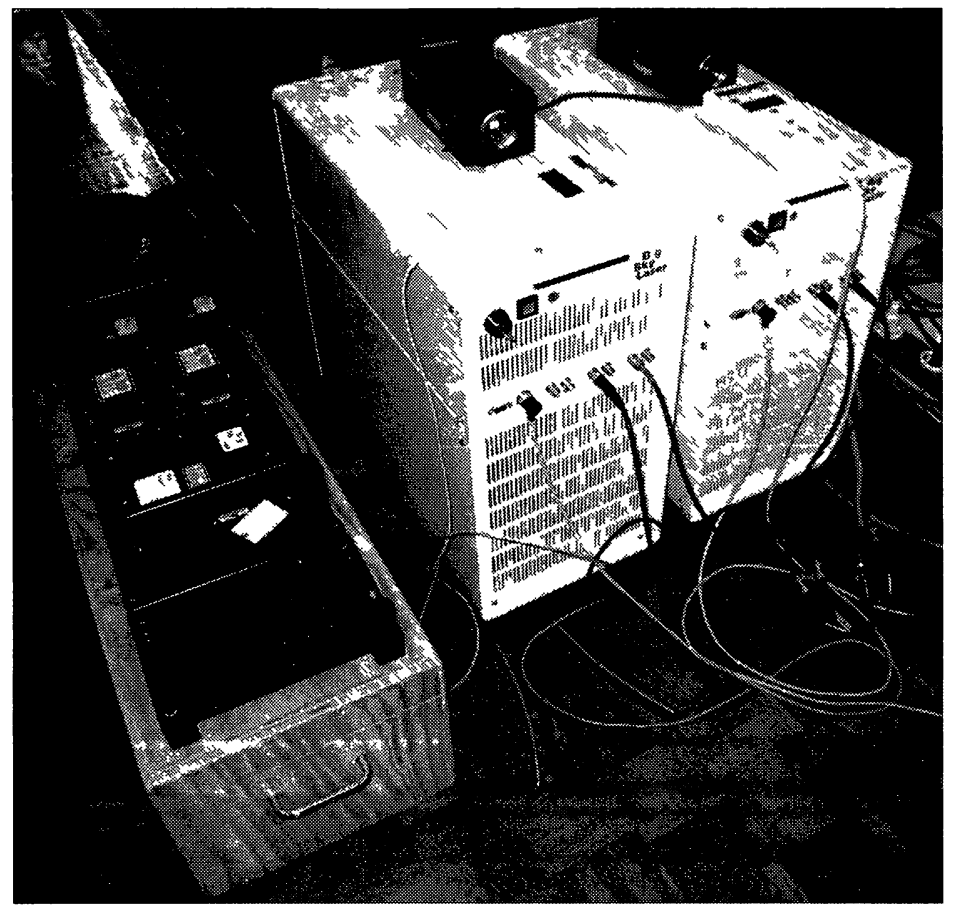

Figure 6-3. The TU Delft PIV System (prior to installation) without lenses

\subsubsection{System Mounting}

The blade was mounted in the tunnel horizontally via an external support bracket at the quarter chord point. This bracket firmly holds the blade in place and permits control of the angle of attack of the blade by means of a calibrated adjustment block affixed to rotating pitching arms, as shown in Figure 6-4. Strain gauges were affixed to the mountıng rods, allowing for an evaluation of the loads experienced to be measured independently from the PIV system. These gauges were calibrated against the precise six-axis balance system featured at the LTT. 


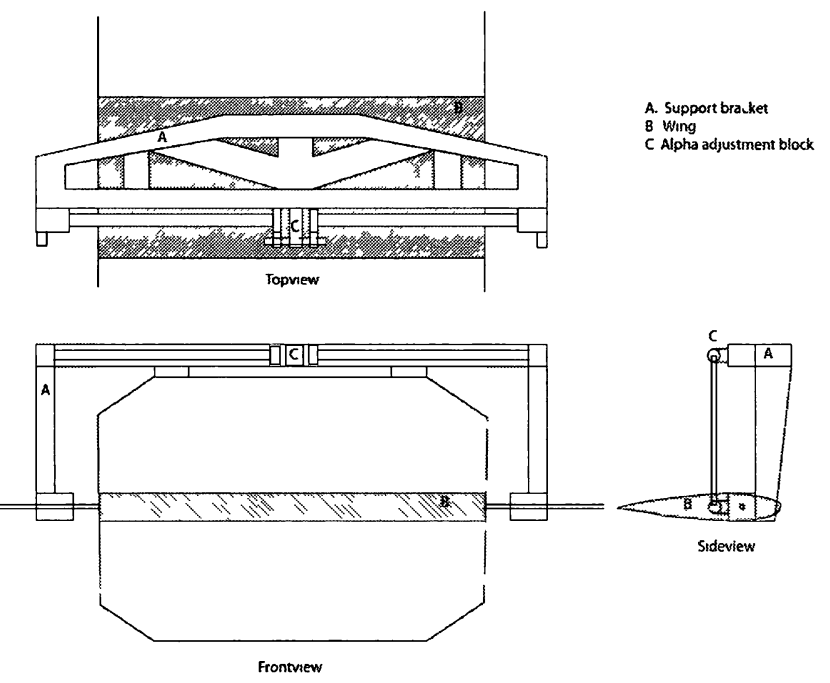

Figure 6-4: Three-view diagram of the DU96W180 blade mounting in the TU Delft LowSpeed Low-Turbulence Tunnel [24].

The laser system was attached to a linear actuator below the airfoil, with a prism redirecting the light vertically. This permitted the laser sheet to travel horizontally in the chordwise direction along the length of the lower surface of the blade. To illuminate the top surface, a mirror system was utilized to reflect some of the laser sheet from above the blade, as shown in Figure 6-5.

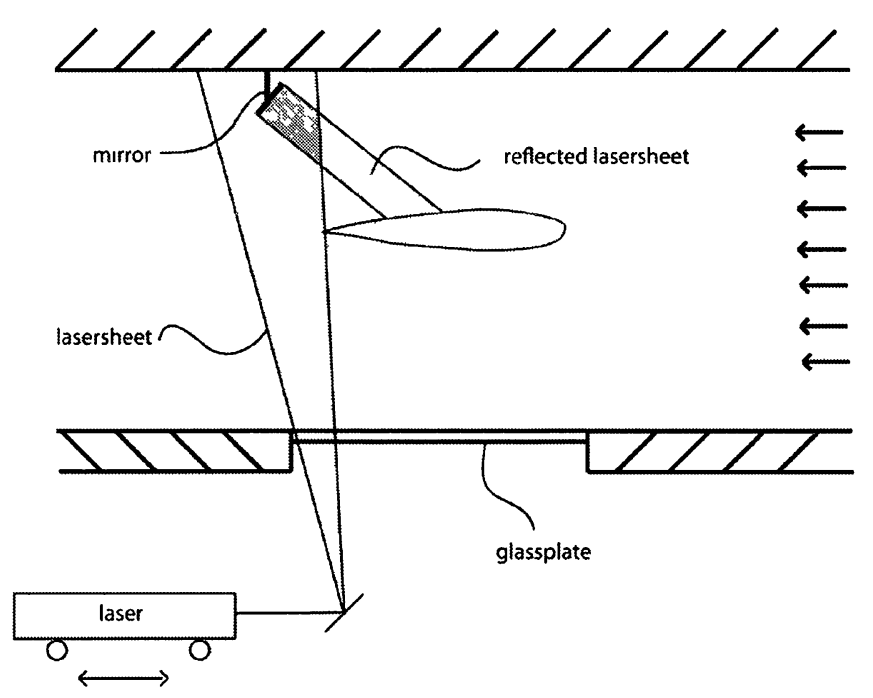

Figure 6-5: Laser and mirror placement [24]. 
Finally, two cameras were mounted to a three dimensional traverse system and positioned in a two dimensional co-planar orientation, as shown in Figure 6-6. The cameras were calibrated with a precisely constructed painted grid, correcting for spatial deviations. The traverse system allowed the cameras to travel horizontally and vertically without interfering with the camera calibration.

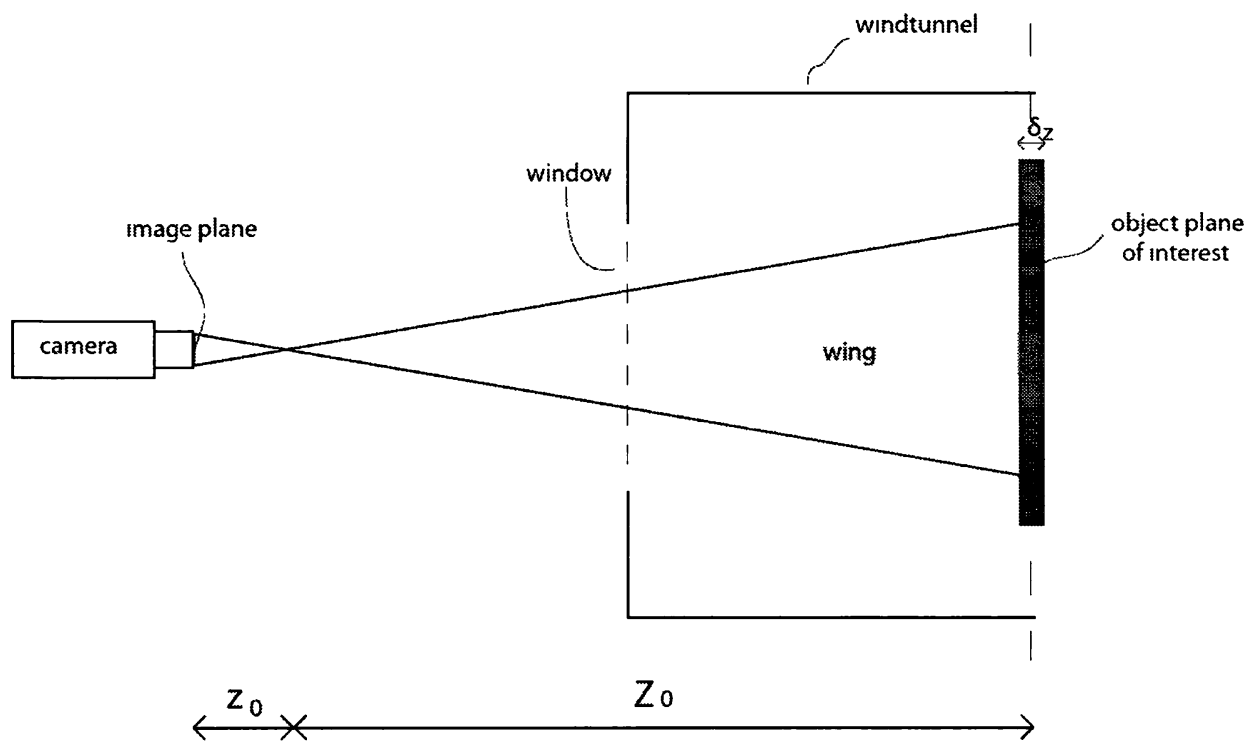

Figure 6-6: Camera position (only one camera shown) [24].

\subsection{Experiment}

To characterize the effect of flap control, the aerodynamic behaviour of the flow around the blade under several conditions must be investigated. The test plan consisted of varying the reduced frequency, flap deflection amplitude and angle of attack of the DU96W180 blade as shown in Table 6-1. The reduced frequency was calculated as $k=2 \pi f \bar{c} / 2 v$ where $f$ is the flap frequency, $\bar{c}$ is the chord length of the airfoil and $v$ is the freestream velocity. 
Table 6-1: Test matrix at TU Delft

\begin{tabular}{|c|c|c|c|c|c|}
\hline$\#$ & AOA & Reynolds \# (Velocity) & Flap Deflection & Flap Frequency & $\begin{array}{c}\text { Reduced } \\
\text { Frequency (k) }\end{array}$ \\
\hline 1 & \multirow{5}{*}{$0^{\circ}$} & \multirow{5}{*}{$700,000(21 \mathrm{~m} / \mathrm{s})$} & $0^{\circ}$ & $0 \mathrm{~Hz}$ & 0 \\
\hline 2 & & & $2^{\circ}$ & $1.34 \mathrm{~Hz}$ & 0.1 \\
\hline 3 & & & $6^{\circ}$ & $1.34 \mathrm{~Hz}$ & 0.1 \\
\hline 4 & & & $2^{\circ}$ & $2.67 \mathrm{~Hz}$ & 0.2 \\
\hline 5 & & & $6^{\circ}$ & $2.67 \mathrm{~Hz}$ & 0.2 \\
\hline 6 & \multirow{5}{*}{$15^{\circ}$} & \multirow{5}{*}{$700,000(21 \mathrm{~m} / \mathrm{s})$} & $0^{\circ}$ & $0 \mathrm{~Hz}$ & 0 \\
\hline 7 & & & $2^{\circ}$ & $1.34 \mathrm{~Hz}$ & 0.1 \\
\hline 8 & & & $6^{\circ}$ & $1.34 \mathrm{~Hz}$ & 0.1 \\
\hline 9 & & & $2^{\circ}$ & $2.67 \mathrm{~Hz}$ & 0.2 \\
\hline 10 & & & $6^{\circ}$ & $2.67 \mathrm{~Hz}$ & 0.2 \\
\hline
\end{tabular}

Note that for two of the cases above, the flap is held stationary at $0^{\circ}$ deflection, to investigate the steady state behaviour of the airfoil. At $0^{\circ} \mathrm{AOA}$, the linear portion of the $C_{L}-\alpha$ curve was investigated, even during $6^{\circ}$ forced flap deflection. However, during the $15^{\circ} \mathrm{AOA}$ test case, the oscillating flap was expected to push the airfoil into a dynamic trailing edge stall, as shown in a CFD study performed earlier by Lindeboom [24]. This dynamic stall regime represents an important portion of turbine performance in practice, and must be fully characterized by this study.

For each case, a macro file was generated to time and fire the PIV system for a precise phase angle of flap deflection. The system was triggered initially by a microswitch at the upmost position of the flap $\left(0^{\circ}\right.$ phase) and was then programmed with the frequency of the system to subsequently capture every $15^{\circ}$ of phase up to $360^{\circ}$ (where 
$180^{\circ}$ represents maximum flap deflection experienced). This process was then repeated 100 times per test case per camera and laser position, permitting an average test case to be generated over 100 cycles.

\subsection{Preliminary Results}

The results below are preliminary, and reflect the work jointly accomplished by Rene C.J. Lindeboom, Carlos J. Simao Ferreira, and Joost J.H.M. Sterenborg of TU Delft and this author. During the four month exchange, this author was tasked with a variety of duties from multiple disciplines including: preparing, installing and configuring the airfoil, PIV system and wind tunnel, as well as quickly designing, building and testing solutions to mechanical, electrical and computational problems under a strict time constraint.

To cover the flow field, 12 camera traverse positions were required, resulting in 24 different overlapping camera angles. Some of these angles were obscured by tunnel sections, and were not recorded. For the $0^{\circ}$ AOA case, the camera fields of view used are graphically depicted in Figure 6-7.

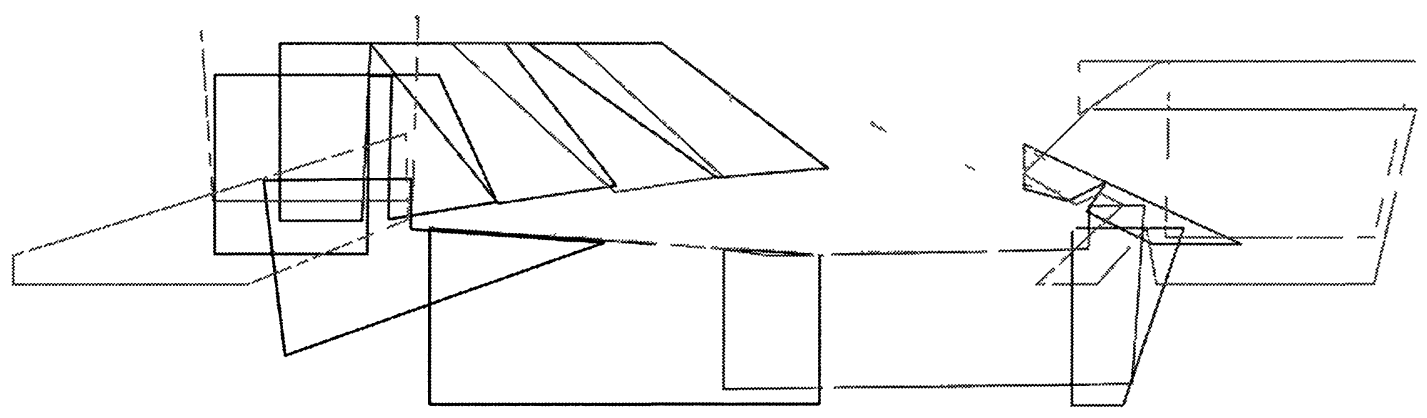

Figure 6-7: Graphical depiction of camera fields of view.

DaVis, a software suite by LaVision, was utilized to record, average, and analyze the data. For test case \#4 (Table 6-1, above), the 100 vector maps for each camera 
position were averaged, and then combined with adjacent fields of view to generate a complete averaged profile around the entire blade, and is shown below. Experimental accuracy, once averaged, is expected to be $\pm 0.05 \mathrm{~m} / \mathrm{s}$ throughout the flow field. Figure 6-8 illustrates the varying velocity profile as a result of the flap oscillations. By further reducing the data in the DaVis imaging software, it is possible to observe the vorticity field, as shown in Figure 6-9.

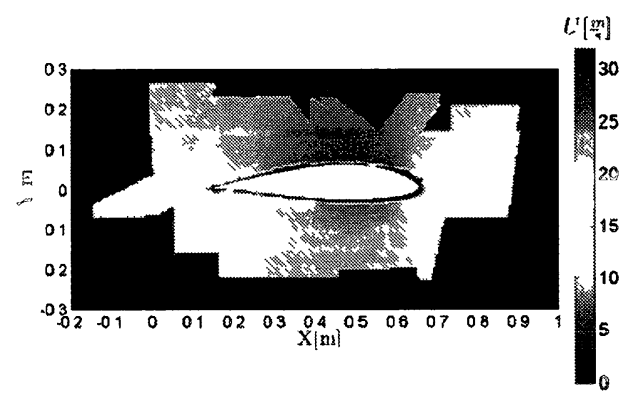

0 degrees phase $\left(0^{\circ}\right.$ flap deflection $)$

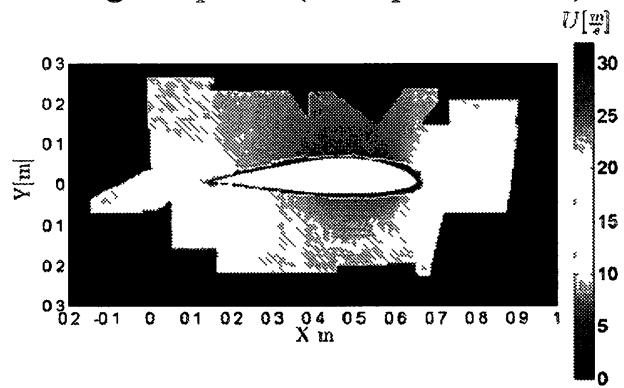

180 degrees phase ( $2^{\circ}$ flap deflection)

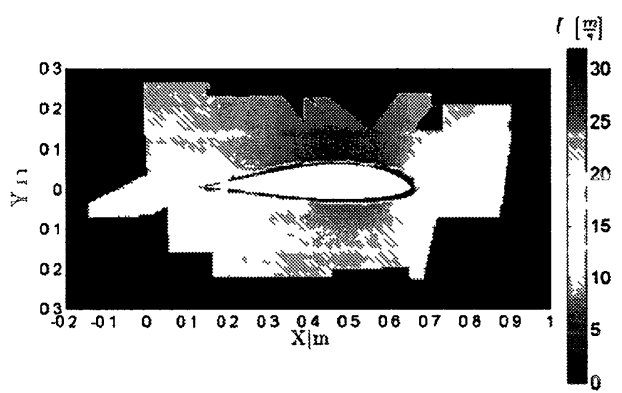

90 degrees phase $\left(1^{\circ}\right.$ flap deflection)

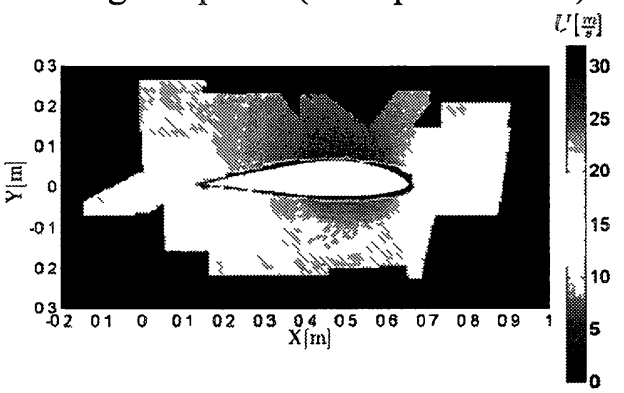

270 degrees phase $\left(1^{\circ}\right.$ flap deflection $)$

Figure 6-8: Total velocity field at selected phase angles with $V_{\infty}=21 \mathrm{~m} / \mathrm{s}, A O A=0^{\circ}$, maximum flap deflection of $2^{\circ}$ at a frequency of $2.67 \mathrm{~Hz}$, and a reduced frequency of 0.2. 


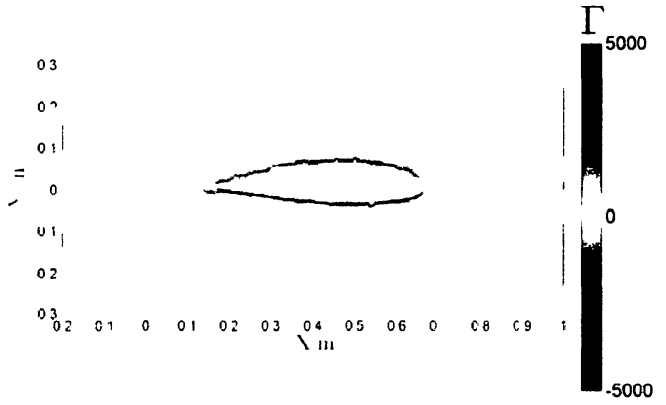

0 degrees phase $\left(0^{\circ}\right.$ flap deflection)

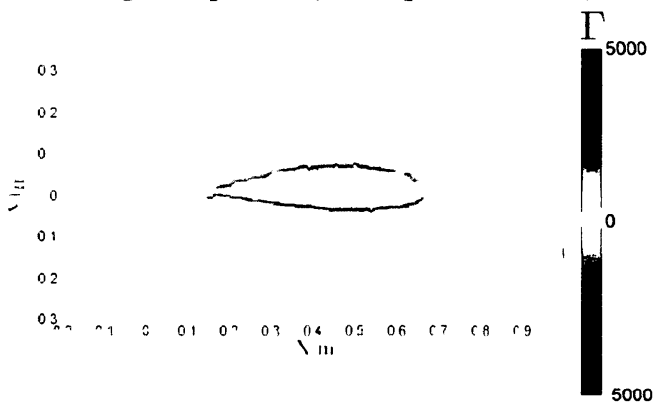

180 degrees phase $\left(2^{\circ}\right.$ flap deflection)

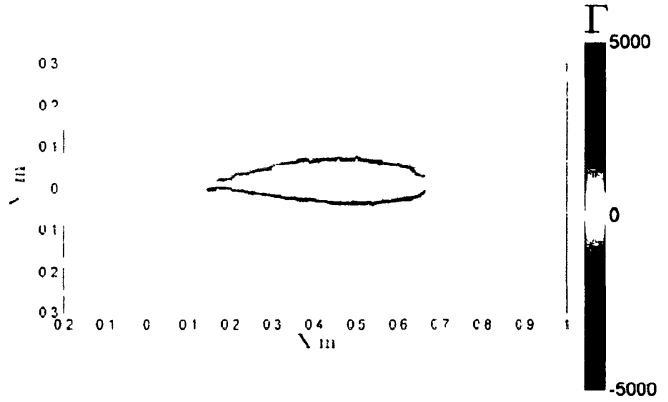

90 degrees phase $\left(1^{\circ}\right.$ flap deflection)

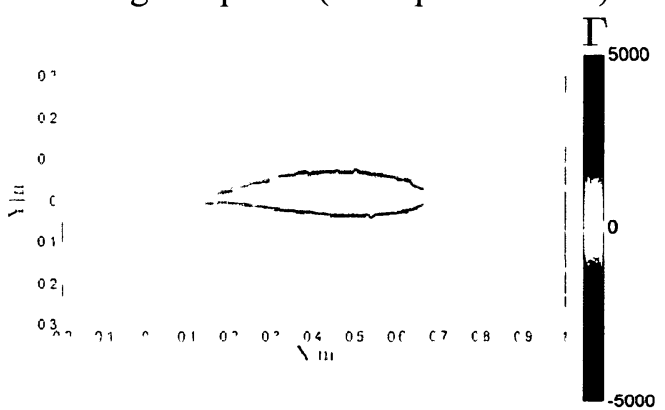

270 degrees phase $\left(1^{\circ}\right.$ flap deflection $)$

Figure 6-9: Vorticity field for selected phase angles with $V_{\infty}=21 \mathrm{~m} / \mathrm{s}, A O A=0^{\circ}$, maximum flap deflection of $2^{\circ}$ at a frequency of $2.67 \mathrm{~Hz}$, and a reduced frequency of 0.2 .

The static pressure contours - shown below in Figure 6-10 - were obtained by means of applying Bernoulli's principle to the recorded atmospheric pressures, temperatures and PIV-obtained velocities. The profile shown is of an oval surrounding the airfoil - depicted as such as a preliminary proof of concept to evaluate the efficacy of the PIV capture and stitching. 


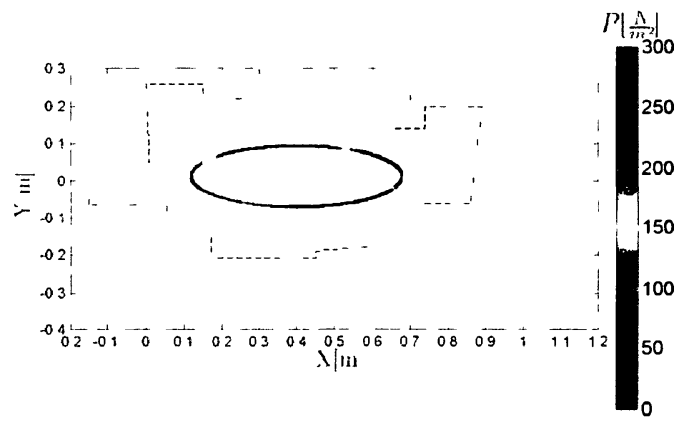

0 degrees phase $\left(0^{\circ}\right.$ flap deflection $)$

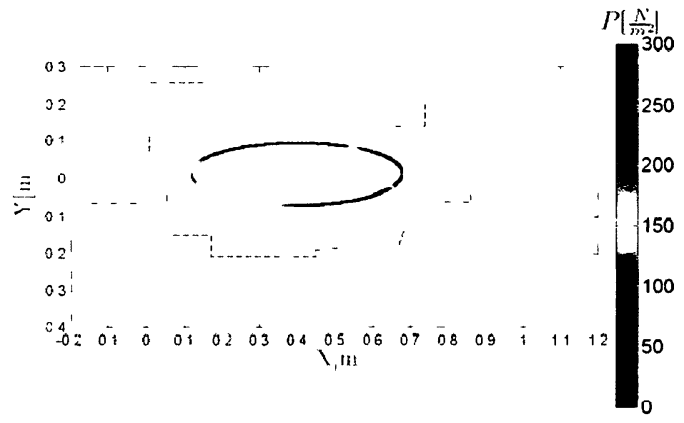

180 degrees phase ( $2^{\circ}$ flap deflection)

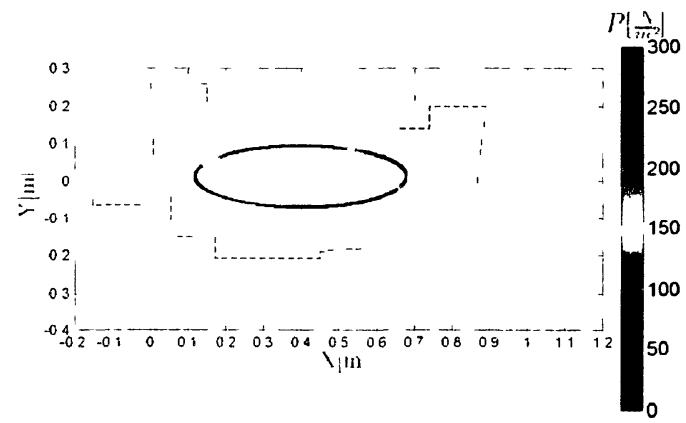

90 degrees phase $\left(1^{\circ}\right.$ flap deflection)

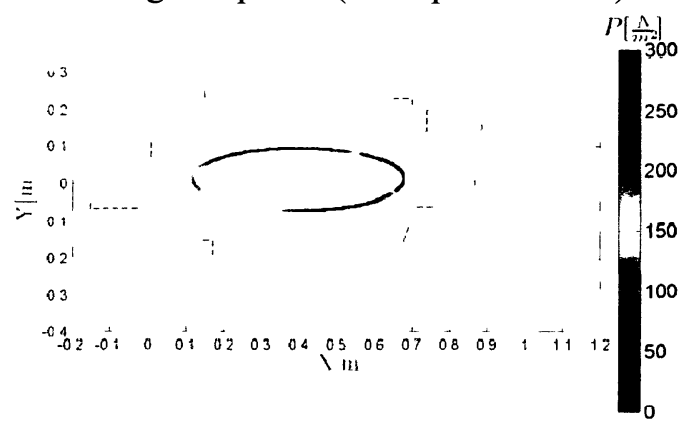

270 degrees phase $\left(1^{\circ}\right.$ flap deflection $)$

Figure 6-10: Pressure contour at selected phase angles with $V_{\infty}=21 \mathrm{~m} / \mathrm{s}, A O A=0^{\circ}$, maximum flap deflection of $2^{\circ}$ at a frequency of $2.67 \mathrm{~Hz}$, and a reduced frequency of 0.2 .

Note that although not entirely visible in the above figures, useful data has been obtained regarding the variations in velocity, vorticity and pressure surrounding the airfoil during the flapping motion. This data, along with future testing, will serve as the basis of confirmation of the flow surrounding the airfoil when compared with results obtained from numerical simulation. Thus, simulations with a higher degree of certainty can be performed to fully develop a control model for practical gust load alleviation and increased wind power capture. 


\section{Chapter 7}

\section{Conclusions and Future Work}

The conclusion to the work completed on the vortex wind tunnel at Carleton University by Burwash, Brassard and Wilkins was to perform a systematic study of airfoil-vortex interaction. The goal of this project was to perform a large number of experiments in a repeatable manner, through the use of an available particle image velocimetry system, as computational simulations were determined to be prohibitively costly and tedious.

The systematic study involved the investigation of 36 test cases varying freestream velocity, vortex miss distance, angle of attack and vortex strength for a vortex impacting a downstream NACA0012 airfoil. Most of the results obtained were as expected - an increase in vortex effect with smaller miss distances or larger freestream velocities or angles of attack. However, the effect of varying the angle of attack is diminished to almost negligible amounts as the freestream velocity increases. Additionally, and most surprisingly, it was also observed that an increase in vortex strength yielded a smaller disturbance by the vortex. It is strongly desirable to pursue this observation further by increasing the number of test cases - perhaps 6-8 different velocities and 3-4 vortex strengths - even at a constant angle of attack and miss distance to observe the effects of increasing the vortex strength. Further, while observing $C_{L_{N D}}$ is a useful measure of the effect of vortex impact and therefore noise and vibration, investigating the noise directly through the pressure contours obtained in Particle Image 
Velocimetry flow maps is desirable for future testing. As the wind tunnel is now configured for such an operation, performing these tests could be expedited. 


\section{References}

[1] Brassard, D., A 2D Transverse Vortex Wind Tunnel for PIV Investigation of Airfoil Vortex Interaction. Ottawa : M.A.Sc Thesis, Carleton University, 2005.

[2] Wilkins, J., Commissioning and Calibration of the Carleton University High SubSonic 2-D Blade Vortex Interaction Investigation. Ottawa : M.A.Sc Thesis, Carleton University, 2005.

[3] Burwash, W., Particle Image Velocimetry Measurements of an Airfoil-Vortex Interaction Event in a Two-Dimensional Wind Tunnel. Ottawa : M.A.Sc Thesis, Carleton University, 2007.

[4] Wong, YG A., A Study on the use of Volterra Integrals for the Identification of Rotor Blade-Vortex Interactions. Ottawa : Carleton University, 2003.

[5] Ilie, M., Aerodynamic, Aeroacoustic and Aeroelastic Investigations of Airfoil-Vortex Interaction using Large-Eddy Simulation. Ottawa : Carleton University, 2008.

[6] Glaßel, H, Kloppel, V and Rudolph, S., "Neural control of helicopter blade-vortex interaction noise." Newport Beach, CA : SPIE 8th International Symposium on Smart Structures and Materials, 2001.

[7] Seath, D D, Kim, J M and Wilson, D R., "Investigation of the parallel blade-vortex interaction at low speed." Journal of Aircraft, 1989, Issue 4, Vol. 26, pp. 328-333.

[8] Tangler, J L., "Schlieren and noise studies of rotors in forward flight." Washington, DC : 33rd American Helicopter Society Forum, 1977.

[9] Lee, S and Bershader, D., "Head-on parallel blade-vortex interaction." s.1. : AIAA Journal, 1994, Issue 1, Vol. 32, pp. 16-22.

[10] Sim, B W and Schmitz, F H., "Blade vortex interaction (BVI) noise: Retreating side characteristics, sensitivity to chordwise loading and unsteady aerodynamics." Atlanta : American Helicopter Society (AHS) Aerome-chanics Specialists Meeting, 2000.

[11] Renzoni, P and Mayle, R E., "Incremental Force and Moment Coefficients for a Parallel Blade-Vortex Interaction." s.1. : AIAA Journal, 1991, Issue 1, Vol. 29. 
[12] Srinivasan, G R, McCroskey, W J and Baeder, J D., "Aerodynamics of TwoDimensional Blade-Vortex Interaction." AIAA Journal, October 1986, Issue 10, Vol. 24, pp. 1569-1576.

[13] Schmitz, F H and Sim, B W., "Radiation and directionality characteristics of advancing side blade-vortex interaction (BVI) noise." Lahaina : 6th IAA/CEAS Aeroacoustics Conference, 2000.

[14] Wong, S H, Papadakis, M and Nizampatham, L S., "Computational investigation of blade vortex interaction noise." Reno, NV : 38th Aerospace Sciences Meeting and Exhibit, 2000.

[15] Oh, W S, Kim, J S and Kwon, O J., "Numerical simulation of two-dimensional blade vortex interactions using unstructured adaptive meshes." s.1. : AIAA Journal, 2002, Issue 3, Vol. 40, pp. 474-480.

[16] Berenger, T, Favier, D and Maresca, C., "Experimental and numerical investigation of rotor aerodynamics in forward flight." s.1. : Journal of Aircraft, 1997, Issue 3, Vol. 34, pp. 394-399.

[17] Yu, Y H., "Rotor blade-vortex interaction noise." s.l. : Progress in Aerospace Sciences, 2000, Vol. 36, pp. 97-115.

[18] Mamou, M., "Unsteady flows past two airfoils in tandem and airfoil-vortex interaction." s.1. : Canadian Aeronautics and Space Journal, 2001, Issue 4, Vol. 47, pp. 357-366.

[19] Caradonna, F X., "An experimental and computational study of rotor-vortex interactions." s.1. : Vertica, 1988, Issue 4, Vol. 12, pp. 315-327.

[20] Raffel, M, Willert, C and Kompenhans, J., Particle Image Velocimetry: A Practical Guide. Berlin : Springer, 1998.

[21] Melling, A., "Tracer particles and seeding for particle image velocimetry." Measurement Science and Technology, 1997, Vol. 8, p. 1406.

[22] Allmaras, S R., "On blockage corrections for two-dimensional wind tunnel tests using the wall-pressure signature method." NASA technical memorandum. Washington DC : NASA, 1987. 86759. 
[23] ITTC., Uncertainty Analysis Particle Imaging Velocimetry. [Online] September 2008. [Cited: June 21, 2010.] http://ittc.sname.org/new\%20recomendations/pdf\%0Procedures\%202008/7.5-01-0303.pdf.

[24] Lindeboom, R C J, Simao Ferreira, C J and Sterenborg, J H M., "Determination of unsteady loads on a DU96W180 airfoil with actuated flap using particle image velocimetry." Delft : TU Delft, 2009.

[25] , TU-Delft Low-Speed Low-Turbulence Wind Tunnel. [Online] [Cited: August 13, 2009.] http://www.lr.tudelft.nl/live/pagina.jsp?id=bf6a0439-5029-4d49-9563$4 \mathrm{ec} 822 \mathrm{e} 4956 \mathrm{~b} \&$ lang=en.

[26] A.A. Lab Systems Ltd., AN-1005: Hotwire \& Film Anemometry System. User Manual.

[27] Dantec Measurement Technology A/S., FlowMap Particle Image Velocimetry Instrumentation. Installation and User's Guide. Skovlunde : s.n.

[28] Bell Helicopter., "Bell 407 Specifications." [Online] [Cited: August 19, 2010.] http://www.bellhelicopter.com/en/aircraft/commercial/pdf/web_407PDB2003_R3.pdf. 


\section{Appendix A: Functional Guide to Data Acquisition}

This appendix intends to provide a how-to guide for operating the equipment utilized for data acquisition in the Carleton University wind tunnel for the study of two-dimensional flows, currently located in ME 2140. Specifically, this guide will cover the operation of the tunnel itself, as well as data acquisition by means of hot wire anemometry and particle image velocimetry. It will also discuss the method to derive the lift coefficient of a test airfoil from the acquired data sets.

\section{A.1 Tunnel Operation}

The tunnel is relatively simple to operate, however there are a few important considerations to take note of. The blower is activated by means of the variable speed control (Figure A-1, below) and must be controlled in the following order:

- Direct power to variable speed control (lever to the down position)

- Ensure the drive frequency is sufficiently low $(<3 \mathrm{~Hz})$ to avoid a rapid start

- Push the start button

- Accelerate blower slowly to desired frequency (velocity control)

- Allow tunnel temperature to become steady state, as documented by Wilkins [2] before testing

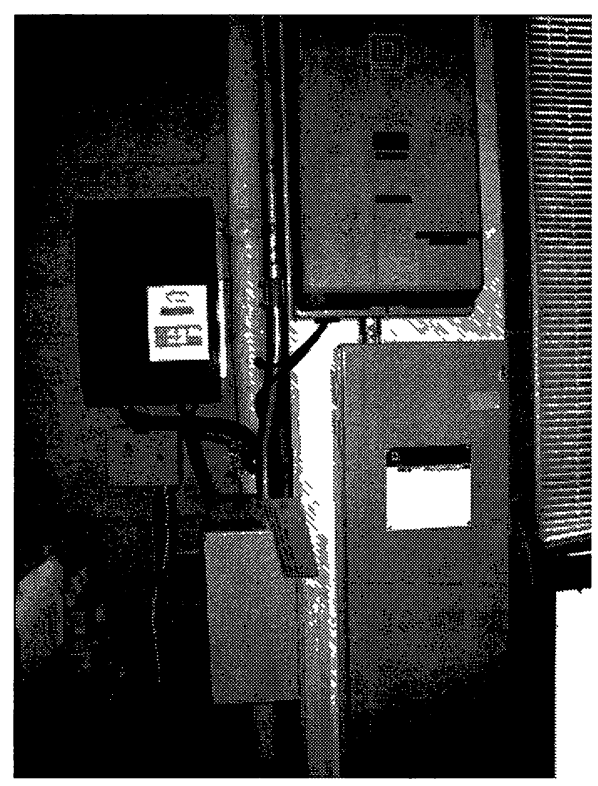

Figure A-1: Power selection lever \& variable speed control 
Similarly, once testing has been completed, it is important to follow the following order:

- Decelerate the tunnel by slowly lowering blower frequency to below $3 \mathrm{~Hz}$

- Push the stop button

- Return power lever to neutral position

\section{A.2 Hot Wire Anemometry}

The hot wire anemometry system provides an excellent means of measuring the velocity profile at a point in the flow at rates up to $10,000 \mathrm{~Hz}$. There is a manual [26] located with the tunnel that fully documents the theory related to the capture of velocity, as well as a more thorough guide for setup and calibration. However, some points are important to note:

- Run the tunnel at high speeds with a towel partially blocking the flow (immediately downstream of the test section) for 30 minutes to remove any tracer particles that remain. (Damage to the probe can occur otherwise)

- Gently handle probe while firmly affixing in desired tunnel location

- Connect the AN-1005 USB box to the computer via USB 2.0 (not a USB 1.0/1.1 port)

- Power on the system

- Run the "Hot Wire" software located on the desktop

- Capture velocity field for desired rate \& duration

\section{A.3 Particle Image Velocimetry}

PIV data capture is a very involved process, with many operations that must occur simultaneously for a successful image map to be obtained. There is a manual included with the Dantec PIV system, and should be referenced for a more comprehensive overview of the PIV capture setup and processing. Also reference Brassard [1] for a detailed look at PIV theory. 


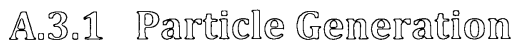

To begin $\mathbb{P I V}$ acquisition, the tumnel must first be seeded with tracer particles. In this tumnel, olive oill is typically used.

- Ensure filuid level is above approximatelly $25 \%$ capacity. To fill, remove the black filler cap (Figure $\mathbb{A}-2$ )

- Ensure plastic tubing is secure to the rear of the aerosol generator

- Tumnel should be running (idleally, warming up to steady-state temperature) before seeding

- Initiallize the seedling by powering on the aerosol generator (white switch)

- Allow tumnel to seed for 3-4 minutes before attempting PIV capture

- During capture, periodic bursts of seeding will be required to maintain particle satureation

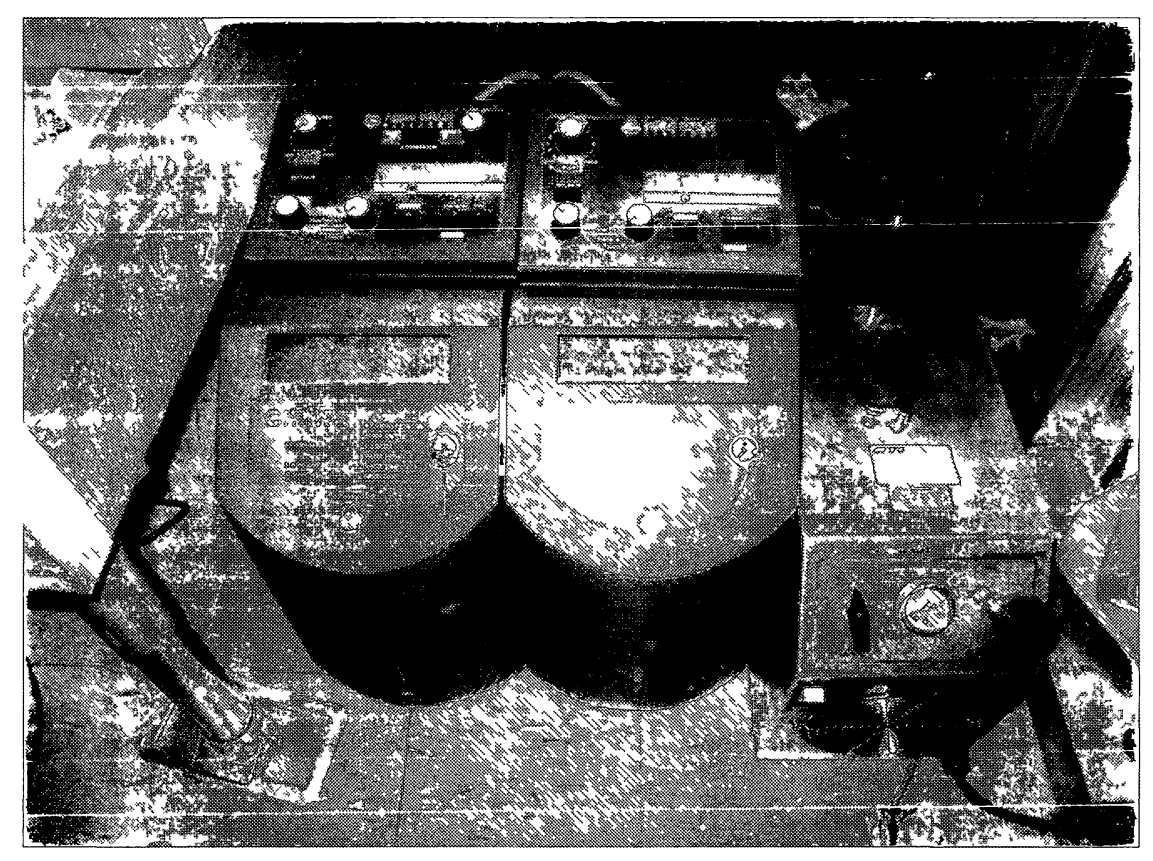

Figure A-2: Newwave Gemini lasers (lefit) of aerosol generator (right) 


\section{A.3.2 PIV Lasers}

The lasers are important to maintain as they are valuable pieces of equipment. Also ensure that laser eye protection is worn whenever working on the laser system at high powers. To operate the lasers:

- Ensure DI (de-ionized) cooling water level is high. If not, top up by means of the front fillers. DI water is available from the Chemistry Department

- Plug in the lasers (orange extension cord)

- Turn both lasers on by turning the keys clockwise (running the lasers monthly will aid in their preservation by preventing sediment build up)

- On the control boxes, ensure the flashlamp power is at zero (fully counterclockwise)

- Push 'standby' and wait for the built in delay

\section{A.3.2.1. Operation without computer}

- Ensure the Qswitch \& Lamp switches on the back of the lasers are set to INT

- Pick repetition mode (fixed, variable or single-shot frequency operation)

- Push 'fire'

- Slowly increase the flashlamp power until the laser light becomes visible

- Once laser safety has been assured, continue increasing laser power to desired level

\section{A.3.2.2. Operation with computer}

- Configure the lasers using the above 'without computer' method, then for PIV capture...

- Ensure the Qswitch \& Lamp switches on the back of the lasers are set to EXT

- Control from computer from this point forward

\section{A.3.2.3. Laser shut down}

- Push 'stop'

- Decrease flashlamp power to minimum

- Turn off keys

- Unplug laser system 


\section{A.3.3 PIV software}

A manual is also present [27] for the operation of the PIV software, however, specific procedures for data capture in this tunnel are included:

- Power the lasers as above for 'with computer' operation

- Ensure orange crossover cable connects control computer to Flowmap 1500 controller (Figure A-3)

- Force computer's network configuration to:

- IP: 10.10 .100 .199

- Subnet Mask: 255.0.0.0

- Turn on the Flowmap 1500 and wait for beep followed by 'ready' light

- Run the FlowManager software on the desktop

- From the Run menu, select 'Initialize Processor' and transfer the software to the Flowmap 1500

- Must be done every time the processor is powered on

- If required:

- Select a new project from the File $\rightarrow$ New menu

- Select a new setup from the Setup $\rightarrow$ New menu

- Configure the following parameters:

- Camera: Kodak Megaplus ES1.0/Type 16

- Laser: Newwave Gemini

- Lens: Nikkor $60 \mathrm{~mm}$ Micro

- Configure 'Processor setup and flow field description' as required by individual test

- Acquisition control: External triggering (configure trigger delay here)

- Flow conditions: Approximate velocity, viscosity, etc.

- Field of view: Calibrate the camera here. Capture a known scale (accurate ruler)

- Add an 'image map' to the processing

- From the Setup menu, select 'Activate'

- From the Run menu, select 'Online/Acquisition' to enter testing mode

- If required, select 'continuous' to focus the camera

- Push Start/Save to begin testing, trigger is linked to vortex generator

- Repeat testing as required 


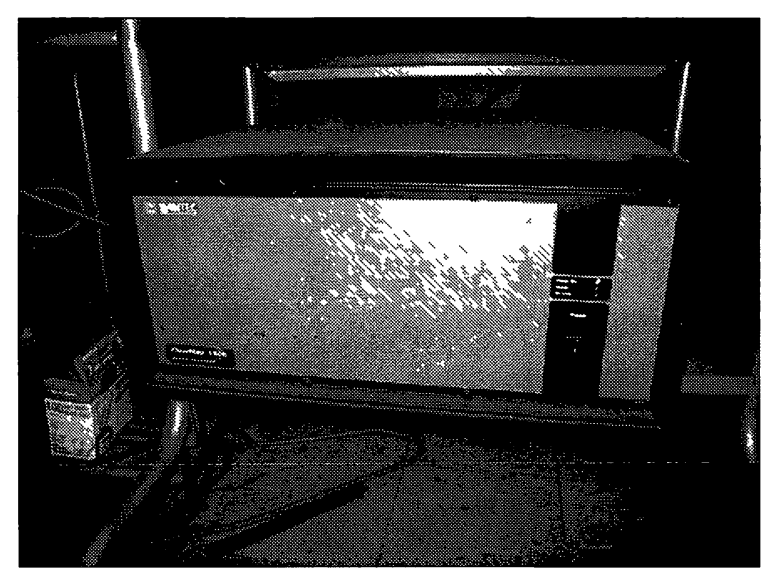

Figure A-3: Flowmap 1500 processor

\section{A.3.4 PIV processing}

- Right click on desired image map, select 'new data set'

- Configure for "Adaptive correlation" processing

- Interrogation window size: $32 \times 32$ pixels

- Refinement steps: 2, Overlap: 50\%

- Enable "minimum peak validation"

- Enable "moving average neighbourhood validation"

- It is possible to perform this step repeatedly automatically by creating an 'analysis sequence'

- Include vector averaging + stitching, as required

- Once velocity field is obtained, similarly add new data sets if the following are desired:

- Filtered data sets

- Vorticity field

- Subtracting mean velocity

- To obtain pressure field:

- File $\rightarrow$ Export $\rightarrow$ Export to Matlab (export the velocity field)

- In Matlab:

- Define a spline for the test airfoil coordinates (rotated if necessary)

- Read the velocities along that path, as a function of $\mathrm{x} / \mathrm{c}$, interpolating if necessary

- Apply Bernoulli's formula (Equation 3.4) to derive the $C_{P}$ field

- Integrate the $C_{P}$ vs $x / \bar{c}$ matrix to obtain $C_{L}$

- Repeat for all streamwise locations of vortex 